\title{
The pathogenesis of panic disorder : the role of cognitions and conditioning in the development of panic disorder
}

\author{
Citation for published version (APA): \\ De Cort, K. (2013). The pathogenesis of panic disorder : the role of cognitions and conditioning in the \\ development of panic disorder. [Doctoral Thesis, Maastricht University]. Universitaire Pers Maastricht. \\ https://doi.org/10.26481/dis.20130703kd
}

Document status and date:

Published: 01/01/2013

DOI:

10.26481/dis.20130703kd

Document Version:

Publisher's PDF, also known as Version of record

\section{Please check the document version of this publication:}

- A submitted manuscript is the version of the article upon submission and before peer-review. There can be important differences between the submitted version and the official published version of record. People interested in the research are advised to contact the author for the final version of the publication, or visit the DOI to the publisher's website.

- The final author version and the galley proof are versions of the publication after peer review.

- The final published version features the final layout of the paper including the volume, issue and page numbers.

Link to publication

\footnotetext{
General rights rights.

- You may freely distribute the URL identifying the publication in the public portal. please follow below link for the End User Agreement:

www.umlib.nl/taverne-license

Take down policy

If you believe that this document breaches copyright please contact us at:

repository@maastrichtuniversity.nl

providing details and we will investigate your claim.
}

Copyright and moral rights for the publications made accessible in the public portal are retained by the authors and/or other copyright owners and it is a condition of accessing publications that users recognise and abide by the legal requirements associated with these

- Users may download and print one copy of any publication from the public portal for the purpose of private study or research.

- You may not further distribute the material or use it for any profit-making activity or commercial gain

If the publication is distributed under the terms of Article $25 \mathrm{fa}$ of the Dutch Copyright Act, indicated by the "Taverne" license above, 


\section{THE PATHOGENESIS OF PANIC DISORDER}

The role of cognitions and conditioning in the development of panic disorder 
(C) Copyright Klara De Cort, Maastricht 2013.

All rights reserved. No part of this thesis may be reproduced or transmitted in any form of by any means, electronic or mechanical, including photocopying, recording, or any information storage or retrieval system without permission from the author, or when appropriate, from the publishers of the publications.

Alle rechten voorbehouden.

Niets uit deze uitgave mag worden verveelvoudigd, opgeslagen in een geautomatiseerd gegevensbestand en/of openbaar gemaakt in enige vorm of op enige wijze, hetzij elektronisch, mechanisch, door fotokopieën, opnamen of op enige andere manier zonder voorafgaande schriftelijke toestemming van de uitgever.

Cover design: www.basik.be

Vormgeving en druk: Datawyse | Universitaire Pers Maastricht

ISBN 9789461592361 


\title{
THE PATHOGENESIS OF PANIC DISORDER
}

\author{
The role of cognitions and conditioning in \\ the development of panic disorder
}

\author{
PROEFSCHRIFT
}

ter verkrijging van de graad van doctor aan de Universiteit Maastricht, op gezag van de Rector Magnificus, Prof. dr. L.L.G. Soete volgens het besluit van het College van Decanen,

in het openbaar te verdedigen op woensdag 3 juli 2013 om 16.00 uur

door

Klara De Cort

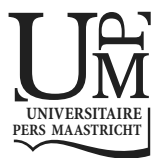




\section{Promotoren}

Prof. dr. I. Myin-Germeys

Prof. dr. E.J.L. Griez

\section{Copromotoren}

Dr. K.R.J. Schruers

Dr. I. Van Diest (Katholieke Universiteit Leuven, België)

\section{Beoordelingscommissie}

Prof. dr. P.A.E.G. Delespaul (voorzitter)

Prof. dr. P.E.H.M. Muris

Dr. D.T. Overbeek

Prof. dr. J.W.S. Vlaeyen (Katholieke Universiteit Leuven, België)

Het onderzoek gepresenteerd in dit proefschrift werd uitgevoerd op het Academisch Angstcentrum van Mondriaan/PsyQ en de School for Mental Health and Neuroscience, Universiteit Maastricht. 
De bal van Maradonna balancerend op zijn voet Het potlood van Picasso

dat het soms niet meer zijn moet Isaac Newton zag een appel en dacht zie ik dat goed Het is niet wat het is het is wat je d'r mee doet

(Bart Peeters) 
Paranimfen

Cindy Debie

Bart Rutten 


\section{Contents}

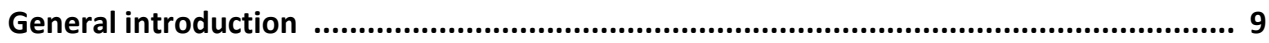

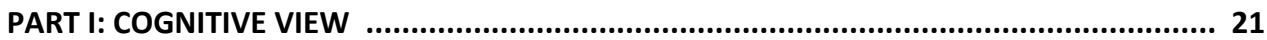

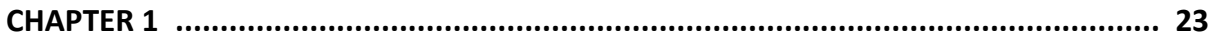

A specific attentional bias in panic disorder?

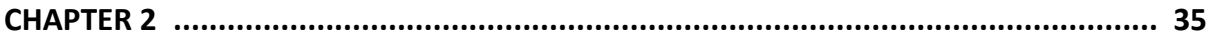

Priming associations between bodily sensations and catastrophic misinterpretations:

Specific for panic disorder?

CHAPTER 3

The weight of cognitions in panic: The link between misinterpretations and panic attacks

PART II: LEARNING THEORY

CHAPTER 4

The role of 'interoceptive' fear conditioning in the development of panic disorder

CHAPTER 5

Interoceptive fear conditioning and panic disorder: a differential design using inspiratory resistive loads and $35 \% \mathrm{CO}_{2}$

General Discussion

Samenvatting en Conclusies

Dankwoord 

General introduction 
Unexpected, recurring panic attacks are the main characteristic of panic disorder (PD), resulting in prolonged periods of anxiety and severe impairment of daily functioning. Panic attacks are periods of intense fear or discomfort that are of sudden onset and accompanied by various bodily sensations such as palpitations, sweating, feeling of breathlessness... However, in the general population panic attacks are common and are in themselves not necessarily pathological. Epidemiological studies showed a prevalence of $22.7 \%$ for panic attacks in the general population, the so called 'non clinical panic attacks'. The prevalence of PD (3.7\%) is high, compared to other psychiatric disorders, but considerably lower than the prevalence of panic attacks. This indicates that most persons do not develop PD after experiencing a panic attack (Kessler et al., 2006; Norton, Zvolensky, Bonn-Miller, Cox, \& Norton, 2008). In primary care, the prevalence of PD is even higher (4-6\%) (Katon, Roy-Byrne, Russo, $\&$ Cowley, 2002). The twelve month prevalence rates are generally between 1 and 3\% (Kessler, Chiu, Demler, \& Waters, 2005; Kessler et al., 2006). For the Dutch population lifetime and twelve month prevalence of respectively 3.8 and $2.2 \%$ are reported (Bijl, Ravelli, \& Van Zessen, 1998). Besides the occurrence of unexpected panic attacks, the presence of anticipatory anxiety towards developing new panic attacks is also necessary for the diagnosis of PD (American Psychiatric Association, 2000).

In epidemiological studies, approximately one third to half of the persons who meet the diagnostic criteria of PD also suffer from agoraphobia (White \& Barlow, 2002). The prevalence of agoraphobia without a history of PD is surprisingly high in some population studies (5,3\%, Kessler et al., 1994). However, this seems to be an artifact of the diagnostic method used; a detailed analysis shows that many respondents with 'agoraphobia' were actually suffering from a specific phobia or turned out to have panic attacks after all (Wittchen, Reed, \& Kessler, 1998). There is a clear sex difference in the incidence of PD: PD without agoraphobia occurs twice as often and PD with agoraphobia is three times as common in women as in men (APA, 2000). Agoraphobia without a history of PD is also more frequently diagnosed in women than in men (Wittchen et al., 1998). Most studies show that the age of onset of PD is usually between 15 and 24 years. Agoraphobia commonly develops during the year following the first panic attacks (White \& Barlow, 2002). The course of PD is usually chronic or recurrent. A study by Keller and colleagues (1994) showed that in 37\% of PD patients, symptoms disappear spontaneously within a year. In PD patients with agoraphobia, the percentage of spontaneous remission was significantly lower (17\%). More importantly, however, a follow-up measurement showed that in most of these 'recovered' patients the symptoms recurred after a few years. PD with or without agoraphobia is often characterized by comorbid problems: more than half of the PD patients also suffer from another anxiety disorder, depression, substance abuse (Brown, Campbell, Lehman, Grisham, \& Mancill, 2001) and/or personality disorders (Grant et al., 2006). In general the comorbidity is higher if there is also agoraphobia (Kessler et al., 2006). 
In spite of many years of research, there is no consensus on pathogenesis of PD. There are at least three prominent psychological theories concerning the development of PD. Anxiety sensitivity (AS) and Cognitive theory (CT) emphasize cognitive aspects of the disorder, Learning theory (LT), on the other hand, focuses on conditioning processes.

AS has been proposed as a risk factor for the development of anxiety disorders (Schmidt, Zvolensky, \& Maner, 2006); especially PD (Reiss, 1991, for a review see Olatunji \& WolitzkyTaylor, 2009). AS refers to individual differences in the fear of anxiety related sensations and the expectation that such sensations can have harmful consequences (McNally, 2002; Reiss, 1997; Reiss, Peterson, Gursky, \& McNally, 1986). AS can be assessed with the Anxiety Sensitivity Index (Reiss et al., 1986). People high in AS may be frightened by harmless palpitations because they believe the sensations will lead to a heart attack, whereas people low in AS do not fear these same sensations because they believe them to be harmless. A number of longitudinal studies have demonstrated that AS is, in fact, related to an increased risk of experiencing naturally occurring panic attacks (in high school adolescents; Hayward, Killen, Kraemer, \& Taylor, 2000; in college students; Li \& Zinbarg, 2007; in military recruits; Schmidt, Lerew, \& Jackson, 1997; Schmidt, Lerew, \& Jackson, 1999), which is in turn especially elevated in PD patients (McNally, 2002) and in first degree relatives of PD patients (van Beek \& Griez, 2003). Further, AS decreases with remission of PD symptoms after treatment (Romano, van Beek, Cucchi, Biffi, \& Perna, 2004; Smits, Powers, Cho, \& Telch, 2004). It appears reasonable to conclude that AS is a risk factor for panic attacks. Nevertheless, the clinical specificity of AS in panic genesis has been questioned by Bouton, Mineka \& Barlow (2001) due to the relatively small amount of overall variance accounted for by AS in the previous cited longitudinal studies (e.g., only $2 \%$ of variance accounted for panic attacks in Schmidt et al., 1999). Further, in some studies AS seems predictive for the subjective reaction to an experimental provocation challenge (Sturges, Goetsch, Ridley, \& Whittal, 1998; Zinbarg, Brown, Barlow, \& Rapee, 2001), while in other experimental studies, AS was not associated with increased risk of $\mathrm{CO}_{2}$-induced panic (Monkul et al., 2010; Perna, Romano, Caldirola, Cucchi, \& Bellodi, 2003). It was stated that AS is not a reliable predictor of panicogenic responses to $\mathrm{CO}_{2}$ in PD patients (Struzik, Vermani, Duffin, \& Katzman, 2004). In conclusion, the hypothesis that AS is a risk factor for panic genesis has obtained support, but the practical and clinical importance is still questionable (Bouton et al., 2001).

The AS theory of panic is related to the cognitive model of panic (Clark, 1986b), wherein panic is believed to be the result of the catastrophic misinterpretation of bodily sensations with uncertain cause. Catastrophic misinterpretations are assumed to be activated in an automatic and reflexive manner (Clark et al, 1997). Panic attacks are thought to arise when a person automatically interprets the somatic sensations as being dangerous and indicative of some impending doom (e.g. heart pounding representing heart attack). Via this way, PD patients become hyper vigilant for bodily sensations resulting in an 'attentional bias' towards physical cues associated with panic. As a result, the patient is more likely to re-activate the 
circle of misinterpretation. Overall, AS theory, emphasizes the fear of anxiety/arousal sensations and not the misinterpretation that the sensations are a sign of imminent catastrophe, as in CT.

In CT it is presumed that distorted 'panic' beliefs in PD are necessary to give rise to pathologic anxiety. Work in this tradition relies on questionnaires (Body Sensation Interpretation Questionnaire, McNally \& Foa, 1987), other introspective self-report methods or on information-processing methods, like reaction time tasks and related indirect measures for making inferences about underlying mechanisms (BSIQ, Austin \& Kiropoulos, 2008; priming test, Clark, 1988; selfreports, Rachman, Levitt, \& Lopatka, 1987; Implicit Association Test, Teachman, Smith-Janik, \& Marker, 2008). A critique concerning self-report measures is that they merely reflect a panic patient's attempt to explain panic symptomatology without being causal for the panic attacks. Moreover, self-report measures are subject to memory biases. Further, self-reports are artificial compared to the quick and reflexive nature of naturally occurring panic attacks (Clark, 1986a; Clark et al., 1997). A methodology that does not rely on the self-report of subjects are reaction time tasks. The emotional Stroop task is especially suitable for investigating the hypothesized specific 'attentional' biases in PD (this thesis, chapter 1 ), the priming task for the hypothesized specific automatic panic associations in PD (this thesis chapter 2). In the emotional Stroop task participants have to name the color in which words are printed while ignoring the meanings of the words. If patients are slow in color-naming emotionally relevant words (compared to neutral), this could be an indication of attentional bias. Up to now, several studies (Kampman, Keijsers, Verbraak, Näring, \& Hoogduin, 2002; Maidenberg, Chen, Craske, Bohn, \& Bystritsky, 1996; van den Heuvel et al., 2005) have investigated attentional bias in PD and did not fully succeed, in contrast with common belief, in demonstrating a PD-specific Stroop effect expressed as a combination of content specificity and disorder specificity. In a priming task, associatively related (e.g. butter-bread) and unrelated (e.g. dust-cats) prime-target pairs are presented. In an equal number of trials the targets are non-words. Participants are asked to categorize targets as quickly as possible as a 'word' or a 'nonword' (lexical decision task). It is hypothesized that if memory representations of bodily sensations automatically activate the representations of associated fearful outcomes, PD patients should respond significantly faster on trials in which the target was preceded by a related fearful prime as compared to unrelated and nonfearful prime (e.g. sandman-suffocate; cardboard-faint). Only a few studies have applied the priming paradigm to panic patients, and their findings are equivocal. Whereas Schniering \& Rapee (1997) failed to find differences between PD patients and healthy controls, Schneider and Schulte (2007) could demonstrate the expected differences but only when the priming effects were calculated (afterwards) for ideographically selected stimuli.

In general, when taking into account the hypothesized content (panic) and disorder specificity in attentional biases and the hypothesized automatic panic associations in PD, studies based on reaction time tasks provide only limited support for this cognitive view (see 
references above). Moreover, it is hypothesized that catastrophic panic cognitions are sufficient and necessary in evoking panic attacks in PD patients. Based on previous studies, however, no conclusions can be made because none of the existing studies was able to unfold a direct causal relationship between catastrophic cognitions and panic attacks. (Austin \& Richards, 2001; Roth, Wilhelm, \& Petit, 2005). There are some experimental studies that give an indication of the occurrence of catastrophic cognitions during experimentally induced panic attacks in patients suffering from PD (Griez \& Schruers, 1998; Whittal \& Goetsch, 1995). However, in those studies panic attacks were evoked by $\mathrm{CO}_{2}$ inhalations or hyperventilation and not directly through catastrophic thinking, so it is difficult to determine the actual cause of the panic attack (the thinking or the provocation itself?). There is however one report of an, unfortunately uncontrolled, experiment by Clark (1988) where the causal role of panic associations in provoking panic attacks was examined and supported in PD patients (in contrast with healthy subjects and recovered PD patients). In this experiment catastrophic thinking was activated through reading associated word pairs (e.g. palpitationsdying). Despite the obvious heuristic value, this observation was never formally replicated in a controlled experiment. In this thesis, chapter 3, we tried to replicate this study in a controlled experiment. Further, a criticism that is often cited in relation to $\mathrm{CT}$ is the lack of a clear explanation for the occurrence of nocturnal panic attacks and 'non fearful' panic, as both phenomena occur in the absence of detectable catastrophic cognitions.

The current status of this line of research is such that there are still a number of questions that need to be addressed empirically. First of all, given the contradictory data that are available, additional research will need to address the main issue of whether panic disorder is truly characterized by specific 'attentional biases' and spontaneous specific (automatic) 'catastrophic misinterpretations'. In the first 2 chapters of this thesis we aimed at examining both issues, respectively using an emotional Stroop paradigm (chapter 1 ) and a priming task (chapter 2) in PD patients and two control groups. Next, in the third chapter we aimed to experimentally test the hypotheses concerning the causal role of catastrophic misinterpretations in eliciting panic attacks in PD. As an improvement over previous studies, in our series of experiments (chapter 1-3), the panic group was compared to an anxious control group and a non-anxious control group to test the disorder specificity of the effects. A further strength of our studies is the selection and validation of panic-relevant and neutral stimuli to test the bias specificity of the observed effects.

Whereas in cognitive theory catastrophic misinterpretations are underlined as important mechanism, in LT a prominent role is given to interoceptive fear conditioning to explain the evolution of a panic attack into a PD. In both models, however, a central place of importance is given to the 'excessive' reaction to somatic sensations. So although these competing models differ in their explanation of the mechanism involved in the development of PD, there is correspondence across the models that somatic sensations are a key aspect of panic attacks. 
A central point of difference between both is, of course, that the cognitive view does not rely on conditioning theory.

The 'alarm theory', introduced by Barlow (1988; Barlow, Brown, \& Craske, 1994), is the first theory that tries to give an explicit explanation for the high prevalence of unexpected 'non clinical' panic attacks in the general population. It is stated that the crucial difference between 'non clinical' and 'clinical' panic attacks is that PD patients develop anxiety focused on the next potential panic attack. As such, the key process in the development of PD is the conditioning of anxiety (Bouton et al., 2001). The 'alarm theory' distinguishes three types of alarms, namely true, false and learned alarms. True alarms are a fear reaction in response to threat or danger that is actually present. Alarms are false if they occur in the absence of real threat or danger. When these alarms (false or true) become associated with external or internal cues (Conditioned Stimulus, CS), they become learned alarms resulting in interoceptive (IC) and exteroceptive conditioning. Through interoceptive fear conditioning (IFC) bodily sensations can act as a predictor for a panic attack (Unconditioned Stimulus, UCS) and evoking conditioned anxiety. IC is a term first described by Razran (1961) and refers to the involvement of interoceptive stimuli in the learning process of classical conditioning. Razran (1961) differentiates between three types of IC. First, 'extero-interoceptive' conditioning in which an external CS predicts an internal UCS. Second, 'intero-exteroceptive' conditioning in which an internal CS becomes the predictor of an external UCS. Third, 'intero-interoceptive' conditioning, in which an internal CS predicts an internal UCS (Razran, 1961). It is hypothesized, as already mentioned, that this latter form, intero-interoceptive conditioning, is particularly important in the pathogenesis of PD (Bouton et al., 2001). Specifically, the initial interoceptive precursors of a panic attack (such as sweating, palpitations...) become CSs, predicting more intense arousal and provoking anxiety as a conditioned response (Razran, 1961). This anxiety response may produce additional and more intense interoceptive stimuli (more palpitations, sweating, faster breathing) that further trigger and potentiate anxiety, spiraling into panic. Anxiety thus becomes a precursor of panic. IFC may explain why panic attacks occur in both the presence and absence of external cues and seem to come "out of the blue". Importantly in this respect, and also countering some known criticism towards LT, is that both phenomenological and neurobiological research confirms that panic and anxiety are descriptively and functionally different (Bouton et al., 2001). Panic refers to a subjective sense of extreme fear, which is accompanied by a massive autonomic surge and strong fight or flight response. In contrast, anxiety refers to apprehensive anticipation of future danger (the danger is not 'actually' present), accompanied by somatic symptoms of tension, vigilance, and worrying. Also, in contrast with CT, IFC can account for panic attacks that occur apparently without identifiable catastrophic misinterpretations (e.g., nocturnal panic attack). Furthermore, it has frequently been demonstrated that aversive emotional learning can occur without conscious representation of learning (Knight, Nguyen, \& Bandettini, 2006; Mineka \& Öhman, 2002; Schultz \& Helmstetter, 2010). Such findings encourage the view 
that declarative cognitions are not necessary for conditioning and thus for development into PD. In LT, however, cognitions are not seen as irrelevant. On the contrary they can even possess the power to elicit panic attacks through verbal conditioning. In this opinion cognitions can become verbal CSs eliciting anxiety on their own. Another criticism towards LT is that it 'over-predicts' panic and 'under-predicts' extinction. However, in conditioning the CS not only triggers conditioned responses but also modulates behavior (mostly) intended to escape from the 'predictive danger' cue. Often this escape- or avoidance behavior is subtle and thus not always visible for the environment. In addition to behavior, the context and other (excitatory and inhibitory) stimuli also influence the conditioning and extinction process (Bouton et al., 2001).

Support for IFC was first given in 1961 (Razran) in an experiment with dogs. In this study rhythmic distention of a dog's intestine (CS) was followed by $10 \% \mathrm{CO}_{2}$ (UCS). After conditioning, the CS evoked respiratory changes similar to the unconditioned reaction as hypothesized. Moreover, the CS was highly resistant to extinction. Establishing IC in the laboratory is very challenging because of the internal nature of the CS. Therefore evidence for IC is very limited and mainly comes from animal studies. Given these difficulties, it is not surprising that the research concerning IFC in PD is relatively new and very limited. However, the first findings in healthy volunteers are promising and seem to give support to the IFC account of PD, but seem to have certain important drawbacks (Acheson, Forsyth, Prenoveau, \& Bouton, 2007; Pappens, Van den Bergh, Vansteenwegen, Ceunen et al., 2011). In the study of Acheson et al. (2007) an inhalation of $5 \mathrm{sec}$ of $20 \% \mathrm{CO}_{2}$ as the CS and $15 \mathrm{sec}$ of $20 \% \mathrm{CO}_{2}$ as the UCS were used. Participants were randomised into three different conditions: CS only, CS-US paired, CS-US unpaired. IFC could be demonstrated in higher skin conductance and self reported fear for both the paired and unpaired condition compared to CS only condition. Surprisingly, an even stronger response was found in the unpaired group. However, since $\mathrm{CO}_{2}$ inhalations were used as both CS and UCS, a clear discrimination between both might have been difficult: the use of an unpaired group with homo-reflexive stimuli as a control condition may have caused unpredictability of the US, and therefore enhanced contextual anxiety. Recently, Pappens et al (2013) investigated interoceptive conditioning by making use of resistive loads. In these studies, a weak inspiratory load (intero-intero) and a neutral picture (extero-intero) served as CS and a severe respiratory load as US. In accordance with Acheson et al. (2007) CSs preceded the UCS in the paired groups, whereas in the unpaired groups there was no association between both. Extero-interoceptive conditioning to the neutral picture evoked greater startle potentiation, an increase in tidal volume and self-reported fear. Intero-interoceptive conditioning to the inspiratory load was most pronounced in the startle blink reactions: stronger defensive mobilization occurred in the paired group in contrast with the unpaired group. Self-reported fear was not clearly affected, however. On the basis of both studies it seems that the use of a homo-reflexive paradigm in which the CS is similar to the onset of the UCS and applied in an unpaired control condition is posing certain 
difficulties in studying IFC. In most studies on fear and appetitive conditioning, the use of a differential paradigm (CS+ is followed by UCS and CS- is not followed by UCS) is quite common and is assumed to be an appropriate paradigm (compared to a single CS design, Lissek et al., 2005) by controlling sensitization effects (= a non-associative mechanism whereby fear responses to any novel, intense or fear-related stimulus are temporarily elevated). Such a paradigm controls for the possibility that relevant CSs are simply more salient or potent as stimuli because superior conditioning requires the demonstration of greater responding to the relevant CS+ relative to the CS-.

Up to now, there is no known study that applies a differential interoceptive conditioning paradigm in the research of panic disorder. Therefore in the second part of this thesis we aimed at conducting a differential interoceptive paradigm. Equally important and further adding to the ecological validity in the research of PD is the use of a truly panicogenic UCS. In a study by our group, it was found that an inhalation of $35 \% \mathrm{CO}_{2}$-enriched air in healthy volunteers induces a condition that meets the formal criteria of panic in current psychiatric nosology. The inhalation of $35 \% \mathrm{CO}_{2}$-enriched air is proposed to be the most salient and ecologically valid UCS in investigating PD (Griez, Colasanti, Van Diest, Salamon, \& Schruers, 2007). Therefore, we performed two interoceptive conditioning studies with a panicogenic US. Chapter 4 concerns an 'interoceptive' conditioning study with imagery scripts as CS and an inhalation of $35 \%$ as UCS. In chapter $\mathbf{5}$ we elaborated on our previous study and aimed at performing an intero-interoceptive conditioning study by making use of interoceptive loads as CS and (also) an inhalation of $35 \%$ as UCS. When breathing through a resistive load, more effort is needed to breathe, which can evoke feelings of dyspnea (Pappens, Van den Bergh, Vansteenwegen, \& Van Diest, 2011). Finally, the general discussion summarizes and discusses all findings.

\section{Panic Attack}

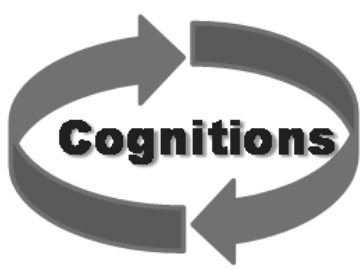

Panic Disorder
Panic Attack

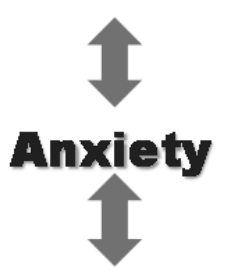

Panic Disorder

Figure: Model of Cognitive Theory (left) and Learning Theory (right)

In sum, this thesis focuses on the development of a panic attack into PD and aims at investigating the Cognitive and Learning account experimentally (figure 1). In CT a central place is given to 'catastrophic' cognitions which is the direct cause of the vicious circle of a panic attack turning into PD. In LT the key component is the conditioning of 'anxiety' (from 
and) for the next panic attack, which causes the development into PD. Further, through the conditioning of 'anxiety' condioned panic attacks can be evoked. 


\section{GENERAL INTRODUCTION}

\section{References}

Acheson, D. T., Forsyth, J. P., Prenoveau, J. M., \& Bouton, M. E. (2007). Interoceptive fear conditoning as a learning model of panic disorder: an experimental evaluation using $20 \% \mathrm{CO}_{2}$ enriched air in a non-clinical sample. Behaviour Research and Therapy, 45, 2280-2294.

American Psychiatric Association. (2000). Diagnostic and statistical manual of mental disorders. (4th ed., text rev ed.). Washington: D.C.: American Psychiatric Press.

Austin, D., \& Kiropoulos, L. (2008). An internet-based investigation of the catastrophic misinterpretation model of panic disorder. Journal of Anxiety Disorders, 22, 233-242.

Austin, D., \& Richards, J. (2001). The catastrophic misinterpretation model of panic disorder. Behaviour Research and Therapy, 39, 1277-1291.

Barlow, D. (1988). Anxiety and its disorders: The nature and treatment of anxiety and panic. New York: Guilford Press.

Barlow, D., Brown, T., \& Craske, M. (1994). Definitions of panic attacks and panic disorder in the DSM-IV: implications of research. Journal of Abnormal Psychology, 103, 553-564.

Bijl, R., Ravelli, A., \& Van Zessen, G. (1998). Prevalence of psychiatric disorder in the general population: Results of the Netherlands Mental Health Survey and Incidence Study (NEMESIS). Social Psychiatry and Psychiatric Epidemiology, 33, 587-595.

Bouton, M. E., Mineka, S., \& Barlow, D. (2001). A modern learning theory perspective on the etiology of panic disorder. Psychological Review, 108, 4-32.

Brown, T., Campbell, L., Lehman, C., Grisham, J., \& Mancill, R. (2001). Current and lifetime comorbidity of the DSM-IV anxiety and mood disorders in a large clinical sample. Journal of Abnormal Psychology, 110, 49-58.

Clark, D. (1986a). Anxiety states: panic and generalized anxiety. In K. Hawton, P. Salkovskis, J. Kirk \& D. M. Clark (Eds.), Cognitive behaviour therapy of psychiatric problems (pp. 52-96). Oxford: Oxford University Press.

Clark, D. (1986b). A cognitive approach to panic. Behaviour Research and Therapy, 24, 461-470.

Clark, D. (1988). A cognitive model of panic attacks. In S. Rachman \& J. D. Maser (Eds.), Panic; psychological perspectives. New Yersey: Lawrence Erlbaum associates.

Clark, D., Salkovskis, P., Breiholtz, E., Westling, B., Öst, L.-G., Koehler, K., et al. (1997). Misinterpretation of body sensations in panic disorder. Journal of Consulting and Clinical Psychology, 65(2), 203-213.

Grant, B., Hasin, D., Stinson, F., Dawson, D., Goldstein, R., Smith, S., et al. (2006). The epidemiology of DSM-IV panic disorder and agoraphobia in the United States: Results from the National Epidemiologic Survey on Alcohol and Related Conditions. Journal of Clinical Psychiatry, 67, 363-364.

Griez, E., Colasanti, A., Van Diest, R., Salamon, E., \& Schruers, K. (2007). Carbon dioxide inhalation induces dose-dependent and age-related negative affectivity. PLOS ONE, 2(10), e987.

Griez, E., \& Schruers, K. (1998). Experimental pathophysiology of panic. Journal of Psychosomatic Research, 45(6), 493-503.

Hayward, C., Killen, J., Kraemer, H., \& Taylor, C. (2000). Predictors of panic attacks in adolescence. Journal of the American Academy of Child and Adolescent Psychiatry, 39, 207-214.

Kampman, M., Keijsers, G. P. J., Verbraak, M. J. P. M., Näring, G., \& Hoogduin, C. A. L. (2002). The emotional Stroop: a comparison of panic disorder patients, obsessive-compulsive patients, and normal controls in two experiments. Journal of Anxiety Disorders, 16, 425-441.

Katon, W., Roy-Byrne, P., Russo, J., \& Cowley, D. (2002). Cost-effectiveness and cost offset of a collaborative care intervention for primary care patients with panic disorder. Archives General Psychiatry, 59, 10981104.

Keller, M., Yonckers, K., Warshaw, M., Pratt, L., Golan, J., Mathews, A., et al. (1994). Remission and relapse in subjects with panic disorder and agoraphobia: A prospective short interval naturalistic follow-up. Journal of Nervous and Mental Disease, 182, 290-296. 
Kessler, R., Chiu, W., Demler, O., \& Waters, E. (2005). Prevalence, severity, and comorbidity of 12-month DSMIV disorders in the National Combidity Survey Replication. Archives of General Psychiatry, 62, 617-627.

Kessler, R., Chiu, W., Jin, R., Ruscio, A., Shear, K., \& Walters, E. (2006). The epidemiology of panic attacks, panic disorder, and agoraphobia in the National Comorbidity Survey Replication. Archives of General Psychiatry, 63, 415-424.

Kessler, R., McConagle, K., Zhao, S., Nelson, C., Hughes, M., Eshleman, S., et al. (1994). Lifetime en 12-month prevalence of DSM-III-R psychiatric disorders in the United States: Results from the National Comorbidity Survey. Archives of General Psychiatry, 51, 8-19.

Knight, D. C., Nguyen, H. T., \& Bandettini, P. A. (2006). The role of awareness in delay and trace fear conditioning in humans. Cognitive, Affective, \& Behavioral Neuroscience, 6(2), 157-162.

Li, W., \& Zinbarg, R. (2007). Anxiety sensitivity and panic attacks: a one-year longitudinal study. Behavior Modification, 31, 145-161.

Lissek, S., Powers, A., McClure, E., Phelps, E., Woldehawariat, G., Grillon, C., et al. (2005). Classical fear conditioning in the anxiety disorders: a meta-analysis. Behaviour Research and Therapy, 43, 1391-1424.

Maidenberg, E., Chen, E., Craske, M., Bohn, P., \& Bystritsky, A. (1996). Specificity of attentional bias in Panic Disorder and Social Phobia. Journal of Anxiety Disorders, 10(6), 529-541.

McNally, R. J. (2002). Anxiety sensitivity and panic disorder. Biological Psychiatry, 52, 938-946.

McNally, R. J., \& Foa, E. (1987). Cognitions and agoraphobia: bias in the interpretation of threat. Cognitive Therapy and Research, 11, 567-581.

Mineka, S., \& Öhman, A. (2002). Phobias and preparedness: The selective, automatic, and encapsulated nature of fear. Biological Psychiatry, 52, 927-937.

Monkul, E., Onur, E., Tural, U., Hatch, J., Alkin, T., Yücel, B., et al. (2010). History of suffocation, state-trait anxiety, and anxiety sensitivity in predicting $35 \%$ carbon dioxide-induced panic. Psychiatric Research, 179, 194-197.

Norton, P. J., Zvolensky, M. J., Bonn-Miller, M. O., Cox, B. J., \& Norton, G. R. (2008). Use of the Panic Attack Questionnaire-IV to assess non-clinical panic attacks and limited symptom panic attacks in student and community samples. Journal of Anxiety Disorders, 22, 1159-1171.

Olatunji B, Wolitzky-Taylor K. 2009. Anxiety sensitivity and the anxiety disorders: meta-analytic review and synthesis. Psychological Bulletin, 135(6):974-999.

Pappens, M., Van den Bergh, O., Vansteenwegen, D., Ceunen, E., De Peuter, S., \& Van Diest, I. (2013). Learning to fear obstructed breathing: comparing interoceptive and exteroceptive cues. Biological Psychology, 92, 36-42.

Pappens, M., Van den Bergh, O., Vansteenwegen, D., \& Van Diest, I. (2011). Psychophysiological responses to inspiratory resistive loads. International Journal of Psychophysiology, 80, 161-165.

Perna, G., Romano, P., Caldirola, D., Cucchi, M., \& Bellodi, L. (2003). Anxiety sensitivity and $35 \% \mathrm{CO}_{2}$ reactivity in patients with panic disorder. Journal of Psychosomatic Research, 54, 573-577.

Rachman, S., Levitt, K., \& Lopatka, C. (1987). Panic: The links between cognitions and bodily symptoms I. Behaviour research and therapy, 25, 411-424.

Razran, G. (1961). The observable unconscious and the inferable conscious in current Soviet psychophysiology: Interoceptive conditioning, semantic conditioning, and the orienting reflex. Psychological Review, 68, 81150.

Reiss, S. (1991). Expectancy model of fear, anxiety, and panic. Clinical Psychological Review, 11, 141-153.

Reiss, S. (1997). Triat Anxiety: it's not what you think it is. Journal of Anxiety Disorders, 11, 201-214.

Reiss, S., Peterson, R., Gursky, M., \& McNally, R. (1986). Anxiety, sensitivity, anxiety frequency, and the prediction of fearfulness. Behaviour Research and Therapy, 24, 1-8.

Romano, P., van Beek, N., Cucchi, M., Biffi, S., \& Perna, G. (2004). Anxiety sensitivity and modulation of the serotonergic system in patients with PD. Journal of Anxiety Disorders, 18, 423-431. 


\section{GENERAL INTRODUCTION}

Roth, W. T., Wilhelm, F., \& Petit, R. (2005). Are current theories of panic falsifiable? Psychological Bulletin, 131(2), 171-192c.

Schmidt, N., Lerew, D., \& Jackson, R. (1997). The role of anxiety sensitivity in the pathogenesis of panic: Projective evaluation of spontaneous panic attacks during acute stress. Journal of Abnormal Psychology, 106, 355-364.

Schmidt, N., Lerew, D., \& Jackson, R. (1999). Prospective evaluation of anxiety sensitivity in the pathogenesis of panic: replication and extension. Journal of Abnormal Psychology, 108, 532-537.

Schmidt, N., Zvolensky, M. J., \& Maner, J. (2006). Anxiety sensitivity: prospective prediction of panic attacks and Axis I pathology. Journal of Psychiatric Research, 40(8), 691-699

Schneider, R., \& Schulte, D. (2007). Panic patients reveal idiographic associations between anxiety symptoms and catastrophes in a semantic priming task. Behaviour Research and Therapy, 45, 211-223.

Schniering, C., \& Rapee, R. (1997). A test of the cognitive model of panic primed lexical decision in panic disorder. Journal of Anxiety Disorders, 6, 557-571.

Schultz, D. H., \& Helmstetter, F. J. (2010). Classical conditioning of automatic fear responses is independent of contingency awareness. Journal of Experimental Psychology: General, 36(4), 495-500.

Smits, J., Powers, M., Cho, Y., \& Telch, M. (2004). Mechanism of change in cognitive-behavioral treatment of panic disorder: evidence for the fear of fear Mediational hypothesis. Journal of Consulting and Clinical Psychology, 72(4), 646-652.

Struzik, L., Vermani, L., Duffin, J., \& Katzman, M. (2004). Anxiety sensitivity as a predictor of panic attacks. Psychiatry Research, 129, 273-278.

Sturges, L., Goetsch, V., Ridley, J., \& Whittal, M. (1998). Anxiety sensitivity and respons to hyperventilation challenge: physiologic arousal, interoceptive acuity and subjective distress. Journal of Anxiety Disorders, $12,103-115$.

Teachman, B., Smith-Janik, S., \& Marker, C. (2008). Automatic associations and panic disorder: trajectories of change over the course of treatment. Journal of Consulting and Clinical Psychology, 76(6), 988-1002.

van Beek, N., \& Griez, E. (2003). Anxiety sensitivity in first-degree relatives of patients with panic disorder. Behaviour Research and Therapy, 41(8), 949-957.

van den Heuvel, O. A., Veltman, D. J., Groenewegen, H. J., Menno, P. W., Merkelbach, J., Cath, D. C., et al. (2005). Disorder-Specific Neuroanatomical Correlates of Attentional Bias in Obsessive-compulsive Disorder, Panic Disorder, and Hypochondrias. Archives of general psychiatry, 62, 922-933.

White, K., \& Barlow, D. (2002). Panic disorder and agoraphobia. In D. Barlow (Ed.), Anxiety and its disorders. The nature and treatment of anxiety and panic (pp. 328-379). New York: Guilford Press.

Whittal, M., \& Goetsch, V. (1995). Physiological, subjective and behavioral responses to hyperventilation in clinical and infrequent panic. Behaviour Research and Therapy, 33(4), 415-422.

Wittchen, H., Reed, V., \& Kessler, R. (1998). The relationship of agoraphobia and panic in a community sample of adolescents and young adults. Archives of General Psychiatry, 55, 1017-1024.

Zinbarg, R., Brown, T., Barlow, D., \& Rapee, R. (2001). Anxiety sensitivity, panic, and depressed mood: a reanalysis teasing apart the contributions of the two levels in the hierarchical structure of the anxiety sensitivity index. Journal of Abnormal Psychology, 110(3), 372-377. 


\section{PART I: COGNITIVE VIEW}





\section{CHAPTER 1}

\section{A specific attentional bias in panic disorder?}

Klara De Cort ${ }^{1}$, Dirk Hermans ${ }^{2}$, Adriaan Spruyt ${ }^{2}$, Eric Griez ${ }^{1}$ \& Koen Schruers ${ }^{1,2}$

${ }^{1}$ Maastricht University, Institute for Mental Health and Neuroscience, the Netherlands

${ }^{2}$ University of Leuven, Center for Learning and Experimental Psychopathology, Belgium

Published as: De Cort, K., Hermans, D., Spruyt, A., Griez, E. \& Schruers, K. (2007). A specific attentional bias in panic disorder? Depression and Anxiety, 25(11), 951-955. 


\begin{abstract}
According to cognitive theories, panic patients are assumed to have an attentional bias towards bodily sensations. To date, there is only some indirect evidence of such a bias measured by an emotional Stroop task. Moreover, the content and disorder specificity of this bias is rather unclear. The aim of the present study was to investigate the specificity of attentional bias in patients with panic disorder (PD). Patients with PD $(n=32)$, patients with mixed anxiety disorders $(n=25)$, and a healthy control group $(n=26)$ performed an emotional Stroop task with three word types: panic threat, general threat, and neutral. There were no differences on reaction times between the different groups, nor on the different word types. Despite the generally accepted existence of attentional biases in anxiety disorders, we found no evidence of a specific attentional bias in patients with PD.
\end{abstract}




\section{Introduction}

Selective attention plays a central role in cognitive theories (Beck, 1998; Beck \& Emery, 1985; Clark, 1986) of panic disorder (PD). The theory states that PD patients misinterpret fearsome somatic sensations as evidence of an impending disaster (e.g., the feeling that one is going crazy, going to faint, or having a heart attack). This misinterpretation results in anxiety and increased bodily sensations, thereby reaffirming the initial misinterpretation. A key aspect of the theory is that people with PD become vigilant for bodily sensations, developing a so-called attentional bias towards cues associated with panic. As a result, the patient is likely to activate the circle of misinterpretation.

The term 'attentional bias' can refer to the kind of disorder (i.e. disorder specificity) or to the type of stimuli used (i.e. content specificity). To speak of a disorder-specific attentional bias, it is necessary to distinguish PD patients from other subjects. To establish a contentspecific attentional bias, panic patients must have a bias towards specific panic-related cues and not towards more general threat and neutral cues. Ideally, in order for an attentional bias to be specific, it must comply with both criteria of specificity.

A well-established instrument for measuring selective attention is the emotional Stroop task (Williams, Mathews, \& MacLeod, 1996), in which participants have to name the color in which words are printed while ignoring the meanings of the words. If patients are slow in color-naming emotionally relevant words, this could be an indication of attentional bias. PD patients are characterized by their fear of fear (Chambless \& Gracely, 1989), their bodily sensations, and their catastrophic misinterpretations (Clark, 1986). Thus, a word is emotionally relevant (McNally, Riemann, \& Kim, 1990) for PD patients and PD patients only (disorder specificity) when it refers to (content specificity) fear per se (e.g., the words panic, anxiety), to its symptoms (e.g., dizziness, palpitations), or to the possible consequences of a panic attack (e.g., heart attack, fainting). In contrast, a general threat word is defined as one that refers to matters of concern in general (e.g., disease, fatality, funeral). A neutral word does not possess any emotional significance and has no referring valence.

During the last 15 years, several studies have investigated attentional bias in PD (Table 1). 
Table 1. Overview of studies on attentional bias and panic disorder using the emotional Stroop task in terms of content specificity and disorder specificity.

\begin{tabular}{lcc}
\hline & Content specificity & Disorder specificity \\
\hline Ehlers et al. (1988) & - & - \\
McNally et al. (1990) & + & - \\
McNally et al. (1992) & + & - \\
McNally et al. (1994) & - & - \\
Maidenberg et al. (1996) & - & - \\
Lundth et al. (1999) & - & + \\
Kampman et al. (2002) & - & - \\
van den Heuvel et al. (2005) & - & - \\
\hline
\end{tabular}

The first study in this field was conducted by Ehlers and colleagues (Ehlers, Margraf, Davies, \& Roth, 1988). In the first experiment, 24 PD patients and normals had to name the color of six word categories presented on flash cards, namely, physical harm, separation, social embarrassment, and three matching neutral word categories. In the second experiment, nonclinical panickers and normals had to name the color of physical threat words and neutral words. The words used in this study referred to general concerns and were not emotionally relevant for the PD patients. Thus, there was no content specificity. In the first experiment, no differences were found in reaction time. In the last experiment, there was an attentional bias for general threat words for both groups. Moreover, no disorder specificity could be found in this study.

In subsequent studies (McNally et al., 1990; McNally, Riemann, Louro, Lukach, \& Kim, 1992), the participants had to name the color of 'catastrophic' words (i.e., words referring to the possible consequences of a panic attack), fear words, bodily sensation words (i.e., words referring to the symptoms of fear), and neutral words. Results showed that PD patients were generally slower than controls. PD patients as well as normals named catastrophic words significantly more slowly than other words. Thus, although there were indications for content specificity, no disorder specificity was found.

Other studies (Maidenberg et al., 1996; McNally et al., 1994) used so-called panic threat words (i.e., words referring to the word 'fear', to a catastrophe, or to a bodily symptom), general threat words, and neutral words. McNally et al. (1994) found that PD patients were significantly slower than normals. Panic patients exhibited greater interference for panicrelated words than for neutral words. However, they showed the same interference for general threat words. Furthermore, healthy volunteers exhibited a pattern of responding that was similar to that of the patients. In the Maidenberg et al. study (1996), similar results were found. Panic patients showed significantly longer response times to panic-related and general threat words than to neutral words. The response times of PD patients were similar to those of control subjects. Thus, in both studies, neither content specificity nor disorder specificity could be demonstrated. 
Only one study reported a specific PD-related Stroop effect (Lundth, Wilkström, Westerlund, \& Öst, 1999) that was not present in the control group. However, when one examines the specific words that were used in the category 'panic' words, it appears that words were also used that have been labeled as general threat words in previous studies (e.g., 'fear', 'pain', 'dreadful', 'torment', 'lethal'). Despite the existence of disorder specificity, no content specificity was present.

The study by Kampman et al. (2002) made use of a category of specific PD-related words. The results showed that PD patients generally responded more slowly than controls, but no attentional bias was found in any of the groups.

Van den Heuvel et al. (2005) also investigated attentional bias in anxiety disorders. Like Maidenberg et al. (1996), they found that PD patients and patients with hypochondriasis did not show a specific attentional bias, but rather a generalized attentional bias towards panicrelated words and words related to obsessive-compulsive disorder.

In sum, when reviewing the relevant literature, it appears that none of the studies succeeded in demonstrating a PD-specific Stroop effect expressed as a combination of content specificity and disorder specificity. Nevertheless, results of these studies are generally interpreted as favoring the existence of such an effect (Bar-Haim, Lamy, Pergamin, BakermansKranenburg, \& van IJzendoorn, 2007; Williams et al., 1996), with the exception of Kampman et al. (2002) and van den Heuvel et al. (2005).

This study explores the existence of a PD-specific Stroop effect while taking into consideration the limitations of previous studies. Most of the studies mentioned had a modest sample size, ranging from 14 to 21 PD patients. Other aspects that did not favor specificity included the broad categorization of panic threat words (Lundth et al., 1999), the use of a non-clinical sample (Ehlers et al., 1988), the lack of a patient control group, and a general threat word type (McNally et al., 1990, Lundth et al., 1999). Consequently, we decided to make use of a relatively larger sample of PD patients and to make a clear differentiation between general threat and panic-related words. We also included, in addition to a healthy control group, a mixed anxiety control group.

\section{Methods}

\section{Participants}

The study involved three groups of participants. In addition to the panic group, an anxious control group and a non-clinical control group were included in the design.

In the panic group, 34 patients were selected who met the DSM-IV criteria for a diagnosis of PD. Two were later excluded due to loss of data, leaving a total of 32 PD patients (17 female). Their mean age was 42.5 years $(S D=12.32)$.

The mixed anxiety group consisted of 25 patients ( 19 female). Of these, $35 \%$ had obsessive-compulsive disorder, $23 \%$ social phobia, $38 \%$ specific phobia, and $4 \%$ generalized anxie- 
ty disorder as their primary diagnosis. Their mean age was 36 years $(S D=13.55)$. All patients were seeking treatment at the Academic Anxiety Center in Maastricht.

The healthy control group consisted of 30 participants (12 females). This group was matched with the panic group for sex and age. Participants had never had a psychiatric disorder diagnosed. Four subjects were excluded because of extremely high anxiety scores on a visual analogue scale (VAS; $>2$ standard deviation) during the experiment. Their mean age was 43.8 years $(S D=10.54)$. They were recruited by advertisement.

\section{Materials}

In the emotional Stroop task, three categories of words were used: 15 panic-related words, 15 general threat words, and 15 neutral words (Table 2). The threat words were derived from former research (Mc Nally et al. 1994, Maidenberg et al., 1996) and referred to their worries. The neutral words were neither positive nor abstract. To rule out a possible difference in results by presentation form, all categories were matched for word length and imagine-ability.

Table 2. Word list for each word type.

\begin{tabular}{lll}
\hline Panic words & General threat words & Neutral words \\
\hline Death & Sickness & House \\
Heart attack & Torture & Pencil \\
Brain tumor & Violence & Pen \\
Collapse & War & Paper clip \\
Going crazy & Accident & Neutral \\
Dizziness & Funeral & Computer \\
Heartbeat & Pain & Identical \\
Fainting & Hate & Signature \\
Suffocation & Loneliness & Common \\
Tingling & Danger & Clothes \\
Dyspnea & Cancer & Cup of coffee \\
Shaking & Abuse & Vacuum cleaner \\
Panic & Robbery & Street lamp \\
Loss of control & Flood & Ruler \\
Chest pain & Rape & Desk chair \\
\hline
\end{tabular}

The stimuli were presented on a personal computer. The words appeared in 12-cm block letters on a Philips color monitor and appeared in the colors red, blue, green, and yellow.

\section{Questionnaires}

All participants were administered the Mini International Neuropsychiatric Interview (MINI, Lecrubier et al., 1997). To rule out possible side effects caused by depressive symptoms, all 
patients also completed the Montgomery-Asberg Depression Rating Scale (MADRS, Montgomery \& Asberg, 1979) and the Self-rating Depression Scale (SDS, Zung, 1965).

\section{Procedure}

In the pre-test screening, all questionnaires were administered after obtaining written informed consent.

In the test phase, when entering the experiment, patients scored their anxiety level on the VAS. The Stroop task was presented on a computer screen. The participants were given the instruction to ignore the meaning of the word and to name its color as quickly as possible by pressing the corresponding button. As soon as the button was pressed, the next word appeared. First, there was a training phase of 20 words, followed by four blocks of 45 words each. Each block consisted of all the words of the different word types. Each word was presented four times throughout the experiment: once in red, once in yellow, once in blue, and once in green. Words were presented randomly ( $45 \times 4$ colors $=180$ words). After the experiment, participants were asked to fill in the VAS to score their anxiety level.

\section{Design}

A repeated measures analysis of variance was conducted with group (three levels: PD patients, anxiety group, normal control) as between-subject variable and word type (three levels: panic-relevant, general threat, and neutral) and block (block 1 - 4) as within-subject variables.

\section{Results}

PD patients had slower responses to all words in contrast to the mixed anxiety group and normal control group, but this was not significantly different. There was an effect of block $(F(3.52)=20.22, p<.0001)$, indicating that over the four blocks, participants were reacting faster, referring to a learning effect.

There were no group differences in reaction times $(F(2.80)=1.35, p=$ n.s., not significant). Nor was there a main effect of word type $(F(2.160)=1.03, p=$ n.s. $)$.

The crucial word $X$ group interaction was not significant $(F(4,160)<1)$, indicating that PD patients, other anxiety patients, and normal controls all had the same pattern of responses to the word types (Table 3).

Because possible Stroop effects can be influenced by depression, a post analysis was performed. The panic group was divided in a high- and low- depressive group depending on their scores on the Montgomery-Asberg Depression Scale ( $<12=$ low depressive group). In 
the panic group with low depressive scores there were no differences in reaction time on the Stroop task. There was no main effect of word-type $F(2.30)=0.52, p=n . s$.).

Table 3. Mean response latencies in milliseconds and median anxiety level on VAS during the experiment (start_VAS = entering experiment, VAS_bef= before experiment, VAS_af = after experiment) of PD patients, Mixed (anxiety) patients, and Normal controls. The standard deviation is included within parentheses.

\begin{tabular}{llll}
\hline Word type & PD patients & Mixed patients & Normals \\
\hline Panic & $826(148)$ & $758(142)$ & $777(142)$ \\
General threat & $816(138)$ & $760(138)$ & $766(148)$ \\
Neutral & $820(121)$ & $764(110)$ & $771(109)$ \\
Start VAS & 24 & 7 & 0 \\
VAS_bef & 23 & 6 & 0 \\
VAS_end & 30 & 5 & 0 \\
\hline
\end{tabular}

During the experiment, anxiety levels were assessed. The panic and mixed anxiety groups had a significantly higher overall anxiety level during the experiment than the normal group (Table 3, $p<0.001$ ). Since anxiety can also influence reaction times, a post hoc analysis was performed on the panic subjects with low anxiety scores. Again, there was no main effect of word type $(F(2.30)=0.26, p=n . s$. $)$.

\section{Discussion}

The results of the present study show that neither PD patients, patients with other anxiety disorders, nor normal controls had longer response latencies to panic-specific threatening stimuli or general threat stimuli than to neutral words. Our results are in sharp contrast to the conclusions of previous research. We did not find any evidence of either disorder specificity or content specificity.

Theoretically, the lack of a specific Stroop effect could be due to suppression by other phenomena. It has been shown that external stressors can suppress a Stroop effect (Amir et al., 1996; Constans, Vasterling, McClosky, Brailey, \& Mathews, 2004; Mathews \& Mackintosh, 1998; Mathews \& Sebastian, 1993; Mogg, Kentish, \& Bradley, 1993). It is conceivable that the experimental set-up was experienced as more stressful by one group of participants than by the others. Indeed, if we look at the level of anxiety during the experiment, it appears that both patient groups were more anxious than the healthy controls. However, PD patients with high or low general anxiety did not differ in reaction times on the Stroop. Moreover, PD patients with the lowest level of general anxiety did not show any attentional bias towards panic words. Therefore, the overall anxiety level does not seem to explain the results.

Another possible source of suppression is the presence of depression (Grant \& Beck, 2005), as shown in recent studies on social anxiety (Musa, Lépine, Clark, Mansell, \& Ehlers, 
2003). In the present study, Stroop reaction times did not differ in participants with low depression scores, indicating that the results cannot be attributed to depression.

Most studies on PD have used the Stroop paradigm to investigate attentional bias. A drawback of this task is that attentional processes are not measured independently (Algom, Lev, \& Chajut, 2004). The dot probe detection task does not have this particular disadvantage. Two studies using the dot probe were performed in PD patients. The first study (Asmundson \& Sandler, 1992) found PD patients to be quicker in detecting physical threat cues than social threat cues. This difference was not observed with control subjects. However, when looking at the specificity of the words used, they also referred to general threat words. An attempt to replicate these findings with more PD-specific words (Asmundson \& Murray, 1994) failed to find an attentional bias favoring panic cues in PD patients. PD patients did not respond differently to dot probes that followed the presentation of panic symptoms/fear, social threat or neutral cues, and they did not differ from control subjects.

More recently, a study was conducted in which heart rate was used to enhance ecological validity for PD (Kroeze \& van den Hout, 2000a). Selective attention for heart rate was measured with a modified dot probe task. PD patients paid more attention to the heart rate than to neutral stimuli compared to normals. However, both groups had the same pattern of responding. Both PD and normal controls shifted their attention away from an accelerated heartbeat, and there was no attentional bias towards an accelerated heartbeat. Thus, even when using threatening sensations, there is no clear indication of a specific attentional bias in PD.

In a subsequent study (Kroeze \& van den Hout, 2000b), PD patients and healthy volunteers were instructed to either hyperventilate, to overbreathe under isocapnic conditions, or to make a neutral movement while performing another reaction time task in which tones of different length had to be discriminated. No difference was found between the two groups. Again, no evidence was found of selective attention to hyperventilatory sensations.

In conclusion, neither studies using a Stroop paradigm, nor those using a dot probe task or stimuli selected on the basis of their ecological validity provide any evidence of a specific attentional bias in PD. The generally accepted view that there is a specific attentional bias in PD is not supported by any available empirical evidence.

Some questions have been raised concerning the sensitivity of the emotional Stroop task as a measure of attentional bias (Algom et al., 2004). However, selective attention has been already demonstrated in some other anxiety disorders (Amir, Freshman, \& Foa, 2002; BarHaim et al., 2007; Becker, Rinck, Margraf, \& Roth, 2001; Lavy, van de Hout, \& Arntz, 1993; Paunovi, Lundth, \& Öst, 2002), not only with the emotional Stroop task but also with the dot probe task. The lack of a specific attentional bias in PD as opposed to some other anxiety disorders needs further investigation and can potentially reveal some underlying mechanisms. Future research could, for instance, combine different paradigms (e.g., emotional Stroop task, dot probe task, eye movement registration) to measure attention and include 
CHAPTER 1

different groups of anxiety disorders (e.g., PD, GAD, Specific phobia, PTSD...). This way, a more detailed distinction could be made between these disorders as for the presence or absence of a specific attentional bias. Discussion on the possible underlying mechanisms, however, is open at this point. 


\section{References}

Algom, D., Lev, S., \& Chajut, E. (2004). A rational look at the emotional Stroop phenomenon, a generic slowdown, not a Stroop effect. Journal of Experimental Psychology: General, 133(3),323-338.

Amir, N., Freshman, M., \& Foa, E. (2002). Enhanced Stroop interference for threat in social phobia. Journal of Anxiety Disorders, 16, 1-9.

Amir, N., McNally, R.J., Riemann, B.C., Burns, J., Lorenz, M., \& Mullen, J. (1996). Suppression of the emotional Stroop effect by increased anxiety in patients with social phobia. Behaviour Research and Therapy, 11, 945-948.

Asmundson, G.J., \& Murray, S.B. (1994). Dot-probe evaluation of cognitive processing biases in patients with panic disorder: a failure to replicate and extend. Anxiety, 1, 123-128.

Asmundson, G.J., \& Sandler, L.S. (1992). Selective attention toward physical threat in patients with panic disorder. Journal of Anxiety Disorders, 6, 295-303.

Bar-Haim, Y., Lamy, D., Pergamin, L., Bakermans-Kranenburg, M., \& van IJzendoorn, M. (2007). Threat-related attentional bias in anxious and nonanxious individuals: a meta-analytic study. Psychological Bulletin, 133(1), 1-24.

Beck, A.T. (1998). Cognitive approaches to panic disorder: theory and therapy. In: Rachman S, Maser JD, editors. Panic, psychological perspectives. Hillsdale, New Yersey: Lawrence erlbaum associates. p 91-111.

Beck, A.T., \& Emery, T. (1985). Anxiety disorders and Phobias. New York: Basic Books.

Becker, E., Rinck, M., Margraf, J., \& Roth, W.T. (2001). The emotional Stroop effect in anxiety disorders: general emotionality or disorder specificity? Journal of Anxiety Disorders, 15, 147-159.

Chambless, D.L., \& Gracely, E. (1989). Fear of fear and the anxiety disorders. Cognitive Therapy and Research, 13, 9-20.

Clark, D.M. (1986). A cognitive approach to panic. Behaviour Research and Therapy, 24, 461-470.

Constans, J.I., Vasterling, J.J., McClosky, M.S., Brailey, K., \& Mathews, A. (2004). Suppression of attentional bias in PTSD. Journal of Abnormal Psychology, 113(2), 315-323.

Ehlers, A., Margraf, J., Davies, S., \& Roth, W.T. (1988). Selective processing of threat cues in subjects with panic attacks. Cognition and Emotion, 2(3), 201-219.

Grant, D., \& Beck, J. (2005). Attentional bias in social anxiety and dysphobia: does comorbidity make a difference? Journal of Anxiety Disorders, 20(4), 520-529.

Kampman, M., Keijsers, G.P.J., Verbraak, M.J.P.M., Näring, G., \& Hoogduin, C.A.L. (2002). The emotional Stroop: a comparison of panic disorder patients, obsessive-compulsive patients, and normal controls in two experiments. Journal of Anxiety Disorders, 16, 425-441.

Kroeze, S., \& van den Hout, M.A. (2000a). Selective attention for cardiac information in panic patients. Behaviour Research and Therapy, 38(1), 63-72.

Kroeze, S., \& van den Hout, M.A. (2000b). Selective attention for hyperventilatory sensations in panic disorder. Journal of Anxiety Disorders, 14(6), 563-581.

Lavy, E., van de Hout, M., \& Arntz, A. (1993). Attentional bias and spider phobia: conceptual and clinical issues. Behaviour Research and Therapy, 31, 17-24.

Lecrubier, Y., Sheehan, D., Weiller, E., Amorim, P., Bonora, I., Sheehan, K. H., et al. (1997). The Mini International Neuropsychiatric Interview (MINI). A short diagnostic structured interview: reliability and validity according to the CIDI. European Psychiatry, 12, 224-231.

Lundth, L.-G., Wilkström, J., Westerlund, J., \& Öst, L.-G. (1999). Pre-attentive bias for emotional information in panic disorder with agoraphobia. Journal of Abnormal Psychology, 108(2), 222-232.

Maidenberg, E., Chen, E., Craske, M., Bohn, P., \& Bystritsky, A. (1996). Specificity of attentional bias in Panic Disorder and Social Phobia. Journal of Anxiety Disorders, 10(6), 529-541. 


\section{CHAPTER 1}

Mathews, A., \& Mackintosh, B. (1998). A cognitive model of selective processing in anxiety. Cognitive Therapy and Research, 22, 539-560.

Mathews, A., \& Sebastian, S. (1993). Suppression of the emotional Stroop effects by fear-arousal. Cognition and Emotion, 7, 517-530.

McNally, R.J., Amir, N., Louro, C.E., Lukach, B.M., Riemann, B.C., \& Calamari, J.E. (1994). Cognitive processing of idiographic emotional information in panic disorder. Behaviour Research and Therapy, 32(1), 119-122.

McNally, R.J., Riemann, B.C., \& Kim, E. (1990). Selective processing of threat cues in panic disorder. Behaviour Research and Therapy, 28(5), 407-412.

McNally, R.J., Riemann, B.C., Louro, C.E., Lukach, B.M., \& Kim, E. (1992). Cognitive processing of emotional information in panic disorder. Behaviour Research and Therapy, 30(2), 143-149.

Mogg, K., Kentish, J., \& Bradley, B. (1993). Effects of anxiety and awereness on color identification latencies for emotional words. Behaviour Research and Therapy, 31, 559-567.

Montgomery, S., \& Asberg, M. (1979). A new depression scale designed to te sensitive to change. British Journal of Psychiatry, 134, 382-389.

Musa, C., Lépine, J.-P., Clark, D.M., Mansell, W., \& Ehlers, A. (2003). Selective attention in social phobia and the moderating effect of a concurrent depressive disorder. Behaviour Research and Therapy, 41, 1043-1054.

Paunovi, N., Lundth, L.-G., \& Öst, L. (2002). Attentional and memory bias for emotional information in crime victims with acute posttraumatic stress disorder (PTSD). Journal of Anxiety Disorders, 16, 675-692.

van den Heuvel, O.A., Veltman, D.J., Groenewegen, H.J., Menno, P.W., Merkelbach, J., Cath, D.C., van Balkom, A.J.L.M., van Oppen, P., \& van Dyck, R. (2005). Disorder-specific neuroanatomical correlates of attentional bias in obsessive-compulsive disorder, panic disorder, and hypochondrias. Archives of General Psychiatry, 62, 922-933.

Williams, J., Mathews, A., \& MacLeod, C. (1996). The emotional Stroop task and psychopathology. Psychological Bulletin, 120, 3-24.

Zung, W.W.K. (1965). A self-rating depression scale. Archives of General Psychiatry, 12, 63-70. 


\section{CHAPTER 2}

\section{Priming associations between bodily sensations and catastrophic misinterpretations: Specific for panic disorder?}

Dirk Hermans ${ }^{1}$, Klara De Cort ${ }^{2}$, Daphne Noortman ${ }^{2}$, Debora Vansteenwegen ${ }^{1}$, Tom Beckers ${ }^{1,3}$, Adriaan Spruyt ${ }^{4}$, Koen Schruers ${ }^{1,2}$

${ }^{1}$ University of Leuven, Center for Learning and Experimental Psychopathology, Belgium

${ }^{2}$ Maastricht University, Institute for Mental Health and Neuroscience, the Netherlands

${ }^{3}$ Amsterdam University, the Netherlands

${ }^{4}$ Ghent University, Belgium

Published as: Hermans, D., De Cort, K., Noortman, D., Vansteenwegen, D., Beckers, T., Spruyt, A. \& Schruers, K. (2010). Priming associations between bodily sensations and catastrophic misinterpretations: specific for panic disorder? Behaviour Research and Therapy; 48(9), 900-908. 


\begin{abstract}
Cognitive models assume that panic disorder is characterized by a tendency to misinterpret benign bodily symptoms (e.g. breathlessness) in a catastrophic fashion (e.g. suffocation). This is a central part of the cognitive model which presents a core focus for treatment. Several studies have supported this hypothesis. These studies have, however, almost always relied on self-report. In addition to susceptibility to biases (e.g. distortions of memory), a limitation of research based on verbal report is its inability to capture the spontaneous/automatic nature that is attributed to these catastrophic interpretations. The present paper reports on two experiments in which a priming procedure was used to test the hypothesis that panic disorder is characterized by spontaneous catastrophic interpretations and whether this effect is 'specific' to panic disorder. In line with predictions from the cognitive model, it was observed in the first experiment that the panic group demonstrated facilitated responses to trials consisting of a 'symptom' prime and a 'catastrophic outcome' target (e.g. breathlessness - suffocate). Similar effects were not observed for an anxious control group and a nonclinical control group, supporting the specificity of this effect. Interestingly, however, significant priming effects were observed for a group of mental health professionals (part of the healthy control group) who had no history of panic disorder. Subsequently, this unexpected observation was explicitly addressed in a second experiment, which confirmed the findings of Experiment 1. Together, these results suggest that associations between mental representations of benign bodily symptoms and catastrophic outcomes might develop as part of professional knowledge and experience, and should not necessarily be viewed as pathogenic. Theoretical and clinical implications are discussed.
\end{abstract}




\section{Introduction}

One of the central tenets of cognitive models of panic disorder (e.g. Clark, 1986, 1988) is that persons suffering from panic disorder (PD) are characterized by a relatively enduring tendency to misinterpret benign bodily sensations as indications of an immediately impending physical or mental catastrophe. Typically, autonomic responses like palpitations, breathlessness or headache are spontaneously interpreted as signals of an impending heart attack, choking or the presence of a brain tumor. This is assumed to be the basis for a vicious circle in which misinterpretations of bodily sensations increase anxiety, which subsequently amplifies the level of these (anxiety related) sensations, which in turn feeds the catastrophic misinterpretations and the level of anxiety that follows from them. This loop can then terminate in a panic attack. Because maladaptive interpretations are viewed as the central element in the cognitive model of panic disorder, they are one of the main targets for treatment according to the cognitive account of PD (e.g. Craske \& Barlow, 2008).

Research has supported the view that patients suffering from panic disorder are characterized by an enhanced tendency to misinterpret benign symptoms. For example, in two studies Clark et al. (1997) administered the Body Sensations Interpretation Questionnaire (BSIQ) to patients suffering from panic disorder and controls. The BSIQ measures negative interpretations in four domains, including bodily sensations for which the cognitive theory predicts that these will be more likely misinterpreted by panic disorder patients (e.g. "You notice that your heart is beating quickly and pounding"). Each item was followed by the question "Why?", after which participants wrote down the first explanation that came to mind (open-ended question). Next, three alternatives were presented, that had to be rankordered for the extent to which "they would be most likely come to your mind if you found yourself in a similar situation" (e.g. for the item presented above: "because you have been physically active", "because there is something wrong with your heart", and "because you are feeling excited"). Finally, participants rated the extent to which they actually believed in these interpretations. Results showed that panic patients were more likely to interpret ambiguous autonomic sensations as signs of immediately impending physical or mental disaster. Moreover, as compared to other anxiety disorder patients and non patients, persons suffering from panic disorder were more likely to believe these interpretations.

Similar to the study of Clark et al. (1997), most studies that investigate catastrophic misinterpretations in panic disorder have been based on self-report. It is well-known that there are several limitations to using self-report measures like the BSIQ, such as distortions by memory biases. David Clark and colleagues pointed to another major limitation, which is that these measures explicitly ask patients to make interpretations of bodily sensations, whereas the interpretations that are assumed to happen in panic attacks are more automatic and reflexive in nature (Clark et al., 1997, p. 211). To assess the more 'automatic' character of these catastrophic misinterpretations, Clark et al. advocated the use of alternative 
measures like priming procedures, which bypass self-report and more directly tap into the memory structures that are at the basis of these misinterpretations.

In the same year, Schniering and Rapee (1997) presented a study in which precisely this type of methodology was employed. They used a variant of the associative priming task in which associatively related (e.g. butter-bread) and associatively unrelated (e.g. dust-cats) prime-target pairs were presented. These trials were intermixed with an equal number of trials on which the target was a nonword (e.g. jird). Participants were asked to categorize targets as quickly as possible as a 'word' or a 'nonword' (lexical decision task). To reduce the impact of strategic processes, the stimulus onset asynchrony (SOA; i.e. the interval between the onset of the prime and the onset of the target) was limited to $240 \mathrm{~ms}$. In line with traditional findings, the authors observed that 'word' responses were significantly faster in case the target was preceded by an associatively related prime, as compared to when it was preceded by an unrelated prime. As a crucial test of the catastrophic misinterpretation hypothesis, the authors also included trials on which the prime referred to a bodily sensation and the target to a catastrophic outcome (e.g. breathlessness-suffocate; dizzy-faint). It was hypothesised that if memory representations of bodily sensations automatically activate the representations of associated fearful outcomes, panic patients should respond significantly faster on these trials as compared to trials on which the target was preceded by an unrelated and nonthreatening prime (e.g. sandman-suffocate; cardboard-faint). A similar effect was not predicted for the non-clinical control group. Even though a significant facilitation effect was observed for the threatening word pairs (as compared to the control trials), Schniering and Rapee (1997) found that this effect was equally strong in the group of panic patients and the nonclinical control group. Hence, the results did not provide support for the cognitive model of panic disorder.

More recently, Teachman, Smith-Janik, and Saporita (2007) employed another measure to assess automatic associations between bodily sensations and their catastrophic interpretations. They used a variant of the Implicit Association Test (IAT; Greenwald, McGhee, \& Schwartz, 1998) in which stimuli were presented that related to bodily changes (heart racing, rapid pulse, sweating, dizzy) or to body parts (arm, leg, shoulder, ear). These stimuli had to be categorized as 'bodily changes' or 'body parts' as fast as possible by pressing one of two keys. In addition, words related to threat (alarming, scary, terrifying, dangerous) or neutral words (e.g. meaningless, trivial) had to be categorized as 'alarming' or 'meaningless'. In line with results typically observed in the IAT, Teachman et al. (2007) predicted that panic patients would perform best if the same key was to be used to categorize stimuli as 'bodily changes' and 'alarming' relative to trial blocks in which the categories 'bodily changes' and 'meaningless' were mapped onto the same response. This was indeed the case. However, contrary to their expectations, no group differences were observed between persons suffering from PD and healthy controls. Similarly, in a previous study in which 'bodily changes' were compared to a category of 'weather changes', also no group differences were ob- 
served, while the 'panicked'/'me' IAT did produce the expected results (Teachman, 2005). In this latter study, groups of participants scoring high and low on Anxiety Sensitivity were compared, a concept which is proposed to be of central importance in panic disorder (Schmidt, Lerew, \& Jackson, 1997).

Finally, also Schneider and Schulte (2007) failed to find differences between a group of panic patients and a group of nonclinical controls when they were compared for a fixed set of prime sentences and target words. In this study participants named catastrophic (e.g. infarction) and neutral target words (e.g. holiday) which were preceded by prime sentences that described an anxiety symptom (e.g. "You notice an increasing palpitation") or a neutral situation (e.g. "You notice an increasing drum of rain"). Prime sentences either preceded the target immediately (inter-stimulus interval, ISI: $0 \mathrm{~ms}$ ) or after $1500 \mathrm{~ms}$. The expected advantage for the panic group in naming latencies for catastrophic targets preceded by 'symptom primes' was not observed.

The whole of these data fails to provide support for the view that panic disorder is characterized by automatic or reflexive catastrophic misinterpretations of bodily symptoms. Schniering and Rapee (1997) actually discussed the possibility that when experiencing palpitations, everyone might consider an equivalent probability that this symptom signals a coronary, but that panic patients attach a greater cost to coronaries than other individuals ( $p$. 568). This would mean that persons suffering from panic disorder are not characterized by an enhanced tendency for spontaneous catastrophic misinterpretations, but do differ from others with respect to the valence associated with these negative outcomes (or the extent to which they believe they can control them). If so, this would be of consequence for the cognitive model of panic disorder.

Another possibility that has been offered is that associations between bodily sensations and certain misinterpretations are so specific and idiosyncratic, and are limited in number, that averaging over fixed sets of word pairs fails to reveal differences between groups of panic patients and nonclinical controls. In the study by Schneider and Schulte (2007) this possibility was investigated. Although priming effects that were calculated on the basis of all trials were similar in panic patients and controls (see above), the authors did find the expected group differences when priming effects were calculated for ideographically selected stimuli. To this end, participants were asked, at completion of the experiment, to explicitly judge as quickly as possible the associative relatedness of all prime-target pairs that were employed in the priming procedure. Assuming that associative strength in memory should be reflected in faster decision times for prime-target pairs that are idiosyncratic associates, trials consisting of stimulus pairs that were responded to fastest were selected for further analyses. Consistent with cognitive models of PD, these analyses now revealed the expected difference (at ISI $0 \mathrm{~ms}$ ) between the panic group (who showed a $20 \mathrm{~ms}$ facilitation effect) and the nonclinical control group (who showed a $-22 \mathrm{~ms}$ inhibition effect). According to the authors, these findings are in line with the idea that panic patients are effectively character- 
ized by automatic catastrophic interpretations, but that the nature of these interpretations is so idiosyncratic that they cannot be picked up when effects are calculated across a large set of generic stimuli.

From a clinical perspective it makes sense to select idiographic stimulus pairs. Whereas some panic patients strongly focus on one type of catastrophe (e.g. heart attack), other patients will fear calamities of a different kind (e.g. brain tumor). This does not take away, however, that such a highly idiosyncratic dependency is not often observed for other types of information processing biases within the study of panic disorder (e.g. attentional bias; Maidenberg, Chen, Craske, Bohn, \& Bystritsky, 1996) or in the study of other disorders (e.g. OCD). In fact, it is common practice to average over sets of stimuli which are assumed to be 'overall' relevant for the participant group under investigation. Also, it remains somewhat unclear why control participants did not exhibit a similar associative priming effect for the panic-related stimulus pairs for which the selection task had indicated that these were probably highly associatively related (and actually demonstrated an opposite trend; - $22 \mathrm{~ms}$ ). Hence, further replication and extension of these interesting findings is justified.

In this context, data from an experiment reported by Lefaivre, Watt, Stewart, and Wright (2006) can also be taken as support for the catastrophic misinterpretation hypothesis. In this study, participants who scored high or low on anxiety sensitivity completed an Extrinsic Affective Simon Task (EAST; De Houwer, 2003). In addition to bodily symptoms (e.g. dizzy, breathless, palpitation), stimulus words included threatening (e.g. faint, suffocate, heart attack) and positive health outcomes (e.g. benign, healthy, innocuous). Similar to the study by Teachman et al. (2007) body parts (e.g. ankle, elbow, nose) were used as a contrast category for the category of bodily symptoms. Results indicated that high anxiety sensitive individuals were significantly faster on trials where target words related to anxiety symptoms were mapped on to the same response key as threatening consequences. No significant difference in performance was found for low anxiety sensitive individuals or when target words were body parts (Lefaivre et al., 2006, p. 295). These findings are consistent with the idea that persons who score high on anxiety sensitivity automatically associate anxiety-related symptoms with harmful consequences. Given the proposed central position of the anxiety sensitivity concept within panic disorder (McNally, 2002), these findings might also speak to this latter condition. A limitation of this study, however, was the small number of participants (high anxiety sensitivity: $\mathrm{n}=10$; low anxiety sensitivity: $\mathrm{n}=12$ ).

In conclusion, we can state that spontaneous catastrophic misinterpretations of bodily sensations are assumed to be a hallmark of panic disorder. Several studies provide support for this cognitive view. However, most of these studies are based on self-report. According to Clark et al. (1997), one of the limitations of these procedures is that patients are explicitly asked to make interpretations, whereas the interpretations that are assumed to happen in panic attacks are more automatic and reflexive in nature. Indirect measures, such as priming paradigms would provide a good alternative in this context. Unfortunately, as we have dis- 
cussed, results from studies that have employed such behavioral procedures have been far from clear-cut.

The current status of this line of research is such that there are still a number of questions that need to be addressed empirically. First of all, given the conflicting data that are available, additional research will need to address the main issue of whether panic disorder is truly characterized by spontaneous (automatic) catastrophic misinterpretations of bodily symptoms. Also, it remains to be examined whether possible effects are indeed highly idiosyncratic, as suggested by the data of Schneider and Schulte (2007), or whether more generic effects can be observed more generally for sets of stimuli (as suggested by the data of Lefaivre et al., 2006). Finally, a question that has not yet been investigated in this context is whether potential effects of automatic misinterpretations are specific to panic disorder (i.e. not a characteristic of anxiety disorders in general). This issue has received extensive attention in studies employing self-report measures (e.g. Clark et al., 1997; Harvey, Richards, Dziadosz, \& Swindell, 1993), where 'anxious control groups' were included (i.e. patients suffering from anxiety disorders other than panic disorder). Such comparisons have, however, not been made within studies employing paradigms that circumvent introspection. Hence, it is an open question whether findings like those reported by Schneider and Schulte (2007) are truly specific for panic disorder.

In an attempt to answer these questions, we investigated automatic catastrophic misinterpretations in a group of persons suffering from panic disorder $(n=31)$, an anxious control group ( $n=25)$, and a nonanxious control group $(n=30)$. An associative priming procedure was used (lexical decision task; SOA $250 \mathrm{~ms}$ ). To maximize the chance of observing the predicted priming effects, all participants from the two clinical groups were included at a moment on which they were actively seeking treatment but did not yet enter the treatment programme.

\section{EXPERIMENT 1}

\section{Methods}

\section{Participants}

Three groups participated in this study: a panic group, an anxious control group and a nonanxious control group. The Panic Group (PG) consisted of 34 outpatients who met DSM-IV criteria for panic disorder. Due to loss of data, three participants were excluded from the analyses. These participants had misunderstood the instructions, because of which a significant proportion of data were lost. The final sample consisted of 31 patients (16 women) with a mean age of 43.4 years $(S D=12.1$; range $=20-64)$. In this group there were 19 patients who showed at least one form of comorbidity (eleven patients with one comorbid disorder, seven with two comorbid disorders and one patient with three comorbid disor- 
ders). In total, there were eleven patients with comorbid depression, five patients with comorbid hypochondriasis, four patients suffering from benzodiazepine or alcohol dependence, four patients with social phobia, two patients with specific phobia, and one patient suffering from GAD. The Anxious Control Group (ACG) consisted of 25 outpatients (19 women) who were diagnosed with an anxiety disorder other than panic disorder (or agoraphobia). Of these, $35 \%$ had obsessive compulsive disorder, $23 \%$ social phobia, $38 \%$ specific phobia, and $4 \%$ generalized anxiety disorder as their primary diagnosis. Their mean age was 36.5 years $(S D=13.6$; range $=18-59)$. All participants from the panic group and the anxious control group were seeking treatment at the Academic Anxiety Center in Maastricht (at the time of testing treatment had not yet started). Diagnoses were based on a semi-structured interview (Mini International Neuropsychiatric Inventory, MINI; Lecrubier et al., 1997) conducted by a psychiatrist or psychologist. The Nonanxious Control Group (NCG) consisted of 30 healthy volunteers ( 12 women) who were recruited by advertisement. Their mean age was 42.7 years $(S D=11.3$; range $=22-59)$. None of the participants in the NCG currently suffered from an anxiety disorder (or any other psychiatric disorder) and had no history of prior psychiatric problems.

\section{Materials}

In addition to the priming procedure, participants were assessed by means of the following instruments:

Panic and Agoraphobia Scale (PAS; Bandelow, 1995). The PAS is a 13-item clinical interview to assess the severity of panic disorder and agoraphobia. Previous work has demonstrated that the PAS has satisfactory values for internal consistency $(\alpha=.86)$, test-retest reliability and correlations with other anxiety scales.

State Trait Anxiety Inventory (STAl; Spielberger, Gorsuch, Lushene, Vagg, \& Jacobs, 1983). Trait anxiety was measured using the Dutch version of the STAl. It has good validity and reliability $(\alpha>$.90) (Van der Ploeg, Defares, \& Spielberger, 1980).

Montgomery-Asberg Depression Rating Scale (MADRS; Montgomery \& Asberg, 1979). The MADRS is a ten-item clinical rating scale to assess severity of depressive symptoms. Previous research showed that the MADRS is characterized by excellent internal consistency (Carmody et al., 2006). We used the Dutch version by Hartong and Goekoop (1985), which has an internal consistency of .91 .

Self-rating Depression Scale (SDS; Zung, 1965). The SDS is a self-report measure of depression consisting of 20 items, with a four-point scale ranging from 'a little of the time' (1) to 'most of the time' (4). Research supports the validity of this measure (Schaefer et al., 1985).

Prime-target word pairs. Four sets of word pairs were used in the priming task. In addition to the crucial Panic-Panic (PP) word pairs there were three types of control pairs: Neutral-Neutral (NN), Panic-Neutral (PN) and Neutral-Panic (NP). The Panic-Panic prime-target 
word pairs consisted of a bodily symptom that is typically experienced during a panic attack (e.g. breathlessness) and the catastrophic misinterpretation that is related to this symptom (e.g. suffocate). Bodily symptoms were always used as prime, misinterpretations as target. Ten PP word pairs were created. Some of the word pairs were selected from work by Clark (1988) (e.g. dizziness - fainting); other word pairs were inspired by clinical phenomenology of panic disorder and previous research (Chambless, Beck, Gracely, \& Grisham, 2000) (e.g. headache - brain tumor). All primes and targets were single Dutch words. An overview of all prime-target word pairs is provided in the Appendix. The Neutral-Neutral control pairs consisted of neutral, panic-unrelated words that were considered to be somewhat associatively related (e.g. flowers - picking; television - newsflash). Primes and targets from the NN list were matched for word length with those of the PP list. The two remaining sets of control pairs consisted of a neutral prime followed by a panic target (NP; e.g. flowers - stroke) or a panic prime followed by a neutral target (PN; e.g. headache - install). Like for the PP pairs, the three sets of control stimuli consisted of ten prime-target pairs (see Appendix).

Nonword targets. In addition to the ten neutral and the ten panic targets, twenty pronounceable nonwords were used as targets in the lexical decision task (e.g. preester; farnasie). In addition to 8 nonwords taken from Hermans, Smeesters, De Houwer, and Eelen (2002), twelve additional nonword targets were created. Length of the 'nonword' targets matched word length of the 'word' targets (neutral; panic).

During the priming task, the presentation of all stimuli, as well as the registration of all responses was controlled by an Affect 3.0 program (Spruyt, Clarysse, Vansteenwegen, Baeyens, \& Hermans, 2010). This program was run on an AMD Athlon personal computer. Responses to targets (word/nonword) were recorded using two keys of the keyboard. For the rating of the word pairs, a tablet PC with touch screen was used (1027 x 748 pixel resolution).

\section{Procedure}

Before the start of the actual study, all participants were screened for presence (panic group) or absence (anxious and nonanxious control groups) of panic disorder (and/or agoraphobia). Participants in the two clinical groups filled out the MADRS and SDS as a part of a larger clinical assessment. The PAS was assessed in this context as well.

At the start of the experiment ${ }^{1}$, participants were informed about the study and signed the informed consent form. Instructions for the priming task were presented on the computer screen. The participant was informed that words would be presented and that the task consisted of categorizing each word as an 'existing' or a 'non-existing' word by pressing one of two keys on the keyboard. Half of the participants pressed the left button for 'words' and right button for 'nonwords'. For the other participants this assignment was reversed. The

\footnotetext{
${ }^{1}$ In addition to the priming task, participants also completed two other tasks that were unrelated to the present research questions. The order of these tasks was counterbalanced.
} 
experiment started with a practice phase (20 trials), during which participants were trained in the classification task. Only target words were presented during this phase. Each trial started with the presentation of a fixation cross during 500 ms. Five hundred milliseconds after termination of the fixation cross, the target word was presented. Targets were selected randomly from the larger set of targets (see above). For half of the practice trials the target was a word; for the remaining trials this was a non-word. Targets disappeared from the screen upon response of the participant.

After the practice phase, 80 experimental trials were presented. Each of the ten primetarget pairs within each of the four trial types (PP, PN, NP, NN) was presented once (see Appendix). In addition, all of the primes were presented once with a nonword target. As a result, each of the 10 panic primes was followed by a panic target on 10 trials, by a neutral target on 10 trials, and by a nonword target on twenty trials. The same was the case for the neutral primes. Assignment of nonword targets to primes was random.

Each of the 80 experimental trials started with the presentation of a fixation cross during $500 \mathrm{~ms}$. Five hundred milliseconds after termination of the fixation cross, the prime word was presented for $200 \mathrm{~ms}$. This was followed by an inter-stimulus interval of $50 \mathrm{~ms}$, after which the target was presented (resulting in a stimulus onset asynchrony of $250 \mathrm{~ms}$ ). Targets remained on the screen until a response was recorded. In case of no response, the target disappeared after $2000 \mathrm{~ms}$. As was the case for the practice trials, participants categorized each target as a 'word' or a 'nonword' by pressing one of two buttons on the keyboard. The inter-trial interval (ITI) ranged between 1000 and 2000 ms, with a mean of 1500 ms. The order of all trials was randomized for each participant.

In addition to the priming task, a subgroup of 20 panic patients and 20 anxious controls also rated the 20 word pairs (panic-panic; neutral-neutral) for the extent to which they elicited anxiety. This was included as an examination of the validity of the word pairs (panicrelated and control) that were included in this study. It was hypothesized that the panicrelated word pairs (e.g. breathlessness - suffocate) would elicit significantly more anxiety in the panic group as compared to the anxious control group; whereas no differences were predicted for the control pairs. During this rating phase, each of the 20 word pairs (see Appendix) was presented once on the computer screen. Presentation duration was 8 seconds, with an ITI that ranged between 12 and $20 \mathrm{~s}$. After each presentation, the participant was asked to indicate the level of anxiety experienced during the presentation of the word pair, on a scale ranging from 0 ('no anxiety at all') to 100 ('the worst imaginable anxiety'). The level of anxiety was marked by tipping with a stylus the correct position on a $20 \mathrm{~cm} \mathrm{x} 1 \mathrm{~cm}$ horizontal visual analogue scale (for more details of this electronic VAS, see van Duinen, Rickelt, \& Griez, 2008). Half of the participants completed the ratings before the priming task; for the other participants the order was reversed. 


\section{Results}

\section{Data reduction}

The data from priming trials on which no response $2.64 \%)$ or a wrong response $2.03 \%)$ was given, were excluded from all analyses. To reduce the impact of outlying values, we also excluded all response latencies (0.64\%) that deviated more than 2.5 standard deviations from a participant's mean latency in a particular priming condition (see Ratcliff, 1993). Subsequently, for each participant and for each experimental condition, mean response latencies were calculated. The means for the three types of control trials (PN, NP, NN) were averaged. Mean response latencies were analyzed using a $3 \times 2$ analysis of variance, with group (panic/anxious controls/nonanxious controls) as a between-subjects variable, and trial type (panic/control) as a within subjects variable.

For the anxiety ratings, t-tests were conducted for each of the 20 word pairs, comparing the scores of the panic group with the scores of the anxious control group.

\section{Clinical instruments}

As expected, the panic group had significantly higher scores on the Panic and Agoraphobia Scale $(M=24.7 ; S D=10.1)$, as compared to the anxious control group $(M=9.12 ; S D=10.3)$, $t(54)=5.68, p<.001$. The two groups did not differ on trait anxiety (STAI-trait), $M_{\text {panic }}=54.5$, $S D=9.2, M_{\text {anxious }}$ controls $=48.7, S D=14.2, t(54)=1.85$, n.s. Similarly, both groups did not differ in their level of depression, as indicated by the scores on the SDS, $M_{\text {panic }}=46.6, S D=$ 9.3, $M_{\text {anxious controls }}=44.0, S D=11.9, t(54)=0.89$, n.s., and the $M A D R S, M_{\text {panic }}=13.3, S D=7.2$, $M_{\text {anxious controls }}=12.6, S D=11.1, t(54)=0.25$, n.s.. These results indicate that in spite of equal levels of depression and general level of anxiety, the panic group had substantially higher levels of symptomatology related to panic and agoraphobia.

\section{Ratings}

When all ten panic-panic word pairs were included, as expected, markedly higher anxiety scores were expressed by the panic group $(M=44.7 ; S D=24.7)$ as compared to the anxious control group $(M=20.8 ; S D=16.7), t(38)=3.58, p<.001$. For the ten neutral word pairs, low anxiety scores were obtained for both the panic group $(M=10.7 ; S D=11.8)$ and the anxious control group ( $M=5.1 ; S D=5.8$ ). Even though both groups did not statistically differ in their ratings of the neutral word pairs, the difference did approach significance, $t(38)=1.89, p=$ .067. Closer inspection revealed that for one particular neutral word pair (groceries - shopping), the panic group experienced significantly more anxiety, $t(38)=2.36, p<.05, M_{\text {panic }}=$ 28.0, $M_{\text {anxious controls }}=9.9$. In retrospect, this word pair was probably strongly related to the agoraphobia component in the panic group. Hence, it was decided to omit the data related 
to this word pair from the priming analyses. For the other nine pairs, there were no reliable differences in anxiety ratings between the two groups. When the rating data were reanalyzed after removing the 'groceries - shopping' item, the two groups no longer differed in their anxiety ratings for the neutral items, $t(38)=1.52, p=.14, M_{\text {panic }}=8.7, S D=11.0, M_{\text {anxious }}$ controls $=4.6, S D=5.5$.

\section{Priming data}

The response latencies were analyzed using a 3 (group: panic/ anxious controls/ nonanxious controls) $\times 2$ (trial type: panic/ control) analysis of variance with repeated measures for the last variable. This revealed a significant main effect of trial type, $F(1,83)=17.6, p<.0001$, $M S E=27651$. Overall, responses were significantly faster for Panic-Panic trials $(M=672 ; S D$ $=115)$ as compared to the control trials $(M=699 ; S D=128)$. As predicted, this main effect was qualified in a reliable Group x Trial type interaction, $F(2,83)=3.2, p<.05, M S E=1806$. Follow-up analyses showed a significant main effect of trial type in the panic group, $F(1,83)$ $=21.0, p<.0001, M S E=1806$. Response latencies for panic-panic trials $(M=687 ; S D=106)$ were significantly shorter as compared to the control trials $(M=736 ; S D=112)$. A similar priming effect was not observed in the anxious control group, $F(1,83)<1, M S E=1806, M_{\text {pan- }}$

ic $=668(S D=99), M_{\text {control }}=679(S D=115)$. Based on these results, the priming task thus clearly supports the assumption that prime stimuli that are related to bodily sensations automatically activate threatening interpretations in panic patients, while a similar phenomenon is absent in anxious controls who have no history of panic disorder and who showed comparable levels of trait anxiety and symptoms of depression.

Quite surprisingly, however, contrast analyses revealed that for the nonanxious control group a significant priming effect was observed as well, $F(1,83)=4.11, p<.05$, MSE $=1806$. Analogous to the panic group, this group responded faster to panic-panic trials $(M=660 ; S D$ $=137)$ than to control trials $(M=682 ; S D=148)$. Because this priming effect was unexpected, further post-hoc analyses were conducted.

\section{Post-hoc analyses for the nonanxious control group (priming data)}

Even though the priming effects for the panic group $(F=21.0)$ and the anxious control group $(F<1)$ were completely in line with predictions, it was striking to observe a significant priming effect for the nonanxious controls. Further inspection of this finding revealed a possible explanation in terms of participant characteristics. As a matter of fact, based on recruitment, this non-anxious control group largely consisted of two subgroups. Sixteen of these 30 participants were volunteers with no affiliation to the mental health profession. In contrast, the other 14 participants were professionals working within the health services (i.e. the Academic Anxiety Center). Among others (e.g. a secretary), this group included persons who were working as a psychiatric nurse, psychologist or social worker, or who were students doing an 
internship as part of psychology-related education. Even though these persons were not currently suffering from panic disorder and had no history of panic or agoraphobia, it could well be argued that due to their education or occupation they had built up a knowledge base concerning panic symptoms and related catastrophic interpretations. It might be argued that this knowledge, which is rooted in long-term memory as part of professional expertise, could serve as a basis for priming effects similar to those observed in the panic patients.

To test this post-hoc hypothesis, the priming effect was analyzed for both subgroups separately. For the volunteers who were not associated with the hospital, the priming effect was absent, $F(1,82)<1, M S E=1806, M_{\text {panic }}=680(S D=133), M_{\text {control }}=692(S D=156)$. For the subgroup of 'mental health professionals', however, the priming effect was significant, $F(1,82)=4.47, p<.05, M S E=1806, M_{\text {panic }}=638(S D=143), M_{\text {control }}=672(S D=143)$.

\section{Discussion}

In this study an associative priming task was employed to assess automatic associations between bodily symptoms and catastrophic misinterpretations in panic disorder. As an improvement over previous studies, the panic group was compared to an anxious control group to test the specificity of the effect. In line with predictions from the cognitive model, facilitated responses were observed for the crucial panic trials in the panic group, but not in the group of anxious controls. To our knowledge, this is the first demonstration of (a) an automatic interpretation effect in a clinical panic group using unselected stimuli, and (b) of the fact that this finding is selective to patients suffering from panic disorder (i.e. not observed in a clinically anxious control group that does not suffer from panic disorder). Post-hoc analyses further revealed that akin to the anxious control group, no priming effect was observed in a group of persons who had no current or previous history of anxiety disorders, and who were not professionally connected to mental health services.

An intriguing finding, however, was that a panic-misinterpretation effect was also revealed in a group of health professionals without history of panic disorder. In this group, presentation of primes related to 'bodily symptoms' automatically activated representations of catastrophic outcomes. Our interpretation of this finding is that for this latter group the 'symptom-catastrophe' associations are part of professional knowledge. This observation is of theoretical and clinical importance, because it seems to indicate that automatic catastrophic interpretations do not necessarily point to 'pathological mechanisms'. Most probably such priming effects are a mere index of the extent to which these concepts are related in memory (i.e. associative strength). This associative strength can be influenced by a number of factors, among which the amount of previous exposure to the contiguous presentation of these concepts. This can be part of one's own personal illness history (e.g. in the case of panic patients) or as part of educational or professional experiences (e.g. in the case of the health professionals). However, because of the post-hoc nature of these arguments, these results need replication before firm conclusions can be drawn. In Experiment 2, we 
therefore selected four groups of participants on an a priori grounds. In addition to a group of panic patients, and anxious control group, two nonclinical control groups were included: one group consisted of mental health professionals and one group consisted of participants who were not professionally (or otherwise) associated with mental health services. Based on the findings of Experiment 1, we predicted significant priming effects for the panic group and the health professionals, but not for the anxious control group and the nonclinical control group people outside the mental health profession.

\section{EXPERIMENT 2}

\section{Methods}

\section{Participants}

Four groups participated in this study. In addition to the panic group and the anxious control group, two nonanxious control groups were included. The first consisted of volunteers who were mental health professionals (in training), and who worked with anxiety patients on a daily basis. The second group was recruited by advertisement and had no professional or educational background relating to anxiety disorders or therapeutic work in general.

The panic group consisted of 20 outpatients (11 women) who met DSM-IV criteria for panic disorder. Their mean age was 40.7 years $(S D=13.5$; range $=20-65)$. In this group, there were eleven patients who showed at least one form of comorbidity (six patients with one comorbid disorder, five with two comorbid disorders). In total, there were nine patients with comorbid depression, two patients with comorbid hypochondriasis, one patient suffering from benzodiazepine dependence, one patient with social phobia, one patient suffering from PTSD, and two patients suffering from GAD. The anxious control group consisted of 20 outpatients ( 9 women) who were diagnosed with an anxiety disorder other than panic disorder (or agoraphobia). Of these, $30 \%$ had OCD, $25 \%$ social phobia, $35 \%$ specific phobia, $10 \%$ generalized anxiety disorder as their primary diagnosis. Their mean age was 41.3 years (SD = 15.1 ; range $=22-61$ ). All participants from the panic group and the anxious control group were seeking treatment at the Academic Anxiety Center in Maastricht (at the time of testing treatment had not yet started). Diagnoses were based on a semi-structured interview (Mini International Neuropsychiatric Inventory, MINI; Lecrubier et al., 1997) conducted by a psychiatrist or psychologist.

The group of nonanxious controls consisted of 15 'professionals' ( 9 women; mean age = $37.4, S D=11.7$; range $=23-55$ ) and 15 'non-professionals' ( 8 women; mean age $=39.1, S D=$ 13.7; range $=22-64$ ) and were matched for age with the two anxious groups. None of the participants in the two nonanxious groups currently suffered from an anxiety disorder (or any other psychiatric disorder) and had no history of prior psychiatric problems. 


\section{Materials and procedure}

Materials (including questionnaires) and procedure were identical to Experiment 1, with the exception of a small amendment in the stimulus materials for the priming task. As was already noted, one of the neutral control pairs in Experiment 1 (i.e. 'groceries - shopping') induced significantly more anxiety in the panic group as compared to the anxious control group, and could thus not be regarded as an appropriate control stimulus. Because of that reason, it was decided to exclude this word pair (and its combinations in PN and NP trials) from the present experiment. To balance the stimulus list, it was decided to delete one of the ten panic-panic pairs as well. For the word pair 'headache - brain tumor' the ratings that were obtained in Experiment 1 were in the expected direction, $M_{\text {panic }}=35.0(S D=33.5)$, $M_{\text {anxious controls }}=26.6(S D=26.8)$, but the difference failed reach the level of significance, $t(38)$ $=0.87, p=.39$. By deleting this word pair from the set, the present priming task was based on 9 panic-panic pairs and 9 neutral pairs (and their combinations in panic-neutral and neutral-panic). As a result, there were 36 trials on which the prime was followed by a word target (9 PP, 9 PN, 9 NP and 9 NN), and 36 trials on which the same primes were followed by a nonword. Because of the reduction in number of word pairs as compared to the previous study, it was decided to double the number of trials. As a result, for the 'word' trials, there was a total of 72 trials, of which $18 \mathrm{PP}, 18 \mathrm{PN}, 18 \mathrm{NP}$ and $18 \mathrm{NN}$.

\section{Results}

\section{Data reduction}

The data from priming trials on which no response $(0.44 \%)$ or a wrong response $(1.90 \%)$ was given, were excluded from all analyses. To reduce the impact of outlying values, we also excluded all response latencies (2.34\%) that deviated more than 2.5 standard deviations from a participant's mean latency in a particular priming condition. Subsequently, for each participant and for each experimental condition, mean response latencies were calculated. As in Experiment 1, the means for the three types of control trials (PN, NP, NN) were averaged.

\section{Clinical instruments}

The pattern of results for the questionnaires was almost identical to that of Experiment 1. The panic group scored significantly higher on the Panic and Agoraphobia Scale $(M=25.6$; $S D=10.3)$, as compared to the anxious control group $(M=4.5 ; S D=7.9), t(38)=7.22, p<$ .001. The two groups did, however, not differ on trait anxiety (STAI-trait), $M_{\text {panic }}=51.4$ (SD = 10.7), $M_{\text {anxious controls }}=46.1(S D=15.1), t(38)=1.28$, n.s.. Similarly, both groups did not differ in their level of depression, as indicated by the scores on the SDS, $M_{\text {panic }}=47.3(S D=11.3)$, $M_{\text {anxious controls }}=40.7(S D=10.7), t(38)=1.89$, n.s., and the MADRS, $M_{\text {panic }}=14.9(S D=7.6)$, 
$M_{\text {anxious controls }}=10.6(S D=9.1), t(38)=1.62$, n.s.. These results indicate that with equal levels of depression and general level of anxiety, the panic group had substantially higher levels of symptomatology related to panic and agoraphobia.

\section{Priming data}

Because of our a priori hypotheses, contrasts between panic trials and control trials were calculated for each of the four groups of participants separately. It was predicted that for the panic patients and the mental health professionals there would be a significant priming effect. No such effect was predicted for the anxious control group and the healthy control group. As hypothesized, panic patients responded significantly faster on panic-panic trials ( $M$ $=685 ; S D=157)$ as compared to control trials $(M=721 ; S D=143), F(1,66)=8.83, p<.005$, $M S E=1498$. A similar effect was observed for the mental health professionals, $F(1,66)=$ $5.31, p<.05, M S E=1498, M_{\text {panic }}=631(S D=122), M_{\text {control }}=664(S D=136)$. For the anxious control group, there was no significant difference between panic-panic trials $(M=716 ; S D=$ 134) and control trials $(M=732 ; S D=131), F(1,66)=1.81$, n.s., $M S E=1498$. Similarly, for the healthy control group, responses to panic trials $(M=642 ; S D=119)$ did not differ from responses to control trials $(M=656 ; S D=132), F(1,66)=1.04$, n.s., $M S E=1498$.

\section{General discussion}

In two studies, we tested whether panic disorder is characterized by a spontaneous (automatic) tendency to interpret benign bodily symptoms in a catastrophic fashion. To circumvent the disadvantages of self-report measures, we employed an associative priming task in which participants had to provide lexical decisions (word vs. nonword) for the targets. On the crucial panic-panic trials, primes were words referring to a bodily symptom (e.g. breathlessness), while the target words referred to a threatening outcome (e.g. suffocate). Control trials consisted of a symptom prime followed by an unrelated neutral target (e.g. palpitations - picking), a neutral prime followed by a catastrophic outcome (e.g. flower - stroke), or a neutral prime and a somewhat related neutral target (e.g. flower - picking). It was predicted that in a group of patients suffering from panic disorder responding should be significantly faster for panic-panic trials as compared to control trials, while no such effect was predicted for a standard nonclinical control group. This is exactly what was observed in Experiments 1 and 2, supporting the cognitive model of panic disorder. To our knowledge, this is the first time that the catastrophic misinterpretation hypothesis was confirmed in a clinical group using a procedure that did not rely on self-report. In several previous studies similar effects could not be observed (e.g. Schniering \& Rapee, 1997; Teachman, 2005, Teachman et al., 2007) or only when the crucial panic stimuli were selected on an individual basis (Schneider $\&$ Schulte, 2007). We will return to these discrepancies in a moment. 
In addition to testing whether panic disorder is characterized by spontaneous catastrophic misinterpretations, we also investigated whether this effect is indeed 'specific' to panic disorder. No previous behavioral studies had included an anxious control group, so conclusions about specificity were awaiting further testing. In both experiments no priming effects were observed for panic-panic pairs in the anxious control group. This group was equal in all respects to the experimental group, except for the fact that they had no current (or history of) panic disorder. Like the panic group they sought treatment at the same academic treatment facility, but for a variety of other disorders including $O C D$, social phobia and generalized anxiety disorder. The fact that this group did not reveal the spontaneous misinterpretations that were observed in the panic group is consistent with the idea that this bias is specific to panic disorder. A similar question has been raised in studies employing self-report questionnaires (e.g. Harvey et al., 1993; McNally \& Foa, 1987), which led to the conclusion that panic patients rate negative interpretations of panic body sensations as more likely to come to mind, and as more believable, than patients with other anxiety disorders, and thus seems to represent a specific feature of panic disorder (Clark et al., 1997, p. 209). The present studies further support the idea of selective and spontaneous negative interpretations.

Even though panic-panic pairs and control pairs were matched for word length, these pairs were not matched for 'associative strength', as the necessary Dutch word association norms were not available for all included stimuli. Future research could take this into account. In any case, even if the pair-types were not equal on associative strength, this does not undermine the crucial interaction with diagnostic group. Future research could also include one additional type of control stimulus. In the present experiments, panic-panic trials were compared to panic-neutral, neutral-panic and neutral-neutral trials. It would, however, also be interesting to include panic-panic pairs that are combinations of non-matching symptoms and outcomes. For instance, 'breathlessness - brain tumor' and 'headache - suffocate' could be used as controls for the experimental pairs 'breathlessness - suffocate' and 'headache - brain tumor'. This would inform us whether the automatic priming of threatening outcomes is specific to the presented primes, or whether the presentation of a specific bodily symptom can activate a whole range of threatening outcomes. A final possible limitation of the studies presented here, is that a 'categorical' approach was followed, rather than a dimensional. The priming effect was studied as a function of diagnostic group, irrespective of severity of the panic complaints. It would be interesting to learn whether priming effects as those observed in Experiments 1 and 2, are indicative of the severity of the panic disorder. Some preliminary analyses based on the Panic and Agoraphobia Scale, indicate that the severity of the complaints in the panic group indeed reliably correlated with an overall index of panic priming (i.e. $\mathrm{RT}_{\text {control }}-\mathrm{RT}_{\text {panic-panic) }}$ in Experiment $1, r(31)=.41, p<.05$. A similar correlation was, however, not present in Experiment 2. Also, no similar correlations were observed for the anxious control group. 
An important, but unexpected finding that emerged in Experiment 1 was that a significant priming effect was observed in a subgroup of the nonclinical control condition. This group of mental health workers displayed a reliable facilitation effect for panic-panic trials which was comparable to that of the panic group in direction and size. Because of the post-hoc nature of this finding, four groups were included on an a priori basis in Experiment 2. The results of Experiment 1 were replicated: significant priming effects were observed in the panic group and the nonclinical group of health professionals, but not in the anxious control group and the nonclinical control group that was unrelated to health care. We believe that these findings suggest that there might be several sources for the accessibility of threatening interpretations. One source can be found in the illness history of panic patients. When bodily symptoms are repeatedly and consciously interpreted in a threatening fashion, these negative interpretations will become more and more accessible for activation. Alternatively, the origin and accessibility of these interpretations might also stem from the training and dayto-day professional activities in mental health workers such as psychologists and psychiatrists.

We believe that this observation has at least two important implications. The first is a methodological one. If education, training and professional experience contribute to the availability of certain cognitive representations and to the accessibility of certain associations, the decision to include groups like psychology students or mental health professionals should be weighed with great care in future experiments. In the introduction we already referred to a series of studies in which no group differences were observed with respect to spontaneous interpretation biases (e.g. Schniering \& Rapee, 1997; Teachman, 2005; Teachman et al., 2007). There can be two explanations for the absence of such group differences. The classic analysis is that the panic group is not characterized by selective interpretations. An alternative explanation, however, should be considered, which is that the control group showed a bias similar to the panic group. In the study of Teachman et al. (2007) spontaneous associations between 'bodily sensations' and 'alarming' did not differentiate between panic patients and healthy controls. The control group in this study, however, was partly recruited through the psychology participant pool. It might well be that the absence of differentiation between the two groups was due to relatively strong panic associations in the group of psychology students (as a result of their education). The results of a previous study from the same lab (Teachman, 2005) can be interpreted in a similar way. In this experiment participants were all psychology students.

A second implication of our findings is a more theoretical one and relates to the causal status of the spontaneous symptom-threat associations with respect to panic. If such selective threat associations can be observed in panic-free participants to the same extent as they are observed in panic patients, this at least raises doubts about these associations being a sufficient basis for increases in anxiety (or even the origin of panic attacks). One possibility is that not the accessibility of these threatening interpretations is of crucial importance, but 
their believability or the extent to which they are embedded in a representational structure of threat-related psychophysiological and motor responses (Lang, 1988). In other words, for both groups the word 'breathlessness' will automatically bring to mind the representation 'suffocate', but only for the panic group this will activate a related network of fear-responses (e.g. avoidance tendencies, high arousal, increased blood pressure,...). In mental health professionals and psychology students the activation of the memory representation of 'suffocation' will not go hand in hand with an activation of these responses and response tendencies. Future research could aim at testing this view. We would predict that panic patients and mental health professionals would show similar priming effects, but that the same word pairs would lead to increased skin conductance responses in the panic group, as well as to avoidance tendencies as measures by tasks such as the Approach-Avoidance Test (Heuer, Rinck, \& Becker, 2007). Further research is also necessary to unravel the role of the accessibility aspect of threat representations. In this context, a recent study by Schneider and Schulte (2008) is highly relevant. Using a priming paradigm, these authors demonstrated that stronger associations between idiographically related anxiety symptoms and catastrophes predicted a smaller reduction in anxiety sensitivity in panic patients in response to a brief cognitive-behavioral treatment (Schneider \& Schulte, 2008, p. 568).

A final element for discussion concerns the observation that group differences in panic priming only emerged after idiographical selection of prime-target pairs in the study of Schneider and Schulte (2007) whereas reliable differences emerged in our studies for an unselected set of prime-targets. To maximize the chance of observing the predicted (differences in) priming effects in the present two studies, all participants from the clinical groups were included on a moment at which they had been actively seeking treatment but did not yet enter the treatment programme. It was assumed that relevant associations between bodily sensations and negative outcomes would be more accessible at that time. However, in the study of Schneider and Schulte (2007) patients were included in a similar fashion. Possible differences in the results might relate to the types of stimulus materials use or the duration of prime presentations. In our studies primes consisted of prime words (e.g. breathlessness), whereas in the study of Schneider and Schulte (2007) prime sentences were employed (e.g. "Your breath seems to you to be obstructed"). Another element, however, might be that some of the control sentences in the study of Schneider were actually emotional opposites of the threatening primes (e.g. "Your breath seems to you to be freed"; "In your chest, you sense more and more clearly relief"; "Your whole body is being gripped by a sensation of calm"). It is well possible that these sentences automatically activated the threatening opposites (for the examples above: obstructed, tightness and agitation). This is reminiscent of findings by Mathews and Klug (1993) who demonstrated that emotional Stroop effects in anxious persons are observed for words related to anxiety, irrespective of their emotional meaning. In their study, a word like 'relaxed' delayed color naming as much as words like 'anxious'. In a similar fashion, it is possible that a selective panic priming effect 
in the Schneider study was not observed for the panic group because some of the control trials actually 'acted' as panic-panic trials and hence obscured the hypothesized difference between the two types of trials. The idiographical selection procedure might then have resulted in significant group differences, not so much because the panic trials were more tailored to the individual, but because the 'inappropriate' control trials were filtered away (i.e. because the categorization as 'unrelated' for these intended unrelated pairs took longer than for other pairs). Of course, future research will need to focus on this possibility in a more direct way. In any case, this study illustrates how subtle factors that are not the focus of a study, such as the nature of the control stimuli and the selection of control participants, can strongly influence results. 
Appendix.

Stimuli for Experiment 1 (original Dutch words with English translations)

\begin{tabular}{|c|c|c|c|}
\hline Panic-Panic & & Neutral-Neutral & \\
\hline $\begin{array}{l}\text { ademnood- } \\
\text { stikken }\end{array}$ & $\begin{array}{l}\text { (breathlessness- } \\
\text { suffocate) }\end{array}$ & $\begin{array}{l}\text { bloemen - } \\
\text { plukken }\end{array}$ & $\begin{array}{l}\text { (flowers - } \\
\text { picking) }\end{array}$ \\
\hline $\begin{array}{l}\text { beven- } \\
\text { verlamming }\end{array}$ & $\begin{array}{l}\text { (shake - } \\
\text { paralyzed) }\end{array}$ & $\begin{array}{l}\text { boekenkast - } \\
\text { installeren }\end{array}$ & $\begin{array}{l}\text { (book case - } \\
\text { install) }\end{array}$ \\
\hline $\begin{array}{l}\text { borstpijn - } \\
\text { hartaanval }\end{array}$ & $\begin{array}{l}\text { (chest pain - } \\
\text { heart attack) }\end{array}$ & $\begin{array}{l}\text { boodschappen- } \\
\text { winkelen }\end{array}$ & $\begin{array}{l}\text { (groceries - } \\
\text { shopping) }\end{array}$ \\
\hline $\begin{array}{l}\text { duizelig - } \\
\text { flauwvallen }\end{array}$ & $\begin{array}{l}\text { (dizziness - } \\
\text { fainting) }\end{array}$ & $\begin{array}{l}\text { krantenartikel- } \\
\text { bestuderen }\end{array}$ & $\begin{array}{l}\text { (paper article - } \\
\text { study) }\end{array}$ \\
\hline $\begin{array}{l}\text { hartklopping- } \\
\text { doodgaan }\end{array}$ & $\begin{array}{l}\text { (palpitations - } \\
\text { dying) }\end{array}$ & $\begin{array}{l}\text { limonade - } \\
\text { drinken }\end{array}$ & $\begin{array}{l}\text { (lemonade - } \\
\text { drink) }\end{array}$ \\
\hline $\begin{array}{l}\text { hoofdpijn- } \\
\text { hersentumor }\end{array}$ & $\begin{array}{l}\text { (headache - } \\
\text { brain tumor) }\end{array}$ & $\begin{array}{l}\text { maaltijd - } \\
\text { klaarmaken }\end{array}$ & $\begin{array}{l}\text { (meal - } \\
\text { prepare) }\end{array}$ \\
\hline $\begin{array}{l}\text { misselijk - } \\
\text { overgeven }\end{array}$ & $\begin{array}{l}\text { (unwell - } \\
\text { throw up) }\end{array}$ & $\begin{array}{l}\text { onkruid - } \\
\text { uittrekken }\end{array}$ & $\begin{array}{l}\text { (weeds - } \\
\text { pull) }\end{array}$ \\
\hline $\begin{array}{l}\text { onwerkelijk- } \\
\text { krankzinnig }\end{array}$ & $\begin{array}{l}\text { (unreal - } \\
\text { insane) }\end{array}$ & $\begin{array}{l}\text { schommelstoel- } \\
\text { wiebelen }\end{array}$ & $\begin{array}{l}\text { (rocking chair - } \\
\text { wiggle) }\end{array}$ \\
\hline $\begin{array}{l}\text { tintelingen- } \\
\text { beroerte }\end{array}$ & $\begin{array}{l}\text { (tremor - } \\
\text { stroke) }\end{array}$ & $\begin{array}{l}\text { televisie - } \\
\text { nieuwsbericht }\end{array}$ & $\begin{array}{l}\text { (television - } \\
\text { newsflash) }\end{array}$ \\
\hline $\begin{array}{l}\text { trillen - } \\
\text { controleverlies }\end{array}$ & $\begin{array}{l}\text { (tremble - } \\
\text { loss of control) }\end{array}$ & $\begin{array}{l}\text { tuintafel - } \\
\text { zomertijd }\end{array}$ & $\begin{array}{l}\text { (garden table - } \\
\text { summer time) }\end{array}$ \\
\hline Panic-Neutral & & Neutral-Panic & \\
\hline $\begin{array}{l}\text { ademnood - } \\
\text { winkelen }\end{array}$ & $\begin{array}{l}\text { (breathlessness- } \\
\text { shopping) }\end{array}$ & $\begin{array}{l}\text { bloemen - } \\
\text { beroerte }\end{array}$ & $\begin{array}{l}\text { (flowers - } \\
\text { stroke) }\end{array}$ \\
\hline $\begin{array}{l}\text { beven - } \\
\text { nieuwsbericht }\end{array}$ & $\begin{array}{l}\text { (shake - } \\
\text { newsflash) }\end{array}$ & $\begin{array}{l}\text { boekenkast- } \\
\text { hersentumor }\end{array}$ & $\begin{array}{l}\text { (book case - } \\
\text { brain tumour) }\end{array}$ \\
\hline $\begin{array}{l}\text { borstpijn - } \\
\text { zomertijd }\end{array}$ & $\begin{array}{l}\text { (chest pain - } \\
\text { summer time) }\end{array}$ & $\begin{array}{l}\text { boodschappen - } \\
\text { stikken }\end{array}$ & $\begin{array}{l}\text { (groceries - } \\
\text { suffocate) }\end{array}$ \\
\hline $\begin{array}{l}\text { duizelig - } \\
\text { wiebelen }\end{array}$ & $\begin{array}{l}\text { (dizziness - } \\
\text { wiggle) }\end{array}$ & $\begin{array}{l}\text { krantenartikel- } \\
\text { doodgaan }\end{array}$ & $\begin{array}{l}\text { (paper article - } \\
\text { dying) }\end{array}$ \\
\hline $\begin{array}{l}\text { hartklopping- } \\
\text { bestuderen }\end{array}$ & $\begin{array}{l}\text { (palpitations - } \\
\text { study) }\end{array}$ & $\begin{array}{l}\text { limonade - } \\
\text { krankzinnig }\end{array}$ & $\begin{array}{l}\text { (lemonade - } \\
\text { insane) }\end{array}$ \\
\hline $\begin{array}{l}\text { hoofdpijn - } \\
\text { installeren }\end{array}$ & $\begin{array}{l}\text { (headache - } \\
\text { install) }\end{array}$ & $\begin{array}{l}\text { maaltijd - } \\
\text { overgeven }\end{array}$ & $\begin{array}{l}\text { (meal - } \\
\text { throw up) }\end{array}$ \\
\hline $\begin{array}{l}\text { misselijk - } \\
\text { klaarmaken }\end{array}$ & $\begin{array}{l}\text { (unwell - } \\
\text { prepare) }\end{array}$ & $\begin{array}{l}\text { onkruid - } \\
\text { controleverlies }\end{array}$ & $\begin{array}{l}\text { (weeds - } \\
\text { loss of control) }\end{array}$ \\
\hline $\begin{array}{l}\text { onwerkelijk - } \\
\text { drinken }\end{array}$ & $\begin{array}{l}\text { (unreal - } \\
\text { drink) }\end{array}$ & $\begin{array}{l}\text { schommelstoel- } \\
\text { flauwvallen }\end{array}$ & $\begin{array}{l}\text { (rocking chair - } \\
\text { faint) }\end{array}$ \\
\hline $\begin{array}{l}\text { tintelingen - } \\
\text { plukken }\end{array}$ & $\begin{array}{l}\text { (tremor - } \\
\text { picking) }\end{array}$ & $\begin{array}{l}\text { televisie - } \\
\text { verlamming }\end{array}$ & $\begin{array}{l}\text { (television - } \\
\text { paralyzed) }\end{array}$ \\
\hline $\begin{array}{l}\text { trillen - } \\
\text { uittrekken }\end{array}$ & $\begin{array}{l}\text { (tremble - } \\
\text { pull) }\end{array}$ & $\begin{array}{l}\text { tuintafel - } \\
\text { hartaanval }\end{array}$ & $\begin{array}{l}\text { (garden table - } \\
\text { hearth attack) }\end{array}$ \\
\hline
\end{tabular}




\section{CHAPTER 2}

\section{References}

Bandelow, B. (1995). Assessing the efficacy of treatments for panic disorder and agoraphobia II. The panic and agoraphobia scale. International Clinical Psychopharmacology, 10, 73-81.

Carmody, T. J., Rush, A. J., Bernstein, I., Warden, D., Brannan, S., Burnham, D., et al. (2006). The Montgomery Äsberg and the Hamilton ratings of depression: a comparison of measures. European Neuropsychopharmacology, 16, 601-611.

Chambless, D. L., Beck, A. T., Gracely, E. J., \& Grisham, J. R. (2000). The relationship of cognitions to fear of somatic symptoms: a test of the cognitive theory of panic. Depression and Anxiety, 11, 1-9.

Clark, D. M. (1986). A cognitive approach to panic. Behaviour Research and Therapy, 24,461-470.

Clark, D. M. (1988). A cognitive approach to panic. In S. Rachman, \& J. Maser (Eds.), Panic: Psychological perspectives. Hillsdale, NJ: Lawrence Erlbaum Associates.

Clark, D. M., Salkovskis, P. M., Breitholz, E., Westling, B. E., Öst, L. G., Koehler, K. A., et al. (1997). Misinterpretation of body sensations in panic disorder. Journal of Consulting and Clinical Psychology, 65, 203-213.

Craske, M. G., \& Barlow, D. H. (2008). Panic disorder and agoraphobia. In D. H. Barlow (Ed.), Clinical handbook of psychological disorders (4th ed.). (pp. 1e64) New York: The Guilford Press.

De Houwer, J. (2003). The extrinsic affective Simon task. Experimental Psychology, 50, 77-85.

Greenwald, A. G., McGhee, D. E., \& Schwartz, J. L. K. (1998). Measuring individual differences in implicit cognition: the implicit association test. Journal of Personality and Social Psychology, 74, 1464-1480.

Hartong, E. G. Th. M., \& Goekoop, J. G. (1985). De Montgomery-Åsberg beoordelingsschaal voor depressie. Tijdschrift voor Psychiatrie, 27, 657-668.

Harvey, J. M., Richards, J. C., Dziadosz, T., \& Swindell, A. (1993). Misinterpretation of ambiguous stimuli in panic disorder. Cognitive Therapy and Research, 17, 235-248.

Hermans, D., Smeesters, D., De Houwer, J., \& Eelen, P. (2002). Affective priming for associatively unrelated primes and targets. Psychologica Belgica, 42, 191-212.

Heuer, K., Rinck, M., \& Becker, E. S. (2007). Avoidance of emotional expressions in social anxiety: the approachavoidance task. Behaviour Research and Therapy, 45, 2990-3001.

Lang, P. J. (1988). Fear, anxiety and panic: context, cognition and visceral arousal. In S. Rachman, \& J. D. Maser (Eds.), Panic: Psychological perspectives (pp. 219-236). Hillsdale: Lawrence Erlbaum.

Lecrubier, Y., Sheehan, D., Weiller, E., Amorim, P., Bonora, I., Sheehan, K., et al. (1997). The MINI International Neuropsychiatric Interview (M.I.N.I.) a short diagnostic structured interview: reliability and validity according to the CIDI. European Psychiatry, 12, 224-231.

Lefaivre, M.-J., Watt, M. C., Stewart, S. H., \& Wright, K. D. (2006). Implicit associations between anxiety-related symptoms and catastrophic consequences in high anxiety sensitive individuals. Cognition \& Emotion, 20, 295-308.

Maidenberg, E., Chen, E., Craske, M., Bohn, P., \& Bystritsky, A. (1996). Specificity of attentional bias in panic disorder and social phobia. Journal of Anxiety Disorders, 10, 529e541.

Mathews, A., \& Klug, F. (1993). Emotionality and interference with color-naming in anxiety. Behaviour Research and Therapy, 31, 57-62.

McNally, R. J. (2002). Anxiety sensitivity and panic disorder. Biological Psychiatry, 52, 938-946.

McNally, R. J., \& Foa, E. B. (1987). Cognition and agoraphobia: bias in the interpretation of threat. Cognitive Therapy and Research, 11, 567-581.

Montgomery, S., \& Asberg, M. (1979). A new depression scale designed to be sensitive to change. British Journal of Psychiatry, 134, 382-389.

Ratcliff, R. (1993). Methods for dealing with reaction-time outliers. Psychological Bulletin, 114, 510-532. 
Schaefer, A., Brown, J., Watson, C., Plemel, D., DeMotts, J., Howard, M., et al. (1985). Comparison of the validities of the Beck, Zung, and MMPI depression scales. Journal of Consulting and Clinical Psychology, 53, 415418.

Schmidt, N. B., Lerew, D. R., \& Jackson, R. J. (1997). The role of anxiety sensitivity in the pathogenesis of panic: prospective evaluation of spontaneous panic attacks during acute stress. Journal of Abnormal Psychology, 106, 355-364.

Schneider, R., \& Schulte, D. (2007). Panic patients reveal idiographic associations between anxiety symptoms and catastrophes in a semantic priming task. Behaviour Research and Therapy, 45, 211-223.

Schneider, R., \& Schulte, D. (2008). Catastrophic associations predict level of change in anxiety sensitivity in response to cognitive-behavioural treatment for panic. Behaviour Research and Therapy, 46, 557-572.

Schniering, C. A., \& Rapee, R. M. (1997). A test of the cognitive model of panic: primed lexical decision in panic disorder. Journal of Anxiety Disorders, 6, 557-571.

Spielberger, C. D., Gorsuch, R. L., Lushene, R., Vagg, P. R., \& Jacobs, G. A. (1983). Manual for the state-trait anxiety inventory. Palo Alto, CA: Consulting Psychologists Press.

Spruyt, A., Clarysse, J., Vansteenwegen, D., Baeyens, F., Hermans, D. (2010). Affect 4.0: a free software package for implementing psychological and psychophysiological experiments. Experimental Psychology, 57(1), 3645.

Teachman, B. A. (2005). Information processing and anxiety sensitivity: cognitive vulnerability to panic reflected in interpretation and memory biases. Cognitive Therapy and Research, 29, 483-503.

Teachman, B. A., Smith-Janik, S. B., \& Saporita, J. (2007). Information processing biases and panic disorder: relationships among cognitive and symptom measures. Behaviour Research and Therapy, 45, 1791-1811.

Van der Ploeg, H. M., Defares, P. B., \& Spielberger, C. D. (1980). Handleiding bij de Zelf-Beoordelings Vragenlijst, ZBV.[Manual of the State-Trait Anxiety Inventory; Dutch adaptation]. Lisse: Swets en Zeitlinger.

van Duinen, M., Rickelt, J., \& Griez, E. (2008). Validation of the electronic visual analogue scale of anxiety. Progress in Neuropsychopharmacology \& Biological Psychiatry, 15, 1045-1047.

Zung, W. W. K. (1965). A self-rating depression scale. Archives of General Psychiatry, 12, 63-70. 



\section{CHAPTER 3}

\section{The weight of cognitions in panic: The link between misinterpretations and panic attacks}

Klara De Cort ${ }^{1}$, Dirk Hermans ${ }^{2}$, Daphne Noortman ${ }^{1}$, Wiesje Arends ${ }^{1}$, Eric Griez ${ }^{1}$, \& Koen Schruers ${ }^{1,2}$

\footnotetext{
${ }^{1}$ Maastricht University, Institute for Mental Health and Neuroscience, the Netherlands

${ }^{2}$ University of Leuven, Center for Learning and Experimental Psychopathology, Belgium
} 


\begin{abstract}
In cognitive theory it is hypothesized that panic attacks are provoked by catastrophic misinterpretations of bodily sensations. The aim of the present study was to investigate the ability of associated word pairs referring to catastrophic thinking (e.g. palpitations-heart attack) in producing panic attacks.

Patients with panic disorder $(n=20)$, patients with mixed anxiety disorders $(n=20)$, and a healthy control group $(n=30)$ participated in the present study. To enhance ecological validity we first conducted a stimulus validation experiment. Subsequently, nine suitable panic and neutral word pairs were presented in block to the participants. Anxiety levels were assessed before and after the presentation. Panic patients were more anxious when reading these word pairs, compared to neutral word pairs. However, none of the participants experienced a panic attack upon reading the word pairs. From the present results it seems that catastrophic thinking is related to the anticipatory anxiety for panic attacks, but not necessarily with the occurrence of the panic attacks themselves.
\end{abstract}




\section{Introduction}

Persons suffering from panic attacks often believe that they are having an acute medical condition and might die at any moment. Cognitive theories (Beck, 1998; Beck \& Emery, 1985; Clark, 1986a\&b) of Panic Disorder (PD) state that these beliefs play a causal role and are therefore crucial in the pathogenesis of panic attacks. Typical beliefs that are held by PD patients are viewed as catastrophic misinterpretations of physical sensations. Specifically, interoceptive stimuli are erroneously interpreted as evidence of an impending disaster, related to their well-being. This misinterpretation results in anxiety and increased bodily sensations, thereby reaffirming the initial misinterpretation. As a consequence, PD patients become hyper vigilant for bodily sensations resulting in an 'attentional bias' towards physical cues associated with panic. As a result, the patient is more likely to re-activate the circle of misinterpretation.

The core of this cognitive perspective entails three hypotheses:

1. Bias specificity: PD patients have specific catastrophic misinterpretations concerning their physical sensations.

2. Disorder specificity: This interpretative bias is assumed to be only specific for PD patients (in contrast with patients suffering from other anxiety disorders).

3. Causality: These specific catastrophic cognitions are regarded as sufficient and necessary in the production of panic attacks.

There is evidence in support of cognitive misinterpretation in PD patients. This includes the use of retrospective (Rachman, Levitt \& Lapatka, 1987) and prospective self-reports (Chambless \& Gracely, 1989; Westling \& Öst, 1993), priming tasks (Clark et al., 1988) and questionnaires (Austin \& Kiropoulos, 2008; Austin \& Richards, 2006; Chambless, Beck, Gracely, \& Grisham, 2000; Clark et al., 1997; Harvey, Richards, Dziadosz, \& Swindell, 1993; McNally \& Foa, 1987). The evidence that these biases are particular and specifically apply to PD patients is less well documented. Much of the conducted studies are based on the Interpretation Questionnaire of McNally and Foa (1987). In this study PD patients and normal controls were asked to read ambiguous scenarios describing either a bodily sensation (e.g. "You feel discomfort in your chest area. Why?") or an external event (e.g. "Your phone rings at 3 AM. Why is someone calling at this time?"). PD patients were significantly more likely than normals to interpret both scenarios in a negative fashion, but only when a broad criterion of harm was used (e.g. "I'm going to panic" in stead of the narrow criterion of harm; "I'm having a heart attack"). These non-specific results have been replicated by Harvey et al. (1993). PD patients were significantly more likely to choose a broad negative interpretation for the bodily sensation, and did not differ from patients suffering from social phobia on the interpretation of the external event. Austin and Richards (2006), in replicating Clark et al. (1997), were the first to demonstrate that PD patients made more specific anxiety harmrelated interpretations (e.g. I'm having a heart attack, narrow criteria of harm) than anxious and non-anxious controls. However, the study failed to find a difference between PD pa- 
tients and social anxiety patients, with regard both to internal and external stimuli. An internet study of Austin and Kiropoulos (2008) was the first to find a specific catastrophic interpretation bias in PD patients in contrast to social anxiety and non-anxious controls. Further, factor analytic and correlational analyses revealed that specific somatic sensations in PD are related to specific catastrophic thoughts (Chambless et al., 2000; Clark et al., 1988). However, no distinctions were made between PD patients and others.

Despite this rather large amount of studies, the pattern of findings only partially give support to the first two hypotheses concerning bias and disorder specificity.

The last premise of the cognitive perspective concerns the hypothesized causal role of specific catastrophic cognitions. It is hypothesized that catastrophic cognitions are sufficient and necessary in evoking panic attacks in PD patients. However, to date, this has never been directly tested. There are some experimental studies which give an indication of more catastrophic misinterpretations during experimentally induced panic attacks in patients suffering from PD in contrast with controls (Griez \& Schruers, 1998; Whittal \& Goetsch, 1995). However, in those studies panic attacks were induced in the laboratory, by $\mathrm{CO}_{2}$ inhalations or hyperventilation, not through catastrophic thinking. Further, catastrophic thinking was only assessed after the manipulation. There is growing evidence in support for the efficacy of cognitive therapy in the treatment of PD (Clark et al., 1994; Siev \& Chambless, 2008). This success of cognitive therapy is often cited as support in favor of the causal role of cognitive misinterpretations in PD (Clark et al., 1994; Siev \& Chambless, 2008). Recent research is studying the mediating role of cognitive change during treatment (Hofman et al., 2007; Teachman, Smith-Janik \& Marker, 2008). Cognitive theory states that improvement during treatment is mediated by changes in catastrophic thinking. Teachman et al (2008) demonstrated with the Implicit Association Test (Greenwald, MCGhee, \& Schwartz, 1998), a measure of automatic panic associations, that over the course of cognitive behavioral treatment automatic panic associations changed and that these changes were correlated with symptom improvement. However, the fact that cognitive therapy is successful does not automatically imply that faulty cognitions are the cause of panic attacks. There is, however, one report of an uncontrolled experiment by Clark et al. (1988) where only associated word pairs (e.g; palpitations-dying, dizziness-fainting; Paired Associated Task) where used to activate catastrophic thinking. It was stated that $83 \%$ of PD patients experienced a panic attack while reading word pairs, in contrast with healthy subjects and recovered PD patients. A panic attack was defined as a sudden increase in anxiety reaching at least 50 on a 100-point scale and accompanied by four or more symptoms. While cited in several books and papers (Bouton, Mineka \& Barlow, 2001; Wells, 1997) and despite the obvious heuristic value, this observation was never formally replicated in a controlled experiment.

In sum, while there is evidence for catastrophic misinterpretation in PD patients, there is only equivocal support for bias and disorder specificity. Further, because of the lack of well controlled studies, the available evidence cannot entirely account for the proposed causal 
role of cognitions in the cognitive theory (Austin \& Richards, 2001; Roth, Wilhelm \& Petit, 2005). To date, support for the three proposed hypotheses is rather limited.

The aim of the present study is to experimentally test the last hypotheses concerning the causal role of catastrophic misinterpretations in eliciting panic attacks in PD. We wanted to experimentally replicate the report of Clark et al. (1988), in attempting to provoke panic attacks by presenting series of associated word pairs referring to catastrophic interpretation (e.g. palpitations-dying).

The present study consists of two experiments. To enhance the validity of our study we first conducted a stimulus validation experiment. We wanted to select anxiety provoking stimuli to use in our controlled experiment. After selecting our word pairs, they were presented in block and anxiety levels were assessed. We hypothesized that only PD patients would display a panic reaction upon reading a block of panic word pairs compared with controls and in contrast with neutral word pairs. A panic attack was defined as an increase in anxiety reaching at least 50 on a 100-point scale. Further, it was expected that a block of panic word pairs would produce more anxiety than a block of neutral word pairs.

\section{EXPERIMENT 1}

Experiment 1 was designed to find suitable word pairs to use in our second Experiment.

\section{Methods}

The study was approved by the Maastricht University Medical Ethics Committee.

\section{Participants}

This experiment involved three groups of participants. In addition to the panic group, an anxious control group and a non-clinical control group were included in the design.

In the panic group, 21 patients (12 female) who met the DSM-IV criteria for PD were selected. Mean age was 42 years $(S D=12.6)$. Thirty-three percent had co-morbid depression.

The 'anxious control' group consisted of 20 patients ( 14 female). Of these, $35 \%$ had OCD, $25 \%$ social phobia, $40 \%$ specific phobia as their primary diagnosis. Their mean age was 36 years $(S D=13.9)$. Twenty five percent had co-morbid depression. All patients were seeking treatment at the Academic Anxiety Center in Maastricht.

The 'healthy control' group consisted of 30 participants (12 female). This group was matched with the panic group for sex and age. Participants had never had a psychiatric disorder. Mean age was 43 years $(S D=11.3)$. They were recruited by advertisement. 


\section{Questionnaires}

The presence of possible mental disorders was evaluated by a trained clinician by means of the Mini International Neuropsychiatric Interview (Lecrubier et al., 1997), based on DSM-IV criteria. All patients were also administered the Panic Agoraphobia Scale (Bandelow, 1995). The PAS is an 13 - item clinical interview assessing panic attacks, anticipatory anxiety and avoidance behaviour, with a range between zero and 52. Previous work has demonstrated that the PAS has satisfactory values for internal consistency, test-retest reliability and correlations with other anxiety scales.

Anxiety levels were measured with an electronic Visual Analogue Scale (eVAS). The eVAS was programmed on a Compaq Tablet PC, TC1000, with a $21,0 \mathrm{~cm} \times 16,0 \mathrm{~cm}$ touch screen having a $1027 \times 748$ pixel resolution. The VAS was a $20 \mathrm{~cm} \times 1 \mathrm{~cm}$ horizontal bar. Participants had to mark their anxiety level by tipping on the bar with a stylus, which had a $1 \mathrm{~mm}$ diameter spherical tip. The scale was anchored from 0 , "no anxiety at all", to 100, "the worst imaginable anxiety". This instrument has been validated for use during $35 \% \mathrm{CO}_{2}$ challenges (van Duinen, Rickelt, \& Griez, 2008). Additionally, The Panic Symptom List (PSL) was used to measure panic symptoms. This list consists of 13 symptoms that can occur during a panic attack. Participants had to score the occurrence of bodily sensations on a five-point Likert scale, ranging from "not at all" to "very much". To assess mood state, the short version of the Profile of Mood States (Wald \& Mellenbergh, 1990) was used. It consists of 32 items referring to five mood states; depression, anger, fatigue, tension and will-power. Participants had to score their current mood states on a five-point Likert scale from "not at all" to "very much". Depressive symptoms were assessed with the Montgomery-Asberg Depression Rating Scale (Montgomery \& Asberg, 1979) and the Self-rating Depression Scale (Zung, 1965). The MADRS is a ten item clinical rating scale to assess severity of depressive symptoms. Previous research showed that the MADRS is characterized by excellent internal consistency (Carmody et al., 2006). We used the Dutch version (Hartong \& Goekoop, 1985). The SDS is a self-report measure of depression consisting of 20 items, with a four-point scale ranging from 'a little of the time' (1) to 'most of the time' (4). Research supports the validity of this measure (Schaefer et al., 1985).

\section{Materials}

In the Paired Associated Task, two categories of words were used: 10 panic-related words and 10 neutral words. Eight threat words were derived from Clark et al. (1988) and consisted of a symptom and its consequence. To make a complete set of 10 words we added two words, relying on former research (Chambless et al., 2000). The neutral words were neither positive nor abstract. To rule out a possible difference in results by presentation form, all categories were matched for word length and imageability. Stimuli were presented on a personal computer. The words appeared in 12-cm block letters on a Philips color monitor. 


\section{Procedure}

In the pre-test screening, all questionnaires were administered after obtaining written informed consent.

In the test phase, to measure possible experimental anticipatory anxiety, participants were asked to score their anxiety level on the eVAS. After the procedure and the aim of the experiment was explained, the participants were asked to fill in the eVAS, PSL and POMS as pre-measurement.

The task was presented on a computer screen. Participants were given the instruction to read the word-pairs in silence. Word-pairs were presented separately with an inter-trial interval that ranged between 12 and 20 seconds. Presentation time was 8 seconds. The presentation order of the word pairs was randomized. After each word pair, participants were asked to score their anxiety level on the eVAS. At the end of the experiment, participants were asked again to score their anxiety level, to fill in the PSL and the POMS.

\section{Design}

The e-VAS, PSL and POMS scores were used as main outcome variables. The KolmogorovSmirnov test was used to test the normality of these variables. Not all variables were normally distributed. Hence, all analyses were performed with non-parametric tests. Therefore median $(=M)$ values are presented in the text. First the Friedman and the Kruskal-Wallis Test were performed to explore for significant differences in the types of word-pairs used and/or in the different groups. If significant differences were noted, the Mann-Whitney Test was performed for the analyses of differences between the different groups and the Wilcoxon Test for the analyses between the different types of word associates. The separate word pairs were analyzed with the Kruskal-Wallis Test. Differences between the groups for VAS, PSL and POMS assessed during the experiment were analyzed with the Mann-Whitney Test. Differences within the groups were analyzed with the Friedman and Wilcoxon Test.

Non-parametric Spearman correlations were used to analyze the relationship between depressive symptoms and anxiety levels.

\section{Results}

\section{Questionnaires}

As expected, the panic group had significantly higher scores on the Panic and Agoraphobia Scale $(M=24.1 ; S D=10.4)$, as compared to the anxious control group, $(M=10.2 ; S D=10.2)$ $t(39)=4.30, p<.001$. The two groups did not differ in their level of depression, as indicated by the scores on the SDS, $M_{\text {panic }}=47, S D=8, M_{\text {anxious controls }}=43.1, S D=12, t(39)=1.251$, n.s., and the MADRS, $M_{\text {panic }}=12.7, S D=7.4, M_{\text {anxious controls }}=12.6, S D=11.4, t(39)=0.038$, 
n.s.. While entering the experiment, panic patients were significantly more anxious than the anxious control patients and both patient groups were significantly more anxious than the healthy volunteers, $\chi^{2}(3, N=71)=26.36, p<.001$. During the experiment panic patients were still more anxious and reported more symptoms than the other groups (see Table 1 ). Further, anxious control patients were also more anxious and reported more symptoms than healthy volunteers, VAS before: $\chi^{2}(3, \mathrm{~N}=71)=29.44, p<.001$, VAS after: $\chi^{2}(3, \mathrm{~N}=71)=$ $30.13, p<.001$, PSL before: $\chi^{2}(3, \mathrm{~N}=71)=33, p<.001$, PSL after $\chi^{2}(3, \mathrm{~N}=71)=29.3, p<.001$. Mood state was similar for the two patient groups, but was significant lower than the healthy volunteers; POMS before: $U=53, \mathrm{~N}_{1}=20, \mathrm{~N}_{2}=30, p<.001 ; U=64, \mathrm{~N}_{1}=21, \mathrm{~N}_{2}=30$, $p<.001$, POMS after: $U=66, \mathrm{~N}_{1}=20, \mathrm{~N}_{2}=30, p<.001 ; U=51, \mathrm{~N}_{1}=21 \mathrm{~N}_{2}=30, p<.001$. Within all groups were no differences in assessment for VAS and PSL measurements. So, during the experiment anxiety levels and symptom reporting stayed the same for all participants (n.s.). For POMS, however, significant differences were noted within the healthy volunteers. Healthy volunteers had a significantly better mood state after the experiment than before; $z=-2.5, \mathrm{~N}$-Ties $=27, p<.012$. Within the patient groups were no significant differences concerning mood state (n.s.).

Table 1. Median values for (e)VAS, PSL and $\mathrm{POM}(\mathrm{S})$ for panic group, anxious controls $(\mathrm{AC})$ and healthy controls $(H C)$. VAS ent $=$ VAS entrance, Pre $=$ before start experiment, Pos $=$ at the end of experiment.

\begin{tabular}{llllllll}
\hline & VAS entr & Pre-VAS & Pos-VAS & Pre-PSL & Pos-PSL & Pre-POM & Pos-POM \\
\hline Panic & 19 & 22 & 35 & 6 & 6 & 32 & 38 \\
AC & 6 & 5 & 4 & 1 & 1 & 32 & 27 \\
HC & 0 & 0 & 0 & 0 & 0 & 7 & 5 \\
\hline
\end{tabular}

\section{Paired Associated Task}

All participants were significantly more anxious when reading panic-relevant word pairs in contrast with neutral word pairs, $\chi^{2}(1, \mathrm{~N}=71)=45.56, p<.001, M_{\text {panic }}=12.1, M_{\text {neutral }}=1.2$. Further, there were significant group differences both for panic, $\chi^{2}(2, N=71)=24.35, p<$ .001 and for neutral, $\chi^{2}(2, \mathrm{~N}=71)=21.94, p<.001$, word pairs.

As expected, panic patients were significantly more anxious with respect to panic word pairs compared to anxious control patients, $U=96.5, \mathrm{~N}_{1}=21, \mathrm{~N}_{2}=20, p<.03, M_{\text {panic }}=51.8$, $M_{\text {anxious controls }}=18.7$ and healthy volunteers, $U=78, N_{1}=21, N_{2}=20, p<.001, M_{\text {healty volunteers }}$ $=1.5$. There were also significant differences between anxious control patients and healthy volunteers both for panic word pairs, $U=169.5, N_{1}=20, N_{2}=30, p<.01, M_{\text {anxious controls }}=18.7$, $M_{\text {healty volunteers }}=1.5$ and for neutral word pairs, $U=133.5, N_{1}=20, N_{2}=30, p<.001, M_{\text {anxious }}$ controls $=2.65, M_{\text {healty volunteers }}=0.6$. Furthermore, there were significant differences between panic patients and healthy volunteers concerning neutral word pairs, $U=91, N_{1}=21, N_{2}=30$, $p<.001, M_{\text {panic }}=5.2, M_{\text {healty volunteers }}=0.6$. There were, however, with respect to neutral word 
pairs no significant differences between the two patient groups $U=162, N_{1}=21, N_{2}=20$, n.s., $M_{\text {panic }}=5.2, M_{\text {anxious controls }}=2.65$.

Inspection of the anxiety levels of the neutral word pairs (see Figure 1) demonstrated that all word pairs were close to zero, with the exception of purchase-shopping. Analyses indeed show that for this word pair significant differences between the panic group and healthy controls, $U=116.5, \mathrm{~N}_{1}=21, \mathrm{~N}_{2}=30, p<.001$ were noted. In retrospect, this word pair was probably strongly related to the agoraphobia component in the panic group.

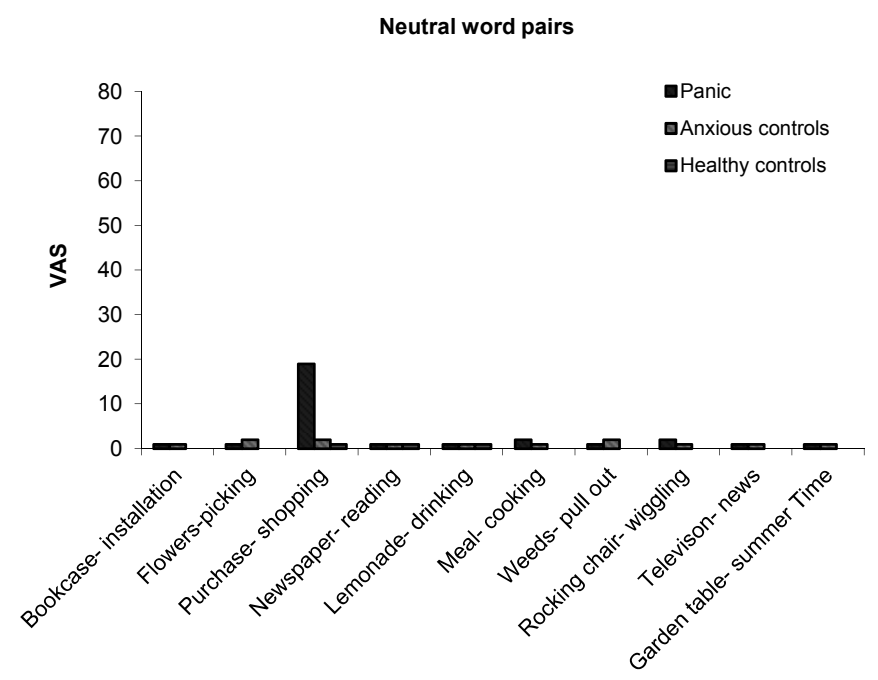

Figure 1. Median level of anxiety on the Visual Analogue Scale on neutral word pairs for panic disorder patients, anxious controls and healthy controls.

In the panic word pairs (Figure 2) we also noticed one outliner, namely headache-brain tumor. This word pair provokes equal anxiety in the patient groups and in the controls, $U=$ 210.5, $\mathrm{N}_{1}=20, \mathrm{~N}_{2}=30$, n.s.; $U=178, \mathrm{~N}_{1}=21, \mathrm{~N}_{2}=20$, n.s.; $U=157, \mathrm{~N}_{1}=21, \mathrm{~N}_{2}=30, p<.002$. Therefore, also this word pair was not appropriate as panic word pair. 


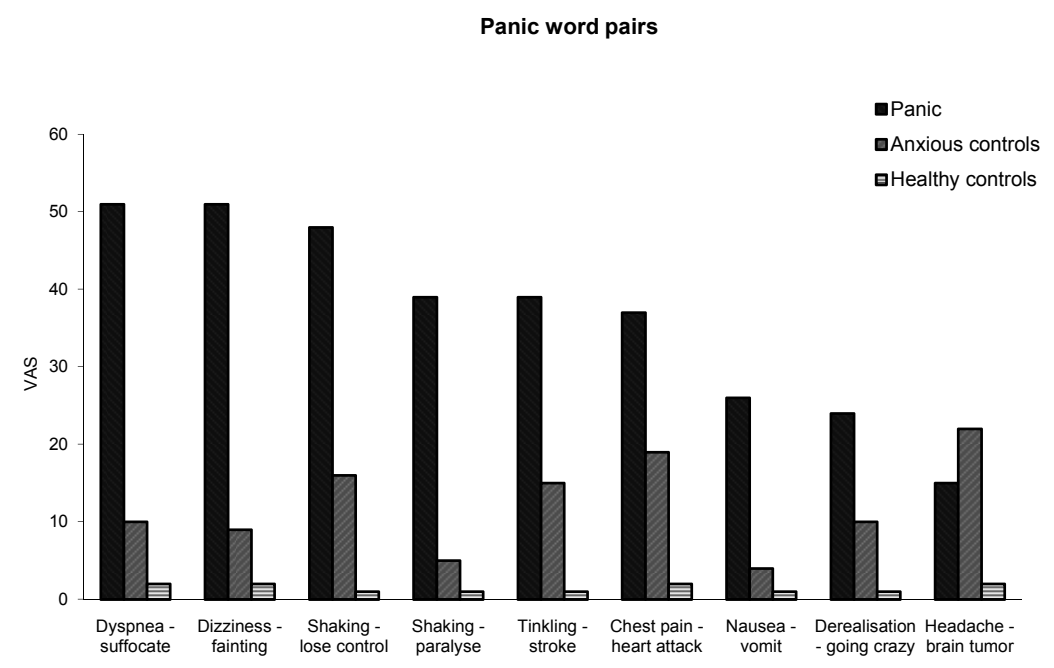

Figure 2. Median level of anxiety on the Visual Analogue Scale on panic word pairs for panic disorder patients, anxious controls and healthy controls.

To assess the relationship between depressive symptoms and anxiety levels on the word pairs correlations were calculated between MADRS scores and mean differences scores between panic and neutral word pairs within the patient groups. There were no significant correlations, nor for panic patients or anxious control patients, $r_{s}=-0.03, \mathrm{~N}=21, n$.s.; $r_{s}=-0.13, \mathrm{~N}$ $=20$, n.s. Meaning that depressive symptoms did not had an influence on our findings.

\section{EXPERIMENT 2}

Experiment 2 was designed to experimentally test the causal role of catastrophic misinterpretations in eliciting panic attacks.

\section{Methods}

\section{Participants}

The study involved three groups of participants: a panic group, an anxious control group and a non-clinical control group.

In the panic group, 20 patients ( 11 female) were selected who met the DSM-IV criteria for PD. Mean age was 40.7 years $(S D=13.5)$. Forty-five percent had co-morbid depression.

The 'anxious control' group consisted of 20 patients ( 9 female). Of these, 30\% had OCD, $25 \%$ social phobia, $35 \%$ specific phobia, $10 \%$ generalized anxiety disorder as their primary diagnosis. Their mean age was 41.3 years $(S D=15.1)$. Twenty-five percent had co-morbid depression. All patients were seeking treatment at the Academic Anxiety Center in Maastricht. 
The 'healthy control' group consisted of 30 participants (17 female). This group was matched with the panic group for sex and age. Participants had never had a psychiatric disorder. Mean age was 38.3 years $(S D=12.5)$. They were recruited by advertisement.

\section{Questionnaires}

The same questionnaires were used as in Experiment 1.

\section{Materials}

In the Paired Associated Task, two categories of word pairs were used: 9 panic-related and 9 neutral word pairs. These 18 word pairs derived from Experiment 1. Nine panic-related word pairs were considered suitable for Experiment 2. Namely, these word pairs provoked more anxiety in panic patients in contrast with healthy controls and/ or other anxious controls. Only 'headache-brain tumor' provoked no differences in anxiety between the patient groups and between the control groups. This word associate was removed for Experiment 2. Overall all neutral word pairs were suitable for experiment 2, with the exception of 'purchaseshopping'. This word associate provoked some anxiety in panic patients and was therefore not appropriate as neutral word. The stimuli were presented in block on a personal computer. The words appeared in 12-cm block letters on a Philips color monitor.

\section{Procedure}

In the pre-test screening, all questionnaires were administered after obtaining written informed consent.

In the test phase, when entering the experiment, patients scored their anxiety level on the eVAS. After more information was given about the experiment participants were asked to fill in the PSL, POMS and eVAS. The task was presented on a computer screen. Before each block of word pairs the participants were asked to fill in the eVAS (= pre-VAS). Further, participants were given the instruction to read the word-pairs. Word-pairs were presented in block (instead separately) in line with the anecdotecal report of Clark et al. (1988). After each block of word-pairs participants were asked to fill in the eVAS to score their highest anxiety level while reading the word pairs (= post -VAS). There were 2 blocks, a panic and a neutral one. Order of blocks was contra-balanced. Presentation time was 3 seconds, with and interval ratio of 2 seconds. The word pairs were randomized. Between each block, participants had to fill in a short questionnaire to prevent possible cross-over effects. At the end of the experiment participants were asked again to score their anxiety level, to fill in the PSL and the POMS. 


\section{Design}

First, the difference between pre-VAS and post-VAS was calculated for each block of wordpairs (= delta-VAS). The median delta-VAS $(=M)$ for both the panic and neutral block of word-pairs was calculated.

Because not all variables were normal distributed all analyses were performed with nonparametric tests. The same tests were used as in Experiment 1.

\section{Results}

\section{Questionnaires}

The pattern of results for the questionnaires was very similar to that of Experiment 1 . The panic group scored significantly higher on the Panic and Agoraphobia Scale $(M=25.5 ; S D=$ $10.3)$, as compared to the anxious control group ( $M=4.5 ; S D=8), t(38)=7.22, p<.001)$. Similarly, both patient groups did not differ in their level of depression, as indicated by the scores on the SDS, $M_{\text {panic }}=47.2, S D=11.2, M_{\text {anxious controls }}=40.7, S D=10.6, t(38)=1.89$, n.s., and the MADRS, $M_{\text {panic }}=15, S D=7.6, M_{\text {anxious controls }}=10.6, S D=9.1, t(38)=1.62$, n.s.. While entering the experiment all patients were significantly more anxious than the healthy controls, $\chi^{2}(3, \mathrm{~N}=69)=11.21, p<.004$ (see Table 2). During the experiment all patients stayed anxious, reported more symptoms and had a lower mood state in contrast with healthy volunteers, VAS before: $\chi^{2}(3, \mathrm{~N}=69)=15.94, p<.001$, VAS after: $\chi^{2}(3, \mathrm{~N}=69)=17.91, p<.001$, PSL before: $\chi^{2}(3, \mathrm{~N}=69)=23.35, p<.001$, PSL after $\chi^{2}(3, \mathrm{~N}=69)=27.4, p<.001$, POMS before: $\chi^{2}(3, \mathrm{~N}=71)=21.19, p<.001$, POMS after: $\chi^{2}(3, \mathrm{~N}=69)=21.8, p<.001$. There were no significant differences between the patient groups, n.s..There were no significant differences within the different groups for VAS, PSL and POMS, n.s..

Table 2. Median values for (e)VAS, PSL and $\mathrm{POM}(\mathrm{S})$ for panic group, anxious controls $(\mathrm{AC})$ and healthy controls $(\mathrm{HC})$. VAS ent $=$ VAS entrance, Pre $=$ before start experiment, Pos $=$ at the end of experiment

\begin{tabular}{llllllll}
\hline & VAS-entr & Pre-VAS & Pos-VAS & Pre-PSL & Pos-PSL & Pre-POM & Pos-POM \\
\hline Panic & 19 & 23 & 18 & 3 & 1 & 28 & 29 \\
AC & 15 & 12 & 13 & 1 & 3 & 27 & 24 \\
HC & 1 & 1 & 0 & 0 & 0 & 9 & 9 \\
\hline
\end{tabular}

\section{Paired Associated Task}

There were significant group differences both for panic, $\chi^{2}(2, N=70)=14.5, p<.001$ and for neutral, $\chi^{2}(2, \mathrm{~N}=70)=16, p<.001$, word pairs. Between the patient groups were no significant differences nor for panic, $U=167, \mathrm{~N}_{1}=20, \mathrm{~N}_{2}=20$, n.s., $M_{\text {panic group }}=3.5, M_{\text {anxious controls }}=$ 3 , or for neutral, $U=168, N_{1}=20, N_{2}=20$, n.s., $M_{\text {panic group }}=3, M_{\text {anxious controls }}=1$, word pairs. 
There were, however significant differences between the patients and the healthy controls, for neutral block: $U=121, \mathrm{~N}_{1}=20, \mathrm{~N}_{2}=30, p<.001 ; U=167, \mathrm{~N}_{1}=20, \mathrm{~N}_{2}=30, p<.004, M_{\text {panic }}$ group $=3, M_{\text {anxious controls }}=1, M_{\text {healthy controls }}=0.1$; for panic block: $U=120, N_{1}=20, N_{2}=30, p<$ $.001, U=181, \mathrm{~N}_{1}=20, \mathrm{~N}_{2}=30, p<.012, M_{\text {panic group }}=3.5, M_{\text {anxious controls }}=3, M_{\text {healthy controls }}=$ 0.1 . Overall, there were no significant differences between the two wordtypes, $\chi^{2}(1, N=70)$ $=3.3$, n.s., $M_{\text {panic words }}=1, M_{\text {neutral words }}=1$. Within the panic group, however, the panic block of word pairs evoked significantly more anxiety than the neutral block of word pairs, $z=1.96$, $\mathrm{N}$-Ties $=15, p<.5, M_{\text {panic words }}=3.5, M_{\text {neutral words }}=3$. There were no differences in anxiety levels between panic and neutral block of word pairs for anxious, $z=1.16, \mathrm{~N}$-Ties $=12$, n.s., $M_{\text {panic words }}=3, M_{\text {neutral words }}=1$ and healthy, $z=1.5, N$-Ties $=17, n . s ., M_{\text {panic words }}=0.1, M_{\text {neutral }}$ words $=0.1$, controls.

Overall delta-VAS values were rather low and following Clark 's definition of a panic attack as "the sudden increase in anxiety reaching at least 50 on a 100 point scale" (Clark et al., 1988, p155), we can conclude that none of the patients had a panic attack.

Correlations between MADRS scores and mean differences scores between panic and neutral word pairs within the patient groups were not significant different, $r_{s}=0.24, \mathrm{~N}=20$, n.s.; $r_{s}=0.13, \mathrm{~N}=20$, n.s.

\section{Discussion}

In the cognitive theory of panic, three hypotheses are proposed regarding catastrophic misinterpretations:

1. These catastrophic misinterpretations concerns their physical sensations (bias specificity)

2. This interpretative bias is assumed to be only specific for PD patients (disorder specificity)

3. These specific catastrophic cognitions are regarded as sufficient and necessary in the production of panic attacks (causality).

Evidence for all of these hypotheses exists but is, to date, not fully conclusive, as explained in the introduction. The present study pertains to the third hypothesis.

To enhance the ecological validity of our study we first conducted a stimulus validation experiment. The results of this led to the selection of a number word pairs that appeared to induce anxiety. Next, we presented these anxiety inducing word pairs repeatedly to panic disorder patients, under the hypothesis that they would trigger panic attacks. Indeed, PD patients were more anxious when reading these word pairs, compared to neutral word pairs. Furthermore, patients were also more anxious than control participants. Both these observations confirm the ecological validity of the experimental setup. However, none of the participants experienced a panic attack upon reading the word pairs. Second, when comparing the anxiety response between PD patients and participants with other anxiety disorders, no significant differences were found. These findings are in contrast with a previous report in 
which $83 \%$ of the PD patients were reported to have a panic attack after reading similar word pairs (Clark et al., 1988).

To explain this discrepancy it might be argued that:

(1) PD patients were not severely ill

(2) There was interference of co-morbid depressive complaints

(3) The sample size was to small.

An accurate comparison is difficult however, since the previous report does not contain complete information in this regard. First, in the present study, panic diagnosis and severity was assessed using standardized scales as well as clinical diagnosis by structured interview. All PD patients had at least moderate to severe panic disorder and this in clear contrast with the 'anxious control' group. Further, there were no differences in experimental anxiety and depressive symptoms between the patients, indicating that the panic patients had substantially higher levels of symptomatology related to panic and agoraphobia. It is therefore unlikely that insufficient panic severity can explain the lack of panic induction in the present study. Second, it is conceivable that depressive symptoms, like a lowered mood state and concentration deficits, could have influenced the panic reaction in the present experiment. However, no significant correlations were found between depressive symptoms and anxiety scores. Neither panic disorder severity nor depression scores were mentioned in the previous report (Clark et al., 1988). Third, theoretically, it is possible that our sample size was insufficient. However, only 12 PD patients, 8 recovered PD patients and 12 healthy controls participated in this previous experiment, compared to 20 PD patients, 20 anxious controls and 30 healthy controls in the present study. In sum, despite the use of carefully selected anxiety inducing word pairs, appropriate sample size, presence of an anxious control group and controlling for depressive symptoms, we were not able to find support for the 'causality hypothesis' in cognitive theory to explain the role of catastrophic cognitions in the occurrence of panic attacks. However, this does not mean that catastrophic thinking does not play a role in the broader concept of panic disorder, for this condition is characterized by anticipatory anxiety and avoidance behavior besides panic attacks. It is very likely that this kind of thinking plays a central role in the anticipatory anxiety that characterizes panic disorder patients. On the basis of phenomenological and neurobiological research Bouton et al. (2001) make a clear distinction between panic and anxiety as two aversive motivational states. It is suggested that panic attacks are descriptively and functionally distinct events when compared with anxiety. Panic refers to a subjective sense of extreme fear, which is accompanied by a massive autonomic surge and strong fight or flight response. In contrast, anxiety refers to apprehensive anticipation of future danger (the danger is not 'actually' present), accompanied by somatic symptoms of tension, vigilance, and worrying. Following this distinction catastrophic misinterpretations seem more related to anxiety than to panic. Catastrophic thinking (and worrying) mostly refers to the anticipation of physical sensation, such as an acute medical condition with fatal result. PD patients were indeed more anxious upon read- 
ing panic word pairs (compared to neutral word pairs), but were not in a state of acute panic. Further, the 'anxious control' group was equally anxious than the PD patients, indicating that catastrophic thinking seems capable of provoking anxiety in most anxiety disorders. Therefore it seems reasonable that catastrophic thinking plays an important role in most anxiety disorders.

On the basis of our results it appears unlikely that catastrophic thinking has a central role in the immediate development of panic attacks. Anxiety can however contribute to the evolution of sporadic panic attacks towards PD through mechanisms such as interoceptive conditioning (Bouton et al., 2001; Mineka \& Oehlberg, 2008; Mineka \& Zinbarg, 2006). 


\section{CHAPTER 3}

\section{References}

Austin, D., \& Kiropoulos, L. (2008). An internet-based investigation of the catastrophic misinterpretation model of panic disorder. Journal of Anxiety Disorders, 22, 233-242.

Austin, D., \& Richards, J. (2001). The catastrophic misinterpretation model of panic disorder. Behaviour Research and Therapy, 39, 1277-1291.

Austin, D., \& Richards, J. (2006). A test of core assumptions of the catastrophic misinterpretation model of panic disorder. Cognitive Therapy and Research, 30(1), 53-68.

Bandelow, B. (1995). Assessing the efficacy of treatments for panic disorder and agoraphobia II. The panic and Agoraphobia Scale. International Clinical Psychopharmacology, 10, 73-82.

Beck, A. T. (1998). Cognitive approaches to panic disorder: theory and therapy. In S. Rachman \& J. D. Maser (Eds.), Panic, psychological perspectives (pp. 91-111). Hillsdale, New Yersey: Lawrence erlbaum associates.

Beck, A. T., \& Emery, T. (1985). Anxiety disorders and Phobias. New York: Basic Books.

Bouton, M. E., Mineka, S., \& Barlow, D. (2001). A modern learning theory perspective on the etiology of panic disorder. Psychological Review, 108, 4-32.

Carmody, T. J., Rush, A. J., Bernstein, I., Warden, D., Brannan, S., Burnham, D., et al. (2006). The Montgomery Asberg and the Hamilton ratings of depression: a comparison of measures. European Neuropsychopharmacology, 16, 601-611.

Chambless, D. L., Beck, A. T., Gracely, E., \& Grisham, J. (2000). Relationship of cognitions to fear of somatic symptoms: a test of the cognitive theory of panic. Depression and Anxiety, 11, 1-9.

Chambless, D. L., \& Gracely, E. (1989). Fear of fear and the anxiety disorders. Cognitive Therapy and Research, 13, 9-20.

Clark, D. (1986a). Anxiety states: panic and generalized anxiety. In K. Hawton, P. Salkovskis, J. Kirk \& D. M. Clark (Eds.), Cognitive behaviour therapy of psychiatric problems (pp. 52-96). Oxford: Oxford University Press.

Clark, D. (1986b). A cognitive approach to panic. Behaviour Research and Therapy, 24, 461-470.

Clark, D. (1988). A cognitive model of panic attacks. In S. Rachman \& J. D. Maser (Eds.), Panic; psychological perspectives. New Yersey: Lawrence Erlbaum associates.

Clark, D. M., Salkovskis, P., Breiholtz, E., Westling, B., Öst, L.-G., Koehler, K., et al. (1997). Misinterpretation of body sensations in panic disorder. Journal of Consulting and Clinical Psychology, 65(2), 203-213.

Clark, D. M., Salkovskis, P., Gelder, M., Koehler, K., Martin, M., Anastasides, P., et al. (1988). Tests of a cognitive theory of panic. In I. Hand \& H.-U. Wittchen (Eds.), Panic and Phobias, vol 2 (pp. 149-158). Berlin: Springer-Verlag.

Clark, D. M., Salkovskis, P., Hackmann, A., Middleton, H., Anastasides, P., \& Gelder, M. (1994). A comparison of cognitive therapy, applied relaxation and imipramine in the treatment of panic disorder. Britisch Journal of Psychiatry, 164, 759-769.

Greenwald, A., MCGhee, D., \& Schwartz, J. (1998). Measuring individual differences in implicit cognition: The implicit association test. Journal of Personality and Social Psychology, 74, 1464-1480.

Griez, E., \& Schruers, K. (1998). Experimental pathophysiology of panic. Journal of Psychosomatic Research, 45(6), 493-503.

Hartong, E., \& Goekoop, J. (1985). De Montgomery-Åsberg beoordelingsschaal voor depressie. Tijdschrift voor Psychiatrie,, 27, 657-668.

Harvey, J., Richards, J., Dziadosz, T., \& Swindell, A. (1993). Misinterpretation of ambiguous stimuli in panic disorder. Cognitive Therapy and Research, 17, 235-248.

Hofman, S., Suvak, M., Barlow, D., Shear, K., Meuret, A., Rosenfield, D., et al. (2007). Preliminary evidence for cognitive mediation during cognitive-behavioral therapy of panic disorder. Journal of Consulting and Clinical Psychology, 75(3), 374-379. 
Lecrubier, Y., Sheehan, D., Weiller, E., Amorim, P., Bonora, I., Sheehan, K. H., et al. (1997). The Mini International Neuropsychiatric Interview (MINI). A short diagnostic structured interview: reliability and validity according to the CIDI. European Psychiatry, 12, 224-231.

McNally, R. J., \& Foa, E. (1987). Cognitions and agoraphobia: bias in the interpretation of threat. Cognitive Therapy and Research, 11, 567-581.

Mineka, S., \& Oehlberg, K. (2008). The relevance of recent developments in classical conditioning to understanding the etiology and maintenance of anxiety disorders. Acta Psychologica, 127, 567-580.

Mineka, S., \& Zinbarg, R. (2006). A contemporary learning theory perspective on the etiology of anxiety disorders:It's not what you thought it was. American Psychologist, 61(1), 10-26.

Montgomery, S., \& Asberg, M. (1979). A new depression scale designed to be sensitive to change. Britisch Journal of Psychiatry, 134, 382-389.

Rachman, S., Levitt, K., \& Lopatka, C. (1987). Panic: The links between cognitions and bodily symptoms I. Behaviour research and therapy, 25, 411-424.

Roth, W. T., Wilhelm, F., \& Petit, R. (2005). Are current theories of panic falsifiable? Psychological Bulletin, 131(2), 171-192c.

Schaefer, A., Brown, J., Watson, C., Plemel, D., DeMotts, J., Howard, M., et al. (1985). Comparison of the validities of the Beck, Zung, and MMPI depression scales. Journal of Consulting and Clinical Psychology, 53, 415-418.

Siev, J., \& Chambless, D.-L. (2008). Specificity of treatment effects: cognitive therapy and relaxation for generalized anxiety and panic disorders. Journal of Consulting and Clinical Psychology, 76(5), iii.

Teachman, B., Smith-Janik, S., \& Marker, C. (2008). Automatic associations and panic disorder: trajectories of change over the course of treatment. Journal of Consulting and Clinical Psychology, 76(6), 988-1002.

van Duinen, M., Rickelt, J., \& Griez, E. (2008). Validation of the electronic visual analogue scale of anxiety. Progress in Neuropsychopharmacology \& Biological Psychiatry, 15(32(4), 1045-1047 Epub.

Wald, F. D., \& Mellenbergh, G. J. (1990). De verkorte versie van de Nederlandse vertaling van de Profile of Mood states. Nederlands Tijdschrift voor de Psychologie, 45, 86-90.

Wells, A. (1997). Cognitive Therapy of Anxiety Disorders: A pratice manual and conceptual guide. Chichester, Engeland: John Wiley \& Sons Ltd.

Westling, B., \& Öst, L.-G. (1993). Relationship between panic attack symptoms and cognitions in panic disorder patients. Journal of Anxiety Disorders, 7, 181-194.

Whittal, M., \& Goetsch, V. (1995). Physiological, subjective and behavioral responses to hyperventilation in clinical and infrequent panic. Behaviour Research and Therapy, 33(4), 415-422.

Zung, W. W. K. (1965). A self-rating depression scale. Archives of General Psychiatry, 12, 63-70. 



\section{PART II: LEARNING THEORY}





\section{CHAPTER 4}

\section{The role of 'interoceptive' fear conditioning in the development of panic disorder}

Klara De Cort ${ }^{1}$, Eric Griez ${ }^{1}$, Marjolein Büchler ${ }^{1}$ \& Koen Schruers ${ }^{1,2}$

${ }^{1}$ Maastricht University, Institute for Mental Health and Neuroscience, the Netherlands

${ }^{2}$ University of Leuven, Center for Learning and Experimental Psychopathology, Belgium

Published as: De Cort, K., Griez, E., Büchler, M. \& Schruers, K. (2012). The role of 'interoceptive' fear conditioning in the development of panic disorder. Behavior Therapy, 43, 1, 203215. 


\begin{abstract}
More than $20 \%$ of the general population experience a panic attack at least once in their lives; however, only a minority goes on to develop panic disorder. Conditioning mechanisms have been proposed to explain this evolution in persons who are susceptible to developing panic disorder upon a 'traumatic' panic attack. According to preparedness theory, some cues are more likely to condition than others, namely, those referring to internal, bodily signals of danger. The aim of the present study was to test this theory in a differential conditioning paradigm, making use of scripts referring to different internal, bodily sensations as CS and inhalation of $35 \% \mathrm{CO}_{2}$ as UCS. Thirty-three healthy volunteers were assigned to three scripts conditions: 'suffocation', 'neutral' or 'urgency'. During acquisition, one of two versions of a particular script was always followed by an inhalation of $35 \% \mathrm{CO}_{2}(\mathrm{CS}+)$ and the other by room air (CS-). Acquisition was followed by a test phase, where only inhalations of room air were administered. In line with our hypothesis, only participants in the suffocation condition exhibited a selective conditioning effect. They were more fearful and showed a significantly higher increase in tidal volume than participants in the two control conditions. Results are discussed with relation to interoceptive conditioning, preparedness and the possible role of tidal volume in PD.
\end{abstract}




\section{Introduction}

Unexpected panic attacks are very common in the general population. In a epidemiological sample, $22.7 \%$ of the population had experienced at least one panic attack (Kessler et al., 2006). However, panic attacks are not in themselves pathological. On the contrary, they seldom progress to panic disorder (PD). When DSM-IV criteria were applied, the prevalence of PD was only 3.7\% (Kessler et al., 2006). In order for a panic attack to develop into PD, not only is the occurrence of unexpected panic attacks necessary, but also anticipatory anxiety concerning the next panic attack or its consequences (DSM-IV, 2000).

Phenomenological and neurobiological research gives a clear indication that panic and anxiety are descriptively and functionally different (Bouton, Mineka \& Barlow, 2001). Panic refers to a subjective sense of extreme fear, which is accompanied by a massive autonomic surge and strong fight or flight response. In contrast, anxiety refers to apprehensive anticipation of future danger (the danger is not 'actually' present), accompanied by somatic symptoms of tension, vigilance, and worrying.

According to the modern learning theory approach of Bouton et al. (2001), panic attacks can evolve into PD if conditioned anxiety about future panic attacks develops in response to interoceptive or exteroceptive cues. Interoceptive conditioning (IC) occurs when the initial interoceptive precursors of a panic attack (sweating, palpitations) become conditioned stimuli, predicting more intense arousal and provoking anxiety as a conditioned response (Razran, 1961). This anxiety response may produce additional and more interoceptive stimuli (more palpitations, sweating, faster breathing) that further trigger and potentiate anxiety, spiraling into panic. Anxiety thus becomes a precursor of panic. IC may explain why panic attacks occur in both the presence (situational) and absence (non-situational) of external cues. It may also explain the phenomenon of conditioned panic attacks, which is an inherent component of PD.

The nature of the conditioned reaction depends on the qualitative nature of the conditioned stimulus (CS) and the temporal relationship between the interoceptive cues (CSs) and the panic attack. The closer and more similar the CS is to the unconditioned stimulus (UCS), the stronger and more similar the conditioned response will be to panic (Bouton et al., 2001). For example Forsyth, Eifert \& Thompson (1996) studied the properties of fear conditioning with video clips as the CS and an inhalation of $20 \% \mathrm{CO}_{2}$ as the UCS. A distinction was made between fear relevant (heart beating arrhythmically/snake) or irrelevant stimuli (swimming sperm/ flowers) and internal (heart beating/ sperm) or external stimuli (snake/flowers) stimuli. They demonstrated a stronger fear conditioning reaction to the fearrelevant video clip than to the fear-irrelevant video clip, especially within the external stimuli. Moreover, the conditioned reaction (CR) of heart rate acceleration and the reported panic symptoms were similar to those for panic. Similar results were established in fear conditioning studies with negative and positive odors as the $\mathrm{CS}$ and a $7.5 \% \mathrm{CO}_{2}$ inhalation as the UCS. Only with the negative odors, the $\mathrm{CR}$ provoked a higher respiratory frequency and more 
symptoms (Devriese et al., 2000; Van den Bergh, Kempynck, Van den Woestijne, Baeyens, \& Eelen, 1995; Van den Bergh, Stegen, \& Van den Woestijne, 1997). It seems that, if interoceptive cues are in closer proximity (in time and in qualitative aspects) to panic they may serve as 'prepared' or 'fear- relevant', and that the conditioned reaction will be more similar to the unconditioned panic reaction. This is similar to the way evolutionary based cues for phobias are more prepared and easier to condition than non-relevant and non-prepared cues, something referred to as the preparedness theory (Öhman \& Mineka, 2001; Seligman, 1971). It describes how evolutionary based (phylogentically fear- relevant) stimuli preferentially evoke fear in an automatic fashion, independent of cognitive processes (Morris, Öhman, \& Dolan, 1998).

Applying the preparedness theory to IC could explain conditioned panic attacks in PD. Panic-relevant and prepared cues can evoke a conditioned response that is more similar to the unconditioned panic reaction. Dyspnea, difficulty breathing, and suffocation appear to be core sensations in panic (Colasanti et al., 2008; Schruers, Van de Mortel, Overbeek, \& Griez, 2004). Breathing is of obvious survival value. Dyspnea may represent the clearest example of a prepared interoceptive cue evoking conditioned panic through IC and leading to PD. Van Diest et al. (2005) demonstrated that merely imagining a suffocation scenario changes respiratory behavior (lower Fractional concentration of end-tidal carbon dioxide or Fet $\mathrm{CO}_{2}$ ) in high-trait anxious women, whereas hearing a script describing a relaxed, depressed or tensed situation does not.

Stegen et al. (1999) were the first to conduct a fear conditioning experiment with suffocation scripts as fear-relevant and neutral scripts as fear-irrelevant CS and an inhalation of $5.5 \% \mathrm{CO}_{2}$ as UCS. They showed that only the fear-relevant scripts could alter respiratory behavior and subjective symptoms as occurs after an inhalation of $\mathrm{CO}_{2}$.

The aim of the present study was to study selective 'interoceptive' fear conditioning in healthy participants using three imaginary scripts (describing suffocation, urgency, and a neutral condition) with a different valence and arousal as the $\mathrm{CS}$ and $35 \% \mathrm{CO}_{2}$-enriched air as the UCS. In line with Razran (1961) who defined 'interoceptive conditioning' as classical conditioning in which either the CS, the UCS, or both are interoceptive, this experiment can be considered as 'interoceptive'.

This study elaborates on the study by Stegen and colleagues (1999) and we adopted the exact same procedure (pause in another room, the amount of trials in both phases and rehabituation) to make it possible to interpret possible differences in results between both studies. However, the present study additionally contains a third 'urgency' script as an 'active control' condition (see materials) and used 35\% $\mathrm{CO}_{2}$-enriched air as the UCS to make the UCS even more stronger and more salient. Forsyth and Eifert (1998) stated that small percentages of $\mathrm{CO}_{2}$-enriched air cause gradual and sustained arousal, while high percentages are responsible for an acute and strong fear response. Previous research in our laboratory 
showed that inhalation of $35 \% \mathrm{CO}_{2}$-enriched air causes symptoms of a panic attack, i.e., arousal, dizziness, feelings of derealization, faster and deeper breathing, and feelings of breathlessness (Griez \& Schruers, 1998). Furthermore, in a recent study by our group, we found that an inhalation of $\mathrm{CO}_{2}$-enriched air induces a condition that meets the formal criteria of panic in current psychiatric nosology (Griez et al., 2007).

Based on the preparedness theory and IC, we expected to find a selective fear conditioning effect (more subjective fear and changes in respiratory measures) in the CS+ suffocation condition in contrast to both control conditions.

\section{Methods}

\section{Participants}

In total 38 healthy volunteers, recruited via advertisements, participated in the study. In the advertisement the exclusion criteria were already mentioned. Five did not meet the inclusion criteria. Exclusion criteria were determined in former research of our laboratory with the $35 \% \mathrm{CO}_{2}$ challenge and involved: any lifetime psychological disorder, cardiac or respiratory disease, epilepsy or cerebral aneurysm, hypertension, familial affective or anxiety disorder in first degree relatives, pregnancy, and the current use of psychotropic medication. The 33 remaining participants, all Caucasian, consisted of 19 women and 14 men with a mean age of 31.61 ( $S D=11.07$ ) years and age range between 20-55 years. The study included three conditions: suffocation, urgency, and a neutral condition. Participants were randomly assigned to one of the different conditions in such a way that there were 11 participants in each. The study was approved by the Medical Ethical Committee of Maastricht University, The Netherlands.

\section{Materials}

\section{Conditioned Stimuli}

Three categories of imaginary scripts were used: one was neutral-positive, one described urgency, and one described a condition of suffocation (appendix). Each category consisted of two scripts, making six scripts in total. The neutral-positive and suffocation scripts were adopted from previous research. In that study merely imaging a suffocation script was able to evoke physical symptoms (Stegen et al., 1999). To address the theory of preparedness, we also developed an 'active control' script, namely, an urgency script (i.e., urgency to urinate) that was neither fear-relevant nor life-threatening, but that also contained elements of physical sensations and was annoying (negatively valenced). The neutral scripts were positively valenced and described a relaxing situation, i.e., sitting in an apartment overlooking the sea or sitting in a living room. The suffocation condition -- being stuck in a sauna or an elevator -was negatively valenced and suggested bodily sensations associated with panic and breath- 
lessness. All scripts were equal in length and proposed sensations. Scripts were presented through headphones.

\section{Unconditioned stimuli}

A single inhalation of $35 \% \mathrm{CO}_{2}$ was used as the UCS. A single inhalation of air was used as a control inhalation. The subject had to inhale through a mask a vital capacity gas mixture of either $35 \% \mathrm{CO}_{2}$ and $65 \% \mathrm{O}_{2}$ or a prepared mixture with concentrations identical to room air $\left(21 \% \mathrm{O}_{2}\right.$ and $\left.78 \% \mathrm{~N}_{2}\right)$. The mask was connected to a gas mixing apparatus. The subject was instructed to exhale as deeply as possible and then to inhale deeply and to hold his/her breath for 4 seconds before exhaling.

\section{Subjective measurements}

The level of fear was measured on a Visual Analogue Scale Fear (VAS F). Participants were asked to score their level of fear with zero meaning "no fear at all" and 100 meaning "greatest fear ever experienced". In addition, the Panic Symptom List (PSL) was used to measure symptoms. This list consists of 13 symptoms that can occur during a panic attack, intensity ranging from "not at all" to "very much". At the end of the experiment, the participants were asked if they were aware of an association between the scripts and the $\mathrm{CO}_{2}$ inhalation.

\section{Physiological measurements}

At the beginning of the study, vital capacity (Ferraris Haloscale ${ }^{\circledR}$ Standard Wright Spirometer), heart rate, and blood pressure (MaxNIBP ${ }^{\mathrm{TM}}$ ) were measured.

Heart rate was measured using an electrical plethysmographical sensor (Nellcor), connected to the left index finger. The sensor was connected to the blood pressure apparatus (CAS740), linked to a computer. A spirometry accessory kit (Datex-Ohmeda Patient Spirometry Accessory Kit) was connected to the mask of the $\mathrm{CO}_{2}$ machine and capnograph (Datex Capnomac Ultima). The capnograph measured respiration rate, tidal volume, and $\mathrm{FetCO}_{2}$. These physiological measurements were registered continuously throughout the experiment. Minute ventilation was calculated as a function of respiration rate and tidal volume.

\section{Questionnaires}

The psychological health of the participants was evaluated diagnostically by a trained clinician using the Mini International Neuropsychiatric Interview (MINI, Lecrubier et al., 1997). In addition, the Montgomery-Asberg Depression Scale (MADRS, Montgomery \& Asberg, 1979), the Self-rating Depression Scale (SDS, Zung, 1965), the Spielberger State/trait Anxiety Scale (STAI, Spielberger, 1983), the Anxiety Sensitivity Index (ASI, Reiss et al., 1986) and the Fear Questionnaire (FQ, Marks \& Matthews, 1979), were administered. The FQ is a 15 item self rating questionnaire, assessing agoraphobia, social and blood-injury phobia, with a range between zero and 120. Finally, the Dutch translation of the Questionnaire Upon Mental Im- 
agery (QMI, Sheehan, 1967) was given to assess the participants' ability to imagine situations.

\section{Procedure}

During the pre-test screening, all questionnaires were administered, blood pressure, heart rate and exclusion criteria for $\mathrm{CO}_{2}$-inhalation were checked. The actual aim of the study was concealed: participants were told that the goal of the study was to study the effect of imagination on physiological parameters (blood pressure, respiration rate). It was explained that more information about the procedure and goal of the study would be given at the end of the experiment. The study was conducted at the Academic Anxiety Centre in Maastricht, the Netherlands. The participants were randomized to the three different script conditions. Before starting, the participants filled in the PSL and the VAS F.

The experiment consisted of four phases: habituation1, acquisition, habituation2, and test. In the habituation 1 phase ( $3 \mathrm{~min}$ ), the participant became familiar with the test environment. He or she sat in a comfortable chair waring a headphone and breathing room air. In this phase, the physiological measures were started. The acquisition phase consisted of six trials of $2 \frac{1}{2}$ minutes each. The two different versions of a given script condition were each presented three times. One script was always followed by a UCS- (room air) and the other script was always followed by a UCS $+\left(35 \% \mathrm{CO}_{2}\right.$ - enriched air). This association between type of script and $\mathrm{CO}_{2}$ inhalation was counterbalanced. The order of the six trials was also counterbalanced across participants. Between trials, participants filled in the PSL and the VAS F. Each trial consisted of three phases: a relaxation phase, a listening and imagination phase, and an inhalation phase. In the relaxation phase ( $1 \mathrm{~min}$ ), the participant sat in the chair while listening to relaxing music through the headphone and breathed room air through the mouthpiece. Subsequently, the listening and imagination phase (1 $\mathrm{min}$ ) started in which the participant heard the script and was asked to imagine this script as vividly as possible while he/she breathed room air. The inhalation phase consisted of a single inhalation of $35 \% \mathrm{CO}_{2}$ enriched air or of room air.

The acquisition phase was followed by a half hour break, during which the participant relaxed in the waiting room. The habituation2 phase was similar to the first one. In the test phase, the trials consisted of the same phases as in the acquisition phase, but the same scripts (CS +/CS-) were only presented two times each and the UCS+ $\left(35 \% \mathrm{CO}_{2}\right.$ - enriched air) was not presented. During the inhalation phase, only inhalations of room air were administered. The annotation of the CS (+ and -) refers to those stimuli previously paired with the UCS in the acquisition phase. Again, before and after each trial, participants were asked to fill in the PSL and the VAS F. 


\section{Design}

The experiment used a double- blinded, randomized design with three separate conditions. Respiration rate, heart rate, tidal volume, and $\mathrm{FetCO}_{2}$ were calculated per minute. Analyses were performed on means per minute for each respiratory measurement.

The Kolmogorov-Smirnov test was used to test the normality of the variables. Only the PSL and VAS F scores were not normally distributed. Therefore we analyzed these variables with non-parametric tests; the Wilcoxon Signed Ranks Test $(z)$, the Mann-Whitney Test $(U)$, the Friedman Test and the Kruskal-Wallis Test $\left(x^{2}\right)$.

The two habituation phases ( $1 \& 2$ ) were analyzed using ANOVA with condition (neutral/ urgency/ suffocation) as the between-subject variable $x$ phase (acquisition/ test) as withinsubject variable. Subsequently, the two habituation phases served as covariates to control for normal fluctuations in the physiological measures.

In the analyses, we made use of difference scores; subjective measurements (VAS F, PSL) were derived from difference scores between pre- and post-trials. Physiological measurements were derived from difference scores between the means of the relaxation phase and the means of the listening and imagination phase.

Moreover, a repeated measures analysis of covariance was conducted with condition (neutral, urgency, suffocation) as the between-subject variable and conditioning (CS+, CS-) and phase (acquisition, test) as within-subject variables. Observed power with a confidence interval of $80 \%$ for all outputs was also calculated.

If significant differences were noted, post-hoc analyses were performed on the adjusted means for the covariates and effect sizes were calculated.

\section{Results}

The results are divided into five sections. The first section concerns the characteristics of the sample. In the second, the analyses of pre-experimental parameters will be described. The third section describes the results of the acquisition phase, and the fourth one the findings of the test phase (conditioning). These sections are divided into subjective findings (Table 2) and physiological findings (Table 3 ). The final section contains the results of the awareness contingency.

\section{Sample Characteristics}

No sex differences were found in symptom reporting, fear, or physiological measures. All scores on the questionnaires concerning severity of anxiety disorders, general anxiety, depression or anxiety sensitivity were well below the clinical value, indicating that our sample consisted of low anxious participants. No differences were observed for the different condi- 
tions either (Table 1). Because of the low anxiety sensitivity scores and the low variability within the different groups further analyses were not possible.

Table 1. Mean scores for the different questionnaires for the different conditions: neutral, urgency and suffocation.

\begin{tabular}{llll}
\hline & Neutral $(\mathrm{N}=11)$ & Urgency $(\mathrm{N}=11)$ & Suffocation $(\mathrm{N}=11)$ \\
\hline MADRS & $0.72(0.78)$ & $1.54(2.34)$ & $0.18(0.4)$ \\
SDS & $29.18(4.26)$ & $29.81(4.6)$ & $28.54(0.4)$ \\
STAI 1 & $27.54(5.27)$ & $29(5.42)$ & $26.9(5.08)$ \\
STAI 2 & $29.63(6.54)$ & $29.9(4.36)$ & $28(6.14)$ \\
FQ & $6.72(2.56)$ & $8.25(3.42)$ & $6.25(2.6)$ \\
ASI & $8.09(4.41)$ & $6.54(4)$ & $4.36(3.66)$ \\
QMI & $70.63(21.1)$ & $86(25.54)$ & $88.18(26.36)$ \\
\hline
\end{tabular}

Note. MADRS = Montgomery-Asberg Depression Scale; SDS = Self-rating Depression Scale; STAI = Spielberger state/trait Anxiety Inventory 1\&2; FQ= Fear Questionnaire; ASI= Anxiety Sensitivity Index; QMI = Questionnaire Upon Mental Imagery. Standard deviations are given between brackets.

\section{Pre-experimental Analyses}

The pre-experimental analyses involved the differences between the habituation means before each phase (habituation $1 \& 2$ ). These analyses indicated that the participants habituated in general to the experimental context. However, there were some differences between the conditions (suffocation/urgency/neutral) for certain physiological responses.

There were no differences in subjective measurements between the habituation phases (1 \& 2): VAS F: $z=0.96, \mathrm{~N}$-Ties $=20, p>.11$, PSL: $z=1.61, \mathrm{~N}$-Ties $=8, p>.34$. Within the habituation phases were also no significant differences between the conditions; VAS- $F$ in habituation $1: x^{2}(2, N=33)=5.629, p>.06$, VAS-F in habituation $2: x^{2}(2, N=33)=2.26, p>.88$, PSL in habituation $1: x^{2}(2, \mathrm{~N}=33)=0.013, p>.10$, PSL in habituation2 $: x^{2}(2, \mathrm{~N}=33)=1.74, p$ $>.50$.

During the first habituation phase (habituation1), all participants displayed a higher heart rate $--F(1.30)=7.34, p<.011$, partial $\eta^{2}=.20$-- than during the second (habituation2).

Analyses resulted in a significant main effect for condition in respiration rate: $F(2.30)=$ $3.80, p<.034$, partial $\eta^{2}=.20$. During the first habituation phase (habituation 1 ), participants in the urgency condition breathed significantly faster than those in the other conditions, $t=-$ 2.63, $\mathrm{df}=20, p<.016, d=-1.12$ and $t=2.40, \mathrm{df}=2, p<.026, d=-1.02$. This effect disappeared in the second phase (habituation2). 


\section{Acquisition}

As expected, inhaling $35 \% \mathrm{CO}_{2}$-enriched air instead of air resulted in significantly greater reactions in both subjective and physiological measurements.

\section{Subjective measures}

After inhaling 35\% $\mathrm{CO}_{2}$-enriched air (CS+ trials), participants reported significantly more fear and experienced significantly more symptoms than after inhaling room air (CS- trial; $z=4.80$, $\mathrm{N}$-Ties $=31, p<.00 ; z=5.01, \mathrm{~N}$-Ties $=33, p<.00)$. Table 2 shows the clear differences in fear and symptom reporting between the CS+ and CS- trials.

Table 2. Mean symptom reporting (PSL) and fear level (VAS F) for both habituation phases and for the CS+-and CS- trials in acquisition and the test phases for the different conditions: neutral, urgency and suffocation.

\begin{tabular}{|c|c|c|c|c|c|c|c|c|c|c|c|c|}
\hline & & & \multicolumn{6}{|c|}{ Acquisition phase } & \multicolumn{4}{|c|}{ Testphase } \\
\hline & \multicolumn{2}{|c|}{ Habituation } & \multicolumn{2}{|l|}{ CS- } & \multicolumn{2}{|l|}{$\mathrm{CS}+$} & \multicolumn{2}{|c|}{ habituation } & \multicolumn{2}{|l|}{ CS- } & \multicolumn{2}{|l|}{$\mathrm{CS}+$} \\
\hline & $M$ & $S D$ & $M$ & $S D$ & $M$ & $S D$ & $M$ & $S D$ & $M$ & $S D$ & $M$ & $S D$ \\
\hline \multicolumn{13}{|l|}{ PSL } \\
\hline Neutral & 0.45 & 0.82 & -0.15 & $0.48^{*}$ & 12.58 & 5.43 & 0.36 & 0.67 & 0.14 & 0.32 & 0.09 & 0.38 \\
\hline Urgency & 0.64 & 1.50 & 0.15 & $1.52^{*}$ & 10.76 & 3.89 & 0.27 & 0.47 & 0.41 & 1.04 & 0.45 & 0.69 \\
\hline Suffocation & 0.36 & 0.67 & -0.27 & $1.74^{*}$ & 8.03 & 5.83 & 0.09 & 0.30 & 0.55 & 0.65 & 0.41 & 0.70 \\
\hline \multicolumn{13}{|l|}{ VAS F } \\
\hline Neutral & 4 & 5.33 & -0.06 & $2.04^{*}$ & 20.15 & 20.25 & 3.64 & 3.72 & 0.36 & 1.87 & 0.09 & 0.38 \\
\hline Urgency & 11.73 & 13.56 & -3.76 & $8.72 *$ & 21.18 & 18.13 & 7.09 & 12.49 & 0.36 & 3.16 & -1.27 & 4.8 \\
\hline Suffocation & 2.82 & 5.91 & -0.82 & $2.54^{*}$ & 7.88 & 7.45 & 2.82 & 3.54 & 0.5 & 1.1 & 2.05 & $4.44^{* *}$ \\
\hline
\end{tabular}

Note. $M=$ mean, $S D=$ standard deviation. Values are difference scores. Significant group differences $\left({ }^{* *}\right)$ and trial differences $\left({ }^{*}\right)$ were observed. $p<.05$.

There were slight differences between the conditions. Participants in the suffocation condition reported fewer symptoms after an inhalation of $35 \% \mathrm{CO}_{2}$-enriched air than volunteers in the urgency $\left(U=34.5, \mathrm{~N}_{1}=11, \mathrm{~N}_{2}=11, p>.087, d=.95\right)$ and in the neutral condition $(U=31$, $\mathrm{N}_{1}=11, \mathrm{~N}_{2}=11, p>.053, d=.80$ ), a difference that nearly reached statistical significance. Further, participants in the suffocation condition reported less fear after inhalation of $35 \%$ $\mathrm{CO}_{2}$-enriched air than volunteers in the urgency condition $\left(U=35, \mathrm{~N}_{1}=11, \mathrm{~N}_{2}=11, p>.094\right.$, $d=.83)$.

\section{Physiological measures}

The physiological measurements were divided into a script imagination and an inhalation phase.

For the script imagination phase (see Table 3), there were no differences between CS+ and CS- trials (respiration rate; $F(1.29)=0.38, p>.5$; tidal volume; $F(1.29)=0.9, p>.35$, minute ventilation; $F(1.29)=0.21, p>.6$ ) and no condition differences (e.g., respiration rate; 
$F(2.29)=0.16, p>.8 ;$ FetCO $_{2} F(2.29)=2.88, p>.07$; tidal volume; $F(2.29)=0.47, p>.6$; $\mathrm{mi}-$ nute ventilation; $F(2.29)=0.17, p>.05)$.

For the inhalation phase, there were significant differences in respiratory behavior between inhalation of $35 \% \mathrm{CO}_{2}$-enriched air and room air. During the inhalations of $35 \% \mathrm{CO}_{2}$ enriched air, minute volume, respiration rate, and tidal volume increased significantly compared with the inhalations of room air; respectively, $F(1.29)=43.33, p<.00$, partial $\eta^{2}=.60$, $F(1.29)=37.47, p<.00$, partial $\eta^{2}=.56$ and $F(1.29)=19.22, p<.00$, partial $\eta^{2}=.40$.

Additionally, the recovery times for heart rate and $\mathrm{FetCO}_{2}$ after inhalations of $35 \% \mathrm{CO}_{2}$ enriched air were significantly longer than after inhalations of room air; $F(1.30)=57.92, p<$ .00 , partial $\eta^{2}=.66$ and $F(1.30)=222.32, p<.00$, partial $\eta^{2}=.88$.

Analyses of the inhalations revealed a significant interaction difference for minute ventilation during inhalations of $35 \% \mathrm{CO}_{2}$-enriched air. $\mathrm{A}$ condition $\mathrm{X}$ inhalation interaction showed that condition differences were present during the inhalations of $35 \% \mathrm{CO}_{2}$-enriched air: $F(2.29)=3.60, p<.04$, partial $\eta^{2}=.20$. Participants in the neutral condition had a marginally higher minute volume than participants in the suffocation condition; $t=1.997, \mathrm{df}=20, p$ $>.06, d=.85$. For tidal volume, marginal interaction differences -- $F(2.29)=2.95, p>.068$, partial $\eta^{2}=.20$-- were observed. 


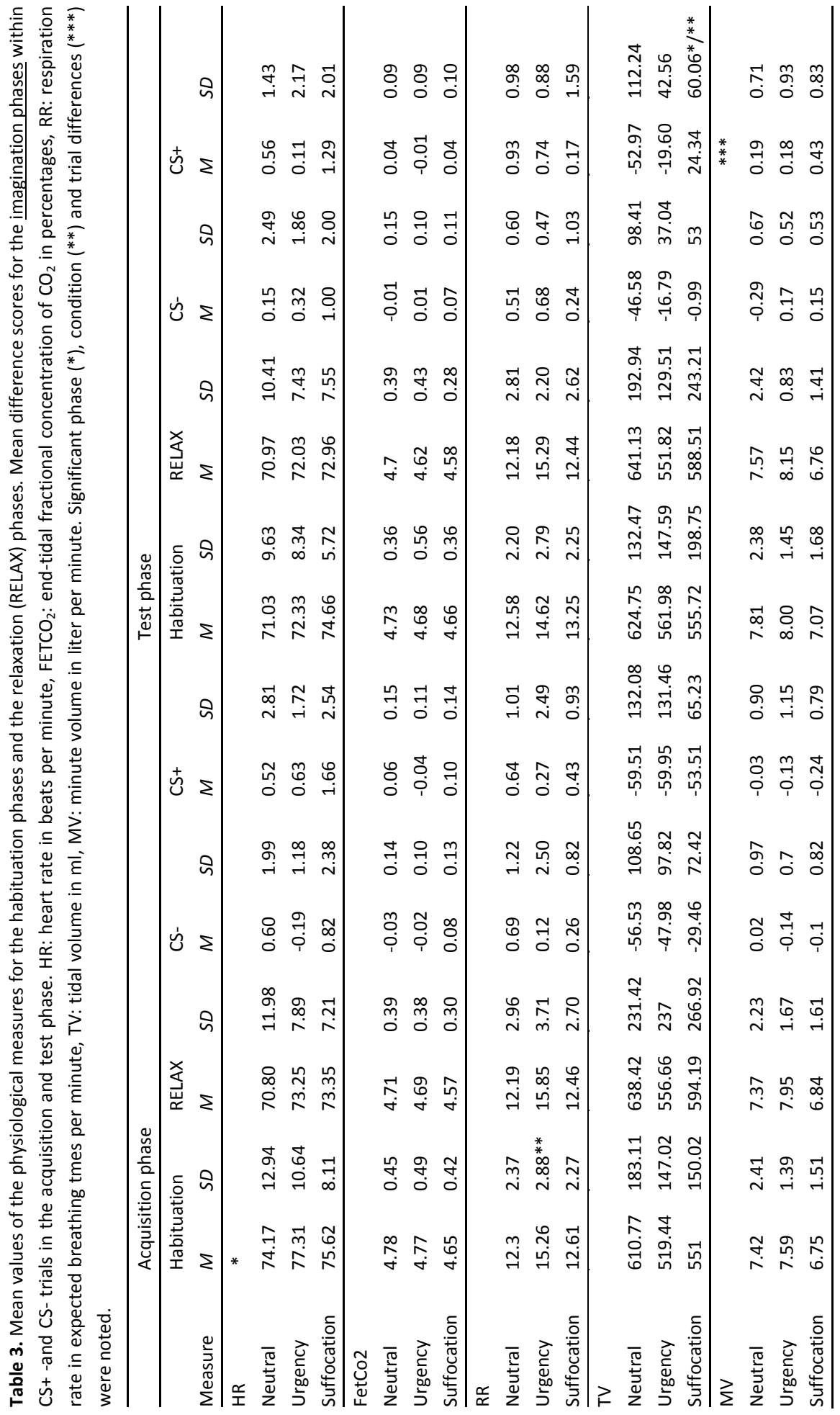




\section{Test Phase}

In line with our hypothesis, only participants in the suffocation condition exhibited a selective conditioning effect relative to the control conditions. However, we did not find significant differences between CS+ and CS- within the suffocation condition.

\section{Subjective measures}

For fear, a selective conditioning effect was observed; participants in the suffocation condition were more fearful during CS+ trials than participants in the urgency condition $(U=33.5$, $\left.\mathrm{N}_{1}=11, \mathrm{~N}_{2}=11, p<.053, d=-.71\right)$ and participants in the neutral condition $\left(U=38.5, \mathrm{~N}_{1}=\right.$ $11, N_{2}=11, p>.093, d=-.62$ ). Further, there were no differences in fear ratings between the conditions during the CS- trials $(p>.35)$. The number of bodily symptoms $(p>.2)$ did not differ among the three conditions. However, there were no significant differences between $\mathrm{CS}+$ and $\mathrm{CS}$ - trials.

\section{Physiological measures}

Participants had a significantly higher minute volume during the $\mathrm{CS}+$ trials than during the CS- trials; $F(1.29)=4.45, p<.04$, partial $\eta^{2}=.13$, observed power of .79 . No other significant differences between CS+ and CS- trials were observed ( $p>.3$, observed power $>.20)$.

Analysis of condition differences indicated a significant selective conditioning effect in tidal volume; $F(1.29)=3.84, p<.033$, partial $\eta^{2}=.21$, observed power of .89 (Fig. 1). Participants in the suffocation condition had a significantly higher tidal volume than those in the urgency and neutral conditions, but only within the CS+ trials; respectively, $t=-2.52, \mathrm{df}=20$, $p<.02$ and $t=-2.32, \mathrm{df}=20, p<.03$. Effect sizes were also high for both analyses, respectively, $d=-1.13$ and -1.04 . Furthermore, no significant differences were observed between the urgency and neutral conditions: $p>.4$. No condition differences were observed in heart rate (observed power of .45), $\mathrm{FetCO}_{2}$ (observed power of .48), respiration rate (observed power of .52), or minute volume (observed power of .46). 


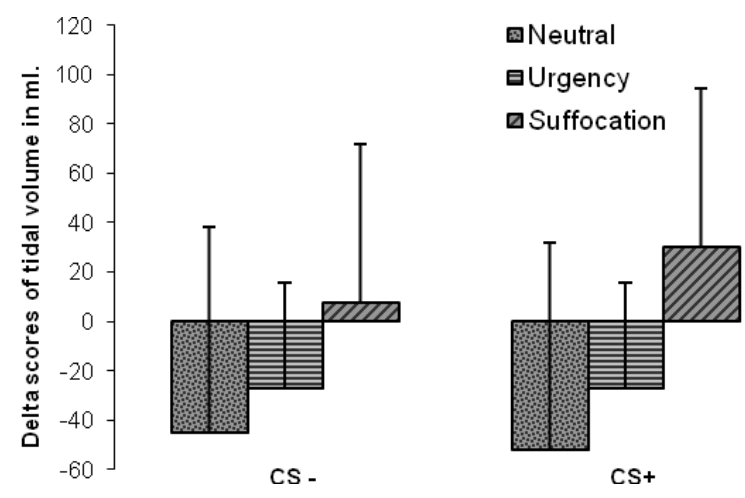

Figure 1. Difference scores (Delta) in tidal volume (in $\mathrm{ml}$ ) for the $\mathrm{CS}+$ and $\mathrm{CS}-$ trials during the test phase for the different conditions: neutral $(\mathrm{N}=11)$, urgency $(\mathrm{N}=11)$ and suffocation $(\mathrm{N}=11)$. Standard deviations are shown by bars. A significant condition effect for CS+ trials was found $(p<.033)$.

Differences in tidal volume between the acquisition (script imagination prior to inhalation) and test phases were also analyzed. A strong main effect of phase -- $F(1.30)=9.46, p<.004$, partial $\eta^{2}=.2$, observed power of .96 -- was observed. Further analyses revealed significant differences between CS+ trials in the acquisition and test phases: $t(3.091), \mathrm{df}=32, p<.004$, $d=-.56$. Findings between CS- trials did not reach significance $(t(1.96), \mathrm{df}=32, p>.06)$. Significant differences in tidal volume between the CS+ scripts of the acquisition and test phases were only observed for participants in the suffocation condition, $t(4.62)$, df $=10, p<.001$, with an high effect size of $d=-1.07$ (urgency: $p>.05$, neutral: $p>.66$ ). In Figure 2, the difference scores of tidal volume are illustrated during the script imagination. Comparing Figure 1 with Figure 2 gives an indication of the condition differences in favor of the suffocation condition. For CS- scripts, no significant differences were noted (suffocation: $p>.14$, neutral: $p>.55$, urgency: $p>.12$ ). These results also demonstrate a selective conditioning effect in the suffocation condition: only participants in the suffocation condition showed altered respiratory behavior after being conditioned with the UCS. 


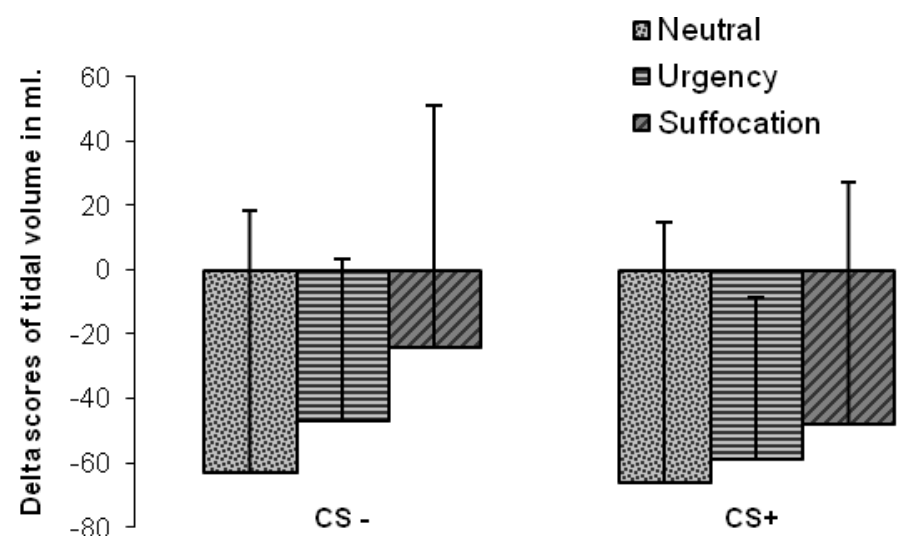

Figure 2. Difference scores (Delta) of tidal volume (in $\mathrm{ml}$ ) for the CS+-and CS- trials in the imagination phase of the acquisition phase for the different conditions: neutral $(N=11)$, urgency $(N=11)$ and suffocation $(N=11)$. Standard deviations are shown in bars. A significant main effect of phase (acquisition, test) only for CS+ trials was found $(p<.0004)$

\section{Contingency awareness and script evaluation}

Only 4 of the 33 participants were aware of an association between the script content and the inhalation of $35 \% \mathrm{CO}_{2}$-enriched air.

\section{Discussion}

In line with our hypothesis, only participants in the suffocation condition exhibited a selective conditioning effect relative to the control conditions. Hearing a suffocation script, which was first associated with $35 \% \mathrm{CO}_{2}(\mathrm{CS}+)$, provoked more feelings of fear and a significantly higher tidal volume than hearing a neutral or urgency script. These differences were not found in CS- trials. Moreover, only after having been paired with $35 \% \mathrm{CO}_{2}$ did the tidal volume (CR) increase during the suffocation script. Tidal volume rose to a level previously seen following inhalation of $35 \% \mathrm{CO}_{2}$ (UR). This increase in tidal volume was not present during the listening/ imagining phase before inhalation. This finding is in line with IC theory: the more the CS resembles the UCS, the more the CR is similar to the UCR (Bouton et al., 2001; Forsyth \& Eifert, 1996; Stegen et al., 1999).

No conditioning effect occurred in the 'active control' condition, a script referring to non-fear- related bodily sensations. From the present data, it appears that fear-relevant stimuli (suffocation script) are more readily conditioned than others (control conditions). This is accounted for by the evolutionary based (phylogenetic fear-relevant) selectiveness of the preparedness theory first postulated by Seligman (Seligman, 1971). Several fear conditioning experiments in humans and in non-human primates have shown stronger conditioning effects with fear-relevant stimuli (slides of snakes, spiders) than with fear-irrelevant 
stimuli (slides of flowers, mushrooms). Moreover, the conditioned reaction to fear-relevant stimuli is similar to the actual unconditioned reaction, i.e., heart acceleration to fearrelevant and deceleration to fear-irrelevant stimuli (Öhman \& Mineka, 2001). Williams and Rhudy (2007), in pursuing Dimberg \& Öhman (1996), were able to generalize these findings with social expressions. Furthermore, in line with preparedness theory, these superior conditioning findings for fear-relevant stimuli were also established when fear-relevant stimuli were administered subliminally through backward masking (without conscious awareness), during conditioning as well as during extinction (Flykt, Esteves, \& Öhman, 2007; Öhman \& Soares, 1993; Soares \& Öhman, 1993). In the present study, only 4 of the 33 participants were aware of the established associations, which is in line with the idea that the fear module is activated automatically and without conscious knowledge. It has frequently been demonstrated that aversive emotional learning can occur without conscious representation of learning (Knight et al., 2006; LeDoux, 1996; Mineka \& Öhman, 2002; Schultz \& Helmstetter, 2010). There is, however, a conflicting view in a review of Lovibond and Shanks (2002). Here it is stated that conscious awareness is necessary in most conditioning paradigms. Further, they question the automaticity of fear learning. So, although there are a variety of studies that have found evidence for conditioning without contingency awareness there are also contradictory findings in the literature.

Another feature of the preparedness theory is independence of cognitive processes. In the present study, the strongest selective conditioning effect was found in a physiological variable, namely tidal volume. In healthy participants, tidal volume normally increases and respiration rate does not change during inhalation of $35 \% \mathrm{CO}_{2}$ - enriched air (Sherwood, 1997). It has been proposed that tidal volume is a more sensitive measure than respiratory rate or subjective reports in panic studies. Shipherd et al., (2001) showed that, after an inhalation of $35 \% \mathrm{CO}_{2}$ - enriched air, the suffocation fear scale was only significantly correlated with tidal volume and not with respiration rate. It was not correlated with anxiety ratings nor with symptom intensity. Another indication of the role of tidal volume in panic can be derived from Beck and Wolf (2001), who studied different reaction patterns to repeated inhalations of $20 \% \mathrm{CO}_{2}$-enriched air. They found that $67 \%$ of the participants habituated to the inhalations, showing less anxiety and a decrease in tidal volume. The other participants, the non-habituators, showed more anxiety and an unstable pattern of tidal volume. Beck and Wolf suggested that their findings indicate that tidal volume parallels the habituation to anxiety, pointing to the importance of tidal volume. Finally, in a study by Schwartz et al., (1996), it was found that the percentage of sighing (double the normal tidal volume) was higher in patients who panicked than in healthy participants during lactate infusions.

A potentially interesting supplementary finding emerged during the present study.

During inhalations of $35 \% \mathrm{CO}_{2}$, participants in the suffocation condition had a lower minute volume than participants in the neutral condition. Subsequently after the inhalation of $35 \% \mathrm{CO}_{2}$, participants in the suffocation condition reported less symptoms than the partici- 
pants in the control condition. Both findings can be interpreted as an indication of behavioral avoidance during inhalation. Conceivably, participants in the suffocation condition were already anticipating the 'danger' by inhaling less deeply, and as a consequence displaying fewer symptoms than the participants in the neutral condition, a hypothesis recently proposed by Fannes et al. (2008) in a negative odor differential conditioning paradigm, with $20 \%$ $\mathrm{CO}_{2}$ as UCS. Their results indicate clearly that participants learned to inhibit their ventilation in response to the CS+ odor during acquisition. The authors conclude that inhibition in ventilation constitute a relevant behavioral index of fear.

In addition, the urgency condition showed also somewhat more symptoms and fear during the inhalations of $35 \% \mathrm{CO}_{2}$ in contrast with the suffocation condition. Despite their different pattern of reaction in self-reports, their physiological measurements during the inhalation were not affected. Closer inspection of the urgency condition revealed two outliers on the VAS-F before starting the experiment. On the other questionnaires (Table 1 ) were, however, no differences between the conditions. We can presume that the urgency condition was more fearful during the first part of the experiment than the other participants (however their ASI or FQ scores were not higher). Resulting in higher respiration rates during the first habituation phase and somewhat more subjective self-reports during the inhalation of $\mathrm{CO}_{2}$ in the acquisition phase.

The design of the present study was based on that of Stegen et al. (1999), but some new elements were introduced. To enhance the salience and the intensity of the UCS, we made use of inhalations of $35 \% \mathrm{CO}_{2}$-enriched air instead of $5.5 \% \mathrm{CO}_{2}$. Additionally, the present study administered the UCS immediately after the script was presented, whereas Stegen et al. (1999) administered the script and the UCS simultaneously. Both methods resulted in conditioning. The present study, however, only found significant differences in minute volume between CS+ -and CS-trials, whereas in the former study other outcome measurements were also affected. Conversely, in the present study, significant condition differences in tidal volume were found that favored the suffocation condition; this could not be demonstrated by Stegen et al. (1999). These differences could be accounted for by differences in contingency awareness between the studies. In the present study only $12 \%$ of the whole group was aware of the associations during acquisition. While in Stegen et al. (1999) and former equivalent studies rates were between 60 - 92\% (Devriese et al., 2000, Van den Bergh et al., 1997, Forsyth et al., 1996) for both conditions. Despite the high awareness rates in both conditions only conditioning was found in the phobic condition. These authors conclude therefore that awareness is not sufficient, although in may have been necessary (in line with Lovibond \& Shanks, 2002). Based on this assumption it would be interesting for future work to make distinctions in awareness to determine the necessity of this in fear conditioning. In a previous study of Grillon (2002) differences were made in awareness. Differential conditioning was only established in the aware group. However, unaware participants were more anxious and subsequently showed more avoidance. We wonder why our participants, with a 
similar procedure and material, were not aware of the contingency. The only differences with former research that we can consider are the low anxious ratings within our participants. Furthermore, the use of a third urgency script, introduced as a new element, in line with preparedness, did not result in selective conditioning.

Some limitations of the present study should be mentioned. First, there were only 33 participants in this study; 11 in each script condition. This small sample size, although sufficient to find a significant conditioning effect with high effect sizes, can also explain why no significant differences were found in the test phase between CS+-and CS- trials. As already mentioned, our sample was preferentially low anxious. We can, subsequently, presume, in line with 'Triple Vulnerability Theory', that our participants were not vulnerable in developing an anxiety or panic disorder through conditioning (Bouton et al., 2001). Nevertheless, we found a conditioning effect, what makes the results even more salient. It is, however, conceivable, that in a more anxious sample an even more robust conditioning effect would have been found, as has been previously demonstrated (Devriese et al., 2000; Van den Bergh et al., 1997). Subsequently, it would be interesting in further work to make distinctions between low and high anxious participants. Second, in this study we made use of equivalent scripts as CS+ and CS- in line with Stegen et al. (1999). These scripts were in each condition (suffocation-urgency-neutral), although different in context, very similar in content. This highly resemblance could made it difficult for participants to discriminate between each other, which could have made it difficult for conditioning to take place. In former studies, the CS+ and CS- were quite different and easier to differentiate.

The present experiment used a single inhalation of $35 \% \mathrm{CO}_{2}$-enriched air as the UCS. A recent study from our laboratory (Griez et al., 2007) showed that, in healthy volunteers, the reaction to a double inhalation of $35 \% \mathrm{CO}_{2}$-enriched air fulfills all of the criteria for a panic attack. To increase ecological validity even further, future studies might consider the use of double inhalations. Another limitation was the use of scripts instead of real bodily sensations as conditioned 'interoceptive stimuli' to enhance the ecologic validity. A recent interoceptive conditioning study (Acheson et al., 2007) used $5 \mathrm{sec}$ of $20 \% \mathrm{CO}_{2}$ as the CS and $15 \mathrm{sec}$ of $20 \%$ $\mathrm{CO}_{2}$ as the UCS but did not include an 'active control' condition. Finally, this experiment used a cross-sectional design, making it difficult to make predictions concerning the long term effects of fear conditioning. Therefore, it would be interesting for further research to also include a test phase a few weeks after the first test phase.

In sum, the present study demonstrates selective 'interoceptive' fear conditioning with respect to suffocation relative to the control conditions, extending previous work by introducing an 'active control' condition as the CS and an inhalation of $35 \% \mathrm{CO}_{2}$ as the UCS.

An important implication of the role of interoceptive conditioning in the development into panic disorder concerns treatment. Treatment should ideally involve exteroceptive and interoceptive exposure techniques, which are already core components of evidence-based treatments. Based on our findings and former studies (Antony, Ledley, Liss, \& Swinson, 2006; 
Lee et al., 2006; Stewart \& Watt, 2008) we suggest that interoceptive exposure is crucial in the therapy. Despite the effectiveness, interoceptive exposure is not always used in the treatment of PD (Sánchez-Meca, Rosa-Alcázar, Marín-Martínez, \& Gómez-Conesa, 2010). Further, interoceptive exposure is mainly established through hyperventilation, spinning, running... Those exercises have shown to each reproduce only a fraction of the panic symptomatology (Antony et al., 2006; Lee et al., 2006). The $35 \% \mathrm{CO}_{2}$ Challenge is, however, very reliable in producing panic symptoms as well in patients as in healthy volunteers (Esquivel, Schruers, Maddock, Colasanti, \& Griez, 2010; Griez et al., 2007; Griez \& Schruers, 1998; Schruers et al., 2011; Schruers et al., 2004). Therefore we propose to make (also) use of the $35 \% \mathrm{CO}_{2}$ challenge in producing panic sensations for 'effective' interoceptive exposure.

For the prevention of panic disorder it is equally important to have better understanding of the underlying mechanism. Anxiety prone persons could be informed about this developmental risk and how to deal with it. By incorporating the 'Triple Vulnerability Theory' (e.g. generalized biological, - psychological and specific psychological vulnerability) with the sensitivity of the $35 \% \mathrm{CO}_{2}$ challenge individuals at risk could be identified. In our laboratory was demonstrated that healthy first degree relatives of patients with panic disorder were more reactive to the challenge than the controls (van Beek \& Griez, 2000). Further, the reaction of healthy volunteers to a double inhalation of $35 \% \mathrm{CO}_{2}$-enriched air fulfills all of the criteria for a panic attack. On the basis of these findings we would suggest that first degree relatives of PD could (also) undergo interoceptive exposure through an inhalation of $35 \% \mathrm{CO}_{2}$. We would expect that the exposure will be less intense, however sufficient to learn how to deal with panic attacks in the future. 


\section{CHAPTER 4}

\section{References}

Acheson, D. T., Forsyth, J. P., Prenoveau, J. M., \& Bouton, M. E. (2007). Interoceptive fear conditoning as a learning model of panic disorder: an experimental evaluation using $20 \% \mathrm{CO}_{2}$ enriched air in a non-clinical sample. Behaviour Research and Therapy, 45, 2280-2294.

American Psychiatric Association. (2000). Diagnostic and statistical manual of mental disorders. (4th ed., text rev ed.). Washington: D.C.: American Psychiatric Press.

Antony, M., Ledley, D., Liss, A., \& Swinson, R. (2006). Responses to symptom induction exercises in panic disorder. Behaviour Research and Therapy, 44, 85-98.

Beck, J. G., \& Wolf, M. S. (2001). Response to repeated $\mathrm{CO}_{2}$ in individuals with elevated anxiety sensitivity: replication with $20 \% \mathrm{CO}_{2}$. Journal of Behaviour Therapy and Experimental Psychiatry, 32, 1-16.

Bouton, M. E., Mineka, S., \& Barlow, D. (2001). A modern learning theory perspective on the etiology of panic disorder. Psychological Review, 108, 4-32.

Colasanti, A., Salamon, E., Schruers, K., Van Diest, R., van Duinen, M., \& Griez, E. (2008). Carbon dioxideinduced emotion and respiratory symptoms in healthy volunteers. Neuropsychopharmacology, 1-8.

Devriese, S., Winters, W., Stegen, K., Van Diest, I., Veulemans, H., Nemery, B., et al. (2000). Generalisation of acquired somatic symptoms in response to odors: A pavlovian perspective on Multiple Chemical Sensitivity. Pschosomatic Medicine, 62, 751-759.

Dimberg, U., \& Öhman, A. (1996). Behold the wrath: Psychophysiological response to facial stimuli. Motivation and Emotion, 20, 149-182.

Esquivel, G., Schruers, K., Maddock, R., Colasanti, A., \& Griez, E. (2010). Acids in the brain: a factor in panic? Journal of Psychopharmacology, 24(5), 639-647.

Fannes, S., Van Diest, I., Meulders, A., De Peuter, S., Vansteenwegen, D., \& Van den Bergh, O. (2008). To inhale or not to inhale: conditioned avoidance in breathing behavior in an odor $-20 \% \mathrm{CO}_{2}$ paradigm. Biological Psychology, 78, 87-92.

Flykt, A., Esteves, F., \& Öhman, A. (2007). Skin conductance responses to masked conditioned stimuli: Phylogenetic/ontogenetic factors versus direction of threat? Biological Psychology, 74, 328-336.

Forsyth, J. P., \& Eifert, G. H. (1996). Systemic alarms in fear conditioning I: A reappraisal of what is being conditioned. Behavior Therapy, 27, 441-462.

Forsyth, J. P., \& Eifert, G. H. (1998). Intensity of systemic alarms in content-specific fear conditioning: comparing $20 \% \mathrm{CO}_{2}$-enriched air as a UCS. Journal of Abnormal Psychology, 107, 291-304.

Forsyth, J. P., Eifert, G. H., \& Thompson, R. N. (1996). Systemic alarms in fear conditioning: II. An experimental methodology using $20 \%$ carbon dioxide inhalation as an unconditioned stimulus. Behavior Therapy, 27, 391-415.

Griez, E., Colasanti, A., Van Diest, R., Salamon, E., \& Schruers, K. (2007). Carbon dioxide inhalation induces dose-dependent and age-related negative affectivity. PLOS ONE, 2(10), e987.

Griez, E., \& Schruers, K. (1998). Experimental pathophysiology of panic. Journal of Psychosomatic Research, 45(6), 493-503.

Grillon, C. (2002). Associative learning deficits increase symptoms of anxiety in humans. Biological Psychiatry, $51,851-858$

Kessler, R. C., Chiu, W. T., Jin, R., Ruscio, A. M., Shear, K., \& Walters, E. E. (2006). The epidemiology of panic attacks, panic disorder, and agoraphobia in the National Comorbidity Survey Replication. Archives of General Psychiatry, 63, 415-424.

Knight, D. C., Nguyen, H. T., \& Bandettini, P. A. (2006). The role of awareness in delay and trace fear conditioning in humans. Cognitive, Affective, \& Behavioral Neuroscience, 6(2), 157-162. 
Lecrubier, Y., Sheehan, D., Weiller, E., Amorim, P., Bonora, I., Sheehan, K. H., et al. (1997). The Mini International Neuropsychiatric Interview (MINI). A short diagnostic structured interview: reliability and validity according to the CIDI. European Psychiatry, 12, 224-231.

LeDoux, J. E. (1996). The emotional brain. New York: Simon \& Schuster.

Lee, K., Noda, Y., Nakano, Y., Ogawa, S., Kinoshita, Y., Funayama, T., et al. (2006). Interoceptive hypersensitivity and interoceptive exposure in patients with panic disorder: specificity and effectiveness. BMC Psychiatry, 6(32), ArtID 32.

Lovibond, P. F., \& Shanks, D. R. (2002). The role of awareness in pavlovian conditioning: empirical evidence and theoretical implications. Journal of Experimental Psychology: Animal Behavior Processes, 28(1), 3-26.

Marks, I., \& Matthews, A. (1979). Brief standard self-rating for phobic patients. Behaviour Research and Therapy, 17, 263-267.

Mineka, S., \& Öhman, A. (2002). Phobias and preparedness: The selective, automatic, and encapsulated nature of fear. Biological Psychiatry, 52, 927-937.

Montgomery, S., \& Asberg, M. (1979). A new depression scale designed to be sensitive to change. Britisch Journal of Psychiatry, 134, 382-389.

Morris, J., Öhman, A., \& Dolan, R. J. (1998). Modulation of human amygdala activity by emotional learning and conscious awareness. Nature, 393, 467-470.

Öhman, A., \& Mineka, S. (2001). Fears, Phobias, and preparedness: toward an evolved module of fear learning. Psychological Review, 108, 483-522.

Öhman, A., \& Soares, J. J. F. (1993). On the automatic nature of phobic fear: Conditioned electrodermal response to masked fear-relevant stimuli. Journal of Abnormal Psychology, 102, 1221-1132.

Razran, G. (1961). The observable unconscious and the inferable conscious in current Soviet psychophysiology: Interoceptive conditioning, semantic conditioning, and the orienting reflex. Psychological Review, 68, 81150.

Reiss, S., Peterson, R. A., Gursky, M., \& McNally, R. J. (1986). Anxiety, sensitivity, anxiety frequency, and the prediction of fearfulness. Behaviour Research and Therapy, 24, 1-8.

Sánchez-Meca, J., Rosa-Alcázar, A., Marín-Martínez, F., \& Gómez-Conesa, A. (2010). Psychological treatment of panic disorder with or without agoraphobia. Clinical Psychological Review, 30, 37-50.

Schruers, K., Esquivel, G., van Duinen, M., Wichers, M., Kenis, G., Colasanti, A., et al. (2011). Genetic moderation of $\mathrm{CO}_{2}$-induced fear by 5-HTTLPR genotype. Journal of Psychopharmacology, 25(1), 37-42.

Schruers, K., Van de Mortel, H., Overbeek, T., \& Griez, E. (2004). Symptom profiles of natural and laboratory panic attacks. Acta Neuropsychiatrica, 16(2), 101-106 (106).

Schultz, D. H., \& Helmstetter, F. J. (2010). Classical conditioning of automatic fear responses is independent of contingency awareness. Journal of Experimental Psychology: General, 36(4), 495-500.

Schwartz, G. F., Goetz, R., Klein, D. F., Endicott, J., \& Gorman, J. M. (1996). Tidal volume of respiration and 'sighing' as indicators of breathing irregularities in panic disorder patients. Anxiety, 2, 145-148.

Seligman, M. E. P. (1971). Phobias and preparedness. Behavior Therapy, 2, 307-320.

Sheehan, P. W. (1967). A shortened form of the Betts' Questionnaire Upon Mental Imagery. Journal of Clinical Psychology, 23, 386-389.

Sherwood, L. (1997). Human physiology from cells to systems. (3th ed. ed.). Belmont: C.A.: Wadsworth Publishing Company.

Shipherd, J. C., Beck, J. G., \& Ohtake, P. J. (2001). Relationships between the anxiety sensitivity index, the suffocation fear scale, and responses to $\mathrm{CO}_{2}$ inhalation. Journal of Anxiety Disorders, 15, 247-258.

Soares, J. J. F., \& Öhman, A. (1993). Preattentive processing, preparedness, and phobias: effects of instruction on conditioned electrodermal responses to masked and non-masked fear-relevant stimuli. Behaviour Research and Therapy, 31, 87-95. 


\section{CHAPTER 4}

Spielberger, C. (1983). Manual for the State-Trait Anxiety Inventory (Form Y). Palo Alto C.A.: Consultants Psychological Press.

Stegen, K., De Bruyne, K., Rasschaert, W., Van de Woenstijne, K. P., \& Van den Bergh, O. (1999). Fear-relevant images as conditioned stimuli for somatic complaints, respiratory behavior, and reduced end-tidal $\mathrm{pCO}_{2}$. Journal of Abnormal Psychology, 108(1), 143-152.

Stewart, S., \& Watt, M. (2008). Introduction to the special issue on interoceptive exposure in the treatment of anxiety and related disorders: Novel applications and mechanism of action. Journal of Cognitive Psychotherapy, 22(4), 291-302.

van Beek, N., \& Griez, E. (2000). Reactivity to a $35 \% \mathrm{CO}_{2}$ challenge in healthy first-degree relatives of patients with panic disorder. Biological Psychiatry, 47, 830-835.

Van den Bergh, O., Kempynck, P. J., Van den Woestijne, K. P., Baeyens, F., \& Eelen, P. (1995). Respiratory learning and somatic complaints: a conditioning approach using $\mathrm{CO}_{2}$-inhalations. Behaviour Research and Therapy, 5, 517-527.

Van den Bergh, O., Stegen, K., \& Van den Woestijne, K. P. (1997). Learning to have psychosomatic complaints: conditioning of respiratory behavior and somatic complaints in psychosomatic patients. Pschosomatic Medicine, 59, 13-23.

Van Diest, I., De Peuter, S., Devriese, S., Wellens, E., Van de Woenstijne, K. P., \& Van den Bergh, O. (2005). Imagined risk of suffocation as a trigger for hyperventilation. Pschosomatic Medicine, 67, 813-819.

Williams, A., \& Rhudy, J. (2007). The influence of conditioned fear on human pain threshold: does preparedness play a role? Journal of Pain, 8(7), 598-606.

Zung, W. W. K. (1965). A self-rating depression scale. Archives of General Psychiatry, 12, 63-70. 


\section{Appendix: Imagination scripts}

\section{Neutral-positive scripts}

You are sitting in your living room reading on a Sunday afternoon. You hear some soft music on the radio. Sitting back, relaxed, you look out of the window. It's a sunny autumn day outside. Red and brown leaves drift slowly down from the trees, and several cars and a truck go by in the street. Wind from the cars blows leaves around that are lying in the street. They scatter onto the pavement and the thick green lawn. You see some children walking with their parents. They have a big bag in which they gather some leaves. You see a man with a dog, playing together in the grass.

You are in an apartment overlooking the sea and soft music is playing on the radio. It is springtime. The sun shines inside through the window. Sitting back, you look out of the window and watch the sea. In the sea you see some white sailing ships; the sails are round because of the wind. On the beach, children are building a sand castle. A few people with a dog are passing by. A group of sea gulls sails away on the wind. If you open the window, you can feel the wind in your hair and you can hear the sea. You taste the salt of the sea.

\section{Urgency scripts}

You are in a meeting and you are listening to the explanation of a new product. You feel the urge to urinate and your bladder is becoming full. The meeting is almost finished, so you decide to wait for your visit to the toilet. Slowly, you get the feeling that your bladder is becoming too full. You try to tighten your muscles to prevent an accident. By trying so hard to tighten your muscles, you get some pain in your stomach. You try to change your position to have some relief, but this helps only for a short time. The pain is getting stronger and your bladder feels as if it will overflow. You are afraid you may wet your pants if the meeting does not end immediately. While waiting for the meeting to finish, time passes slowly and the pain in your stomach continues to get worse.

You are sitting in the bus en route to Spain. With every sign of a restaurant, you hope that the driver will decide to stop for a break. For half an hour now, you have had to go to the toilet. You have the feeling that you cannot wait any longer now. You tighten your muscles to prevent wetting your pants. You feel a heavy pain in your stomach and you try to relax your muscles. However, you notice immediately that it has the wrong effect, so again you tighten your muscles to prevent yourself from having an accident. After half an hour, your bladder seems to be getting fuller and heavier. The pain is becoming worse, and when the bus finally stops, you notice that you have difficulty standing. The urine in your bladder is pressing heavily and you cannot run hard enough because of the urge. Slowly, you get out of the bus.... 


\section{Suffocation scripts}

You are alone taking a steam bath. The temperature of the sauna has increased and is starting to become unbearable. Great buckets of sweat roll down your skin and mingle with the condensed moisture from the swirling clouds of steam. The heavy fog hampers your breathing and you take deep, rapid gulps of the seemingly liquid air. You tense all the muscles of your forehead, squinting to exclude the burning steam from your eyes, as they dart from left and right. In vain, you try to find the exit through the steamy mist. Your heart pounds wildly as you pull with all your strength on the door, which is jammed shut. Everything becomes black.

You are alone in an elevator. It is very small and has no ventilation. You start feeling short of breath. It slowly becomes unbearable. You want to leave this place as soon as possible, but when the elevator stops the door is stuck. You are sweating and your heart is pounding wildly. In despair, you start pushing all the buttons, but nothing helps. You're perspiring heavily and you gasp for breath. It appears that there is almost no air available anymore in this little place. Your heart leaps into your mouth as you pull on the door with all your strength. It remains jammed shut. Everything becomes black. 


\section{CHAPTER 5}

\section{Interoceptive fear conditioning and panic disorder:} A differential design using inspiratory resistive loads and $35 \% \mathrm{CO}_{2}$

\footnotetext{
Klara De Cort ${ }^{1}$, Ilse Van Diest ${ }^{2}$, Anouk Janssen ${ }^{1}$, Meike Pappens ${ }^{2}$, Omer Van den Bergh ${ }^{2}$, Lies Goossens ${ }^{1}$, Eric Griez ${ }^{1}$ \& Koen Schruers ${ }^{1,3}$

${ }^{1}$ Maastricht University, Institute for Mental Health and Neuroscience, the Netherlands

${ }^{2}$ University of Leuven, Research Group Health Psychology, Belgium

${ }^{3}$ University of Leuven, Center for Learning and Experimental Psychopathology, Belgium
} 


\begin{abstract}
Interoceptive fear conditioning has been proposed to explain why only a minority of the persons who ever experienced a panic attack develop panic disorder. In this study, interoceptive fear learning was investigated with panic-relevant inspiratory resistive loads as conditioned stimuli and a single inhalation of $35 \% \mathrm{CO}_{2}$ as the unconditioned stimulus. High and low anxiety sensitivity healthy participants $(\mathrm{N}=66)$ received either a moderate intensity load followed by the UCS (CS+) and a light load followed by room air breathing (CS-) or the reversed combination, referred to as LOAD+ or LOAD- condition, respectively. Three CS+ and 3 CS- acquisition trials were followed by the same number of test trials in which no UCS were administered. Self-reported anxiety, breathing behavior and skin conductance during the CSs in the acquisition phase was dominated by mere responding to the differences in loads, especially in participants scoring low on anxiety sensitivity. Despite these load effects in acquisition, learning-related differences in the test phase could be demonstrated in all measurements. Interestingly, although discriminative learning seems irrespective of anxiety sensitivity, participants scoring high on anxiety sensitivity stayed aroused during the test phase. The present differential design was able in establishing interoceptive fear conditioning with a panicogenic US.
\end{abstract}




\section{Introduction}

Almost 1 out of 4 persons of the general population experience at least one panic attack in their lives (Kessler et al., 2006). However, only in 3.7\% this panic attack evokes subsequent lasting anxiety, impairing one's life and evolving into Panic Disorder (PD, Kessler et al., 2006). To explain the development from a panic attack to PD, interoceptive fear conditioning (IFC) has been proposed as an important mechanism (Bouton, Mineka, \& Barlow, 2001; Mineka \& Zinbarg, 2006). IC is a term first described by Razran (1961). In IC either the conditioned stimulus (CS), the unconditioned stimulus (UCS) or both the CS and UCS are interoceptive (referred to as intero-extero, extero-intero and intero-intero, respectively). Interointeroceptive fear conditioning occurs when a relatively 'low intensity' interoceptive stimulus (CS) becomes associated with an inherently aversive interoceptive stimulus (UCS), resulting in the interoceptive CS provoking a conditioned reaction (CR). Based on previous evidence, Bouton et al. (2001) proposed that the closer and more similar the CS is to UCS, the stronger and more similar the CR will be to the UR. Similar to the 'preparedness' of evolutionary relevant cues, such as snakes or spiders, to become conditioned fear cues in simple phobias (Öhman \& Mineka, 2001; Seligman, 1971), interoceptive cues such as breathlessness and palpitations may be prepared cues for a panic attack, facilitating interoceptive fear conditioning in PD. This may be especially the case when the interoceptive CS is salient and constitutes a sensation that is also part of the panic attack itself.

Respiratory symptoms like dyspnea and feelings of suffocation refer to a vital function and appear to be core sensations in panic (Colasanti et al., 2008; Schruers, Van de Mortel, Overbeek, \& Griez, 2004). Feelings of dyspnea seem to be a salient interoceptive cue in evoking conditioned anxiety (CR) through IFC and leading to PD. In a previous conditioning study (De Cort, Griez, Büchler, \& Schruers, 2012, in line with; Stegen, De Bruyne, Rasschaert, Van de Woenstijne, \& Van den Bergh, 1999), we wanted to evoke feelings of dyspnea (CS) through script imagery and used an inhalation of $35 \% \mathrm{CO}_{2}$ as UCS. Despite the interesting conditioning results, both in fear scores and respiratory measures, the use of scripts instead of CS evoking bodily sensations by itself was a clear limitation in that study. Therefore, in the present study we wanted to evoke actual feelings of dyspnea as CS through the administration of resistive respiratory loads.

By adding respiratory loads, more effort is needed to breathe which can evoke feelings of dyspnea (Pappens et al., 2010; Pappens, Van den Bergh, Vansteenwegen, \& Van Diest, 2011; von Leupoldt \& Dahme, 2005) and as a consequence subjective distress, both in healthy people and in persons suffering from PD. Recently, Pappens et al. (2013) compared intero-intero and extero-intero variations of interoceptive fear conditioning with resistive loaded breathing as UCS in a CS-UCS paired and CS-UCS unpaired group design. Exterointeroceptive conditioning to the neutral picture (CS) evoked greater startle potentiation, an increase in tidal volume and self-reported fear only in the paired group. Whereas interointeroceptive conditioning to the inspiratory load was most pronounced in the startle blink 
reactions: stronger defensive mobilization occurred in the paired group in contrast with the unpaired group. Self-reported fear was not clearly affected however. In a next study with a breathing occlusion as UCS, which is perceptual different from an inspiratory load, was used several indications of conditioned responding were observed on startle, skin conductance and UCS expectancies to the interoceptive CS in the paired group compared to the unpaired group (Pappens, Smets, Vansteenwegen, Van den Bergh, \& Van Diest, 2012). Although these studies have clearly demonstrated fear learning to an interoceptive, panic relevant CS, the UCSs used did not provoke a panic attack. An interoceptive fear conditioning paradigm with a truly panicogenic UCS may further add to the ecological validity of a possible laboratory model of a learning account for panic disorder.

Earlier we showed that an inhalation of $35 \% \mathrm{CO}_{2}$-enriched air in healthy volunteers induces a condition that meets the formal criteria of a panic attack in current psychiatric nosology (Griez, Colasanti, Van Diest, Salamon, \& Schruers, 2007). Acheson, Forsyth, Prenoveau \& Bouton (2007), used an inhalation of $5 \mathrm{sec}$ of $20 \% \mathrm{CO}_{2}$ as the CS and $15 \mathrm{sec}$ of $20 \% \mathrm{CO}_{2}$ as the UCS. Surprisingly, stronger responses in skin conductance and fear ratings were found in the unpaired compared to the paired group. However, since $\mathrm{CO}_{2}$ inhalations were used as both CS and UCS, participants could not distinguish the beginning of the UCS from the CS, resulting in a partial reinforcement of and conditioning to the CS in the unpaired group. This was confirmed in a follow-up study in which fear learning to the interoceptive CS did not occur in the unpaired group when an external discriminative cue was added to the CS (Acheson, Forsyth, \& Moses, 2011).

In a meta-analysis of classical conditioning among anxiety disorders (Lissek et al., 2005) was found that anxiety patients differ from healthy controls not only through greater excitatory conditioning to danger cues (CS+), but also through impaired inhibitory learning to safety cues (CS-). Elevated Anxiety Sensitivity has been proposed as a risk factor for the development of anxiety disorders (Schmidt, Zvolensky, \& Maner, 2006) and especially PD (Reiss, 1991). It refers to individual differences in the fear of anxiety related sensations and the expectation that such sensations can have harmful consequences (McNally, 2002; Reiss, 1997; Reiss, Peterson, Gursky, \& McNally, 1986). Since this study is conducted to establish a laboratory model of the pathogenesis of PD, healthy participants were divided into relatively high an low Anxiety Sensitivity (AS) based on the scores of the Anxiety Sensitivity Index (ASI) to make a comparison possible between two groups with a putatively different risk in developing PD.

In sum, in the present study we wanted to examine whether feelings of dyspnea signaling a subsequent panic attack would lead to a conditioned anxiety response (expressed in skin conductance, respiration and self-reports), through intero-interoceptive fear conditioning. Two inspiratory loads, one of low and one of moderate intensity, acted as CS+ and CS- in a differential conditioning paradigm with $35 \% \mathrm{CO}_{2}$-enriched air as UCS. During acquisition, 3 $\mathrm{CS}+$ were followed by a $35 \% \mathrm{CO}_{2}$ inhalation and $3 \mathrm{CS}$ - by a room air inhalation. For half of the 
participants, a moderate load served as CS+ and a light load as CS-, referred to as LOAD+ condition. This was reversed for the other half, referred to as LOAD- condition. We mainly expected to find an intero-interoceptive fear conditioning effect, as demonstrated by increases in respiratory measures, skin conductance responses and anxiety ratings in response to the $\mathrm{CS}+$ (associated with $35 \% \mathrm{CO}_{2}$ ) compared to the $\mathrm{CS}$ - (associated with room air). Further, we expected that the high AS group exhibit stronger conditioning to the CS+ and impaired conditioning to the CS-.

\section{Methods}

\section{Participants}

Sixty-six healthy volunteers (all Caucasian, 39 women, mean age $=28 \pm 9.75$; range $=19$ - 60 years) were recruited via advertisement. Exclusion criteria were determined in former research of our laboratory with the $35 \% \mathrm{CO}_{2}$ challenge and involved: any lifetime psychological disorder, important cardiovascular or respiratory disease, epilepsy, cerebral aneurysm, pregnancy, current use of psychotropic medication and history of anxiety disorder in first degree relatives. Before the start of the study all participants gave written informed consent. In line with a previous study (De Cort et al., 2012), low and high AS volunteers were determined using a median split (score $=17$ ) on the ASI (see self-report measurements). Participants were randomly allocated to the LOAD+ or LOAD- condition. The LOAD-condition eventually included 32 (18 low AS/14 high AS) and the LOAD+ 34 (17 low AS/17 high AS). Due to equipment failure and implementation errors, data analysis of the respiratory data included 31 LOAD- (18 low AS/13 high AS) and 32 LOAD+ (15 low AS/17 high AS) participants. For skin conductance 30 LOAD- (18 low AS/ 12 high AS) and 32 LOAD+ (15 low AS/17 high AS) participants were available. In return for participation, the volunteers received a voucher worth thirty euro's. The study was approved by the Medical Ethical Committee of Maastricht University, The Netherlands.

\section{Materials}

\section{Conditioned Stimuli}

Two linear inspiratory resistive loads were used: one of $0.49 \mathrm{kPa} \mathrm{I}-1 \mathrm{~s}$ and one of $1.96 \mathrm{kPa}$ I-1 s (Hans Rudolph, Inc.) The first load can be considered as light because the resistive effect lies just above the perceptual threshold (Bloch-Salisbury, Harver, \& Squires, 1998). The second load is moderate compared to loads used in other studies (von Leupoldt \& Dahme, 2005). Both loads were presented for 7 seconds on the inspiratory branch of the breathing system. In former research it is demonstrated that on the basis of a psychophysiological response pattern (fear, arousal, unpleasantness, SCR, startle) a moderate load is distinguishable from a light load (Pappens et al., 2010; Pappens et al., 2011). However, because of the 
importance of discriminablity in a IFC-design we asked the participants at the end of the experiment if they could discriminate between both loads (see also self-report measurements).

Unconditioned stimuli

A single inhalation of $35 \% \mathrm{CO}_{2}$ was used as UCS. A single inhalation of air was used as the CScontrol inhalation: The subject had to inhale through a mouthpiece a vital capacity gas mixture of either $35 \% \mathrm{CO}_{2}$ and $65 \% \mathrm{O}_{2}$ or a prepared mixture with concentrations identical to room air $\left(21 \% \mathrm{O}_{2}\right.$ and $\left.78 \% \mathrm{~N}_{2}\right)$, contained in standard gas cylinders. After decompression, the gases were led through a wide vinyl tube with a demand valve at the end. The subject was instructed to exhale as deeply as possible and then to inhale deeply and to hold his/her breath for 4 sec before exhaling.

\section{Self-report measurements}

The psychological health of the participants was evaluated diagnostically by a trained clinician using the Mini International Neuropsychiatric Interview (MINI, Lecrubier et al., 1997). In addition, the Montgomery-Asberg Depression Scale (MADRS, Montgomery \& Asberg, 1979), the Self-rating Depression Scale (SDS, Zung, 1965), the Spielberger State/trait Anxiety Scale (STAI, Spielberger, 1983), the Anxiety Sensitivity Index (Reiss et al., 1986) and the Fear Questionnaire (FQ, Marks \& Matthews, 1979), were administered. The ASI is a 16-item questionnaire to measure AS. The items specify possible negative consequence of experiencing anxiety (illness, embarrassment or additional anxiety). An individual's AS score is the sum of the scores on the 16 items. The FQ is a 15 item self rating questionnaire, assessing agoraphobia, social and blood-injury phobia, with a range between zero and 120.

The level of fear for the UCS (inhalation) was measured on a Visual Analogue Fear Scale (VAS F). Participants were asked to score their level of fear between zero meaning "no fear at all" and 100 meaning "most extreme fear ever experienced". In addition, the Panic Symptom List (PSL) was used to measure symptoms during the inhalation. This list consists of the 13 DSM IV symptoms of a panic attack, collecting intensity ratings ranging from " 0 - not at all" to " 4 - very much". The VAS-F and PSL (see also procedure) were administrated between the trials, namely before (= pre-measurement) and after each trial (post-measurement). The number of panic attacks was calculated for each group by subtracting the pre from the postmeasurement. The criteria for a panic attack were an increase of at least 25 units on the VAS-F, plus an increase in at least four neurovegetative symptoms on the PSL (Verburg, Perna, \& Griez, 2001).

Anxiety level related to the CS was measured continuously during CS presentations with a custom built dial representing a scale ranging from 0 "no anxiety at all" till 100 "greatest anxiety ever experienced" (Vansteenwegen, Iberico, Vervliet, Marescau, \& Hermans, 2008).

Contingency awareness was assessed at the end of the experiment through the following questions: 1 = "Do you think certain events were linked together? If so, which ones?", 2 = "Did you notice the difference between low and high resistance?", 3 = "Was the $\mathrm{CO}_{2}$ - 
enriched air according to you following: a. high resistance; b. low resistance; c. random; d. no idea?"

\section{Physiological measurements}

The breathing apparatus consisted of a mouthpiece which was connected to a microbial filter (MicroGard, VIASYS) mounted on a heated pneumotachograph (Fleisch no. 2, Epalinges, Switzerland), an instrument measuring airflow. The pneumotachograph was connected to a non-rebreathing valve ensuring the separation of inspiratory and expiratory air. The inspiratory side of the non-rebreathing valve was connected with a 3-way $Y$-valve (stopcock type). The loads and decompressor of the $\mathrm{CO}_{2}$ enriched and normal air were connected to this $\mathrm{Y}$ valve, enabling easy switching between loaded or unloaded breathing and $\mathrm{CO}_{2}$ enriched air and normal air. An infrared $\mathrm{CO}_{2}$-monitor (Poet II, Criticare, Waukesha, WI) sampled air from the mouthpiece to measure fractional concentration of $\mathrm{CO}_{2}$. Both the signals from the sidestream $\mathrm{CO}_{2}$-monitor and from the pressure transducer (Sine Wave Carier Demodulator CD15, Valydine EngineeringTM) attached to the pneumotachograph, were sampled at $50 \mathrm{~Hz}$ and were calibrated using a $1 \mathrm{~L}$ syringe and a $7.5 \% \mathrm{CO}_{2}$ mixture, respectively.

Skin conductance was recorded with Fukuda standard $\mathrm{Ag} / \mathrm{AgCl}$ electrodes ( $1 \mathrm{~cm}$ diameter) filled with KY-gel and attached to the palm of the non-dominant hand, which was first cleaned with tap water. The inter-electrode distance was $2.5 \mathrm{~cm}$. The Coulbourn skin conductance coupler (V71-23) provided a constant 0.5V across the electrodes. The analogue signal was passed through a 12-bit AD converter and digitized at $10 \mathrm{~Hz}$.

The airflow, end-tidal $\mathrm{CO}_{2}$ and the skin conductance signals were recorded using Affect 4.0 software (Hermans, Clarysse, Baeyens, \& Spruyt, 2005). The respiration signals were treated off-line with PSychoPHysiological Analysis (PSPHA, DeClerck, Verschuere, Crombez, \& Devlieger, 2006), a modular script-based program which was further developed to generate and apply calibration factors for each signal. All waveforms were visually inspected offline and technical abnormalities and movement artifacts were eliminated using the PSPHA software.

\section{Procedure}

During the pre-test screening, all questionnaires were administered; blood pressure, heart rate and exclusion criteria for $\mathrm{CO}_{2}$-inhalation were checked. The actual aim of the study was concealed: participants were told that the goal of the study was to study the effect of a respiratory load on physiological parameters (respiration rate, heart rate). It was explained that more information about the procedure and goal of the study would be given at the end of the experiment. The study was conducted at the Academic Anxiety Centre in Maastricht, the Netherlands.

Participants sat in a comfortable chair in front of the mouthpiece of the breathing apparatus. Subsequently, electrodes were attached to the hand for the skin conductance meas- 
urements. Thereafter instructions concerning the experiment were given and a practice trial was run. During the trials participants breathed through a mouthpiece with a nose clip. In addition, they were informed that they could stop their participation at any moment during the experiment. After the instructions the experiment started.

The experiment (see Figure 1) consisted of two conditions: LOAD+ and LOAD-. In the LOAD+ the moderate load was used as CS+, and the light load as CS-. In the LOAD- this was reversed: the light load was CS+ and the moderate load was CS-. The procedure for each condition was the same. Every participant received 12 trials with a 2 min intertrial interval (ITI), subdivided in two phases: acquisition and test. The acquisition and test phase consisted of six trials each, in which the CS+ and CS- was presented 3 times in a semirandomized order. A trial started with a baseline measurement $(20 \mathrm{sec})$ followed by a load $(7 \mathrm{sec})$ and ended with a vital capacity inhalation of either $\mathrm{CO}_{2}$-enriched air (CS+ condition) or room air (CScondition). During the CS presentation participants rated their anxiety level with a custom built dial on a 0 to 100 scale (Vansteenwegen et al., 2008). Before (pre-measurement) and after (post-measurement) each trial participants filled in the VAS-F and PSL to assess the number of panic attacks during the UCS.

After the acquisition phase, the test phase was automatically started and included only vital capacity inhalations of room air following CS+ or CS-.

At the end of the experiment participants were asked about their contingency awareness.

Four fixed presentation orders were made with the restriction that a specific CS never occurred three times or more in a row. Half of the orders started with $\mathrm{CS}_{+}$, the other half with CS- trials. Conditions were counterbalanced across presentation orders and the participants were randomized across orders.

The breathing cycle was monitored online by Affect 4.0. Loads (CS) were manually turned on and off at the inspiratory side of the non-rebreathing valve prior to the targeted inspiration. Also the $35 \% \mathrm{CO}_{2}$ and normal air were presented at inspiratory onset and were manually turned on and off by the experimenter during the expiratory phase. Skin conductance and airflow were registered. 


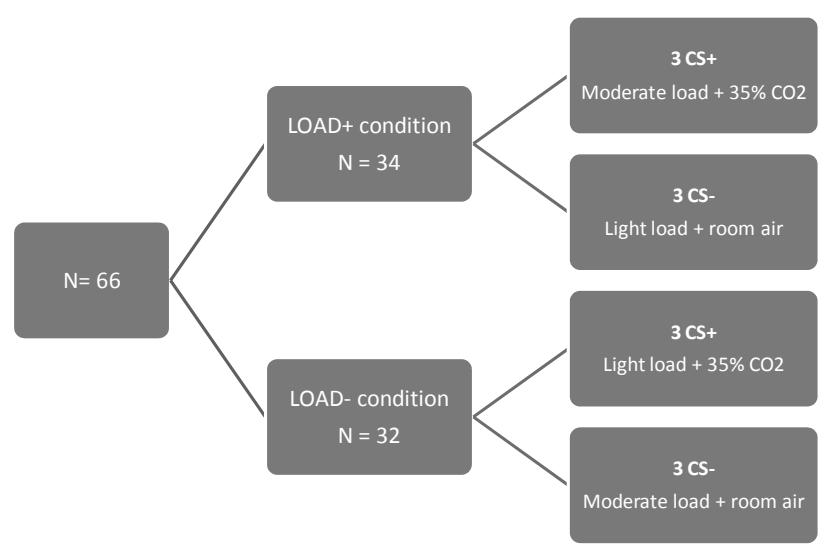

Figure 1. Experimental design of the LOAD+ and LOAD- condition in acquistion phase.

\section{Data and statistical design}

The respiratory parameters consisted of Tidal Volume in $\mathrm{ml}$, Minute Ventilation in $\mathrm{ml}$ per minute and Fractional End-Tidal $\mathrm{CO}_{2}$ in percent $\left(\mathrm{FetCO}_{2}\right)$. Through the PSPHA software the respiratory data were extracted per breathing cycle and then averaged across the CS period and used to calculate mean differences (CS-period minus baseline). Skin conductance responses were calculated by subtracting the mean skin conductance level (SCL) during $1 \mathrm{sec}$ prior to stimulus onset from the maximum $\mathrm{SCL}$ during $7 \mathrm{sec}$ following stimulus onset. The data were range corrected $\left(\mathrm{SCR} / \mathrm{SCR}_{\max }\right)$ in order to obtain a less skewed distribution (Lykken \& Venables, 1971). To calculate the number of panic attacks during the UCS, the mean values of the PSL and VAS-F before the trials were subtracted from those after the trials. The anxiety level of the CS was determined by one single anxiety level given during the CSperiod.

The Kolmogorov-Smirnov test was used to test the normality of the variables. If variables were not normally distributed, they were analyzed with non-parametric tests; the Wilcoxon Signed Ranks Test $(z)$, the Mann-Whitney Test $(U)$, the Friedman Test and the Kruskal-Wallis Test $\left(x^{2}\right)$.

The acquisition phase and test phase were separately analyzed in Repeated Measures ANOVAs with Condition (LOAD+; LOAD-) and Anxiety Sensitivity (low, high) as between subject variables, and with CS-Type (CS+; CS-) and Trial (3 levels) as within subject variables.

It should be noted that a differential conditioning paradigm with two loads of different intensities may confound mere load effects (= different responding caused by different intensities of loads; Pappens et al. 2011) with effects acquired through learning. For example, a significant interaction between CS-type and Condition may simply indicate mere load effects when in both conditions responses to the moderate load are larger than to the light 
load. To indicate learning effects we therefore also directly compared the responses to the same load when it was CS+ compared to when it was CS-.

Statistical significance for all analyses was accepted at a significance level of $p<.05$ (2tailed). Greenhouse-Geisser corrections were applied when appropriate. Uncorrected degrees of freedom and corrected $p^{\prime} s$ will be reported together with partial $\eta^{2}$. Statistical analyses for all measures were accomplished with PASW Statistics 18.

\section{Results}

In the first section we describe the characteristics of the sample. In the second, the self reports of the unconditioned stimuli will be described. The third section describes the analyses of the responses to the conditioned stimuli. This section is divided into self-report findings, respiratory findings and skin conductance, with the results of the acquisition and test phase described separately. Only significant results will be reported.

\section{Sample Characteristics}

All scores on the questionnaires assessing depression, general anxiety and severity of anxiety disorders were well below the clinical values. Further we categorized the participants in a high versus low AS group, based on median split of the ASI results (see Table 1). The high AS group scored significantly higher on all questionnaires compared to the low AS group, except for the MADRS. Furthermore, less than $10 \%$ of the participants reported being aware of the contingency between the CS+ and UCS (6/64); 80\% of the participants answered they had been able to discriminate between both loads.

Table 1. Mean scores of the Questionnaires divided in low and high anxiety sensitivity. Standard deviations mentioned in brackets.

\begin{tabular}{llll}
\hline & M-total & M-Low AS & M-High AS \\
\hline MADRS & $.25(.84)$ & $.26(.96)$ & $.24(.7)$ \\
SDS & $27.8(3.8)$ & $26.5(4)^{*}$ & $29.3(2.9)$ \\
STAI-state & $27.8(5.2)$ & $26.5(5.2)^{*}$ & $29.3(4.8)$ \\
STAI-trait & $28.4(5.5)$ & $26.8(4.4)^{*}$ & $30.3(6.1)$ \\
FQ-A & $1.4(2.4)$ & $.73(1.5)^{*}$ & $2.1(2.9)$ \\
FQ-B & $3(3.9)$ & $2(2.9)^{*}$ & $4.2(4.5)$ \\
FQ-S & $5.6(4.7)$ & $3.6(3.3)^{*}$ & $8(5)$ \\
FQ & $10(8.9)$ & $6.3(6.4)^{*}$ & $14.3(9.5)$ \\
ASI & $16.2(8.3)$ & $9.5(3.7)^{*}$ & $23.8(4.7)$ \\
\hline
\end{tabular}

Note: High AS = ASI score <17; Low AS = ASI score >16; MADRS = Montgomery-Asberg Depression Scale; SDS = Self-rating Depression Scale; STAl-state = State Trait Anxiety Inventory-state; STAI-2 = State Trait Anxiety Inventory-trait; FQ-A = Fear Questionnaire Agoraphobia subgroup; FQ-B = Fear Questionnaire Blood-injury subgroup; FQ-S = Fear Questionnaire Social subgroup ; FQ = Fear Questionnaire Total; ASI = Anxiety Sensitivity Index. * significant differences between high and low anxiety; $p<.05$. 


\section{Unconditioned stimuli}

There was no difference in PSL and VAS-F scores between the LOAD+ and LOAD- condition ( $p$ $>$.12). After an inhalation of $35 \% \mathrm{CO}_{2}$ participants reported more symptoms and fear than after an in inhalation of room air (PSL: $x^{2}(11, N=64)=360.15, p<.01$; VAS-F: $x^{2}(11, N=64)=$ $323.78, p<.01)$. There were no differences between low and high AS participants on selfreports.

Thirty-nine percent (low AS: 19\%, high AS: 20\%) of the participants fulfilled the criteria for an experimental panic attack following inhalation of $35 \% \mathrm{CO}_{2}$. After inhaling room air none of the participants experienced a panic attack.

\section{Conditioned stimuli}

Self-report measures

\section{Acquisition}

During acquisition no learning effects in anxiety levels could be observed. In both conditions participants reported more anxiety during the CS- than during the CS+ (main effect CS-Type, $F(1,61)=4.68, p<.03$; LOAD+: CS-: $M=6.5 ; S D=1.3$; CS +: $M=5.7 ; S D=1.2$; LOAD-: CS-: $M$ $=7 ; S D=1.4, C S+: M=5.3 ; S D=1.3)$. Although the interaction with Condition was not significant, further exploration of this peculiar finding suggests mere load effects in the LOADcondition (moderate as CS- > light load as CS+), while in the LOAD+ condition no differences related to CS Type (+/-) were found (LOAD-: $F(1,30)=3.8, p=.06$, partial $\eta^{2}=.1$; LOAD+: $F(1,33)=2.3$, n.s., partial $\left.\eta^{2}=.04\right)$.

\section{Test phase}

In the test phase, however, we observed differential responding in the LOAD+ condition, but not in the LOAD- condition (leading to a main effect of CS-Type: $(F(1,62)=5.1, p<.03$, partial $\eta^{2}=.08$ and a CS-Type $X$ Condition interaction: $F(1,62)=6.8, p<.1$, partial $\left.\eta^{2}=.1\right)$. In the LOAD+ condition $(F(1,32)=9, p<.01)$ anxiety ratings for CS+ were higher than for CS-, In the LOAD- condition CS+/- did not differ from each other $(F(1,60)=.1$, n.s.), see Figure 2 . More specific testing (to indicate learning effects in stead of load effects) showed that the moderate load as CS- (that is, in the LOAD-condition) induced less anxiety compared to the same load as CS+ (in the LOAD+ condition), $\left(F(1,31)=4.8, p<.035\right.$, partial $\eta^{2}=.1$, see Figure 3 ), indicating differential learning effects. 


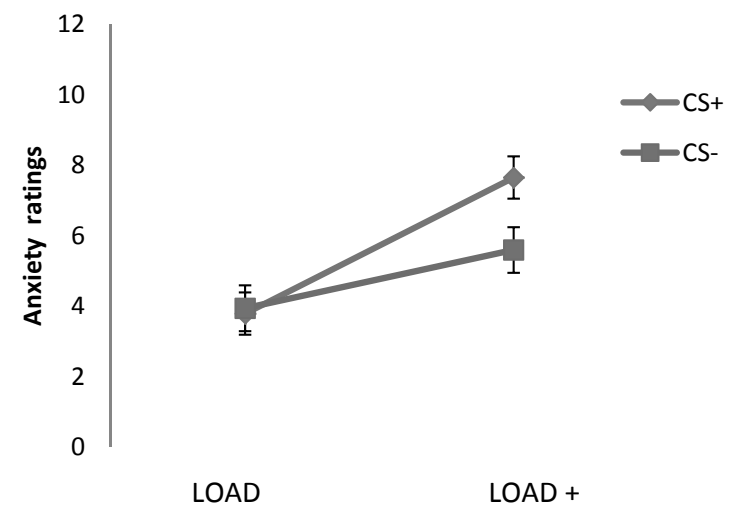

Figure 2. Mean anxiety ratings for CS+ and CS- in the LOAD- and LOAD+ condition during the test phase. Standard errors are presented in bars.

\section{Moderate load}

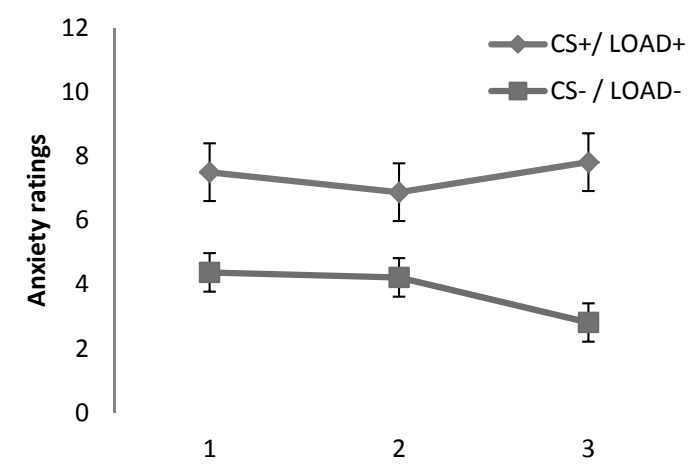

Figure 3. Mean anxiety ratings for the moderate load as CS+ and as CS- across the three trials during test phase. Standard errors are presented in bars.

A significant CS-Type $\times$ Trial $\times$ AS interaction was found $\left(F(2,124)=4.1, p<.02\right.$, partial $\eta^{2}=$ .06). Further testing revealed that in the high AS group the participants scored higher on anxiety on the last test trial for CS+ compared to CS- $(F(1,29)=7.2, p<.01$, see Figure 4$)$. In the low AS group no differences in scores across the trials emerged $(F(2,66)=1.0, n$.s. $)$. 


\section{Low AS group}

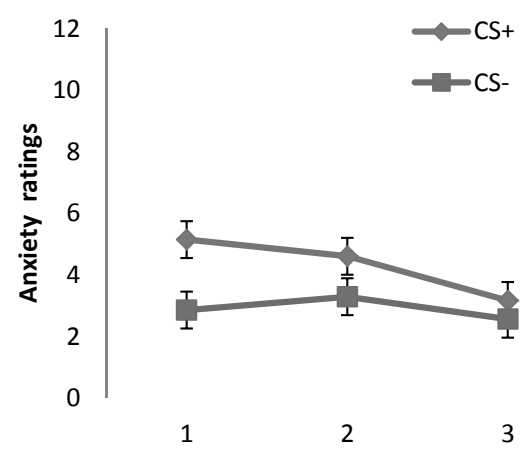

\section{High AS group}

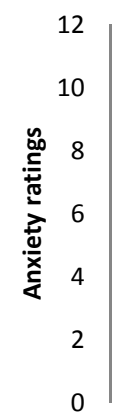

$\rightarrow \mathrm{CS}+$<smiles>C[SiH3]</smiles>

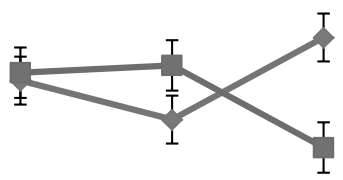

1

Figure 4. Mean anxiety ratings for CS+ and CS- in the low Anxiety Sensitvity group (AS, left panel) and high Anxiety Sensitivity group (AS, right panel) across the three trials during test phase. Standard errors are presented in bars.

\section{Respiratory measures}

\section{Acquisition}

During acquisition, respiratory behavior was characterized by (physiologically expected) hypoventilation in response to the load stimuli. This showed up (see Figure 5, trial 1-3) as a stronger decrease in minute ventilation to the moderate load compared to the light load. In the LOAD- condition, ventilation was more reduced to the CS- (moderate load) than to the CS+ (light load), while this pattern was reversed in the LOAD+ condition (leading to a CS-Type $x$ Condition interaction, $F(1,60)=10.8, p<.01$, partial $\eta^{2}=.15$; LOAD-: $F(1,29)=6.54, p<$ .02 , partial $\eta^{2}=.2$; LOAD+: $F(1,31)=4.3, p<.05$, partial $\left.\eta^{2}=.12\right)$. These load-related differences were already present at the start of the trial $\left(F(1,60)=7.25, p<.01\right.$, partial $\left.\eta^{2}=.11\right)$. Additional findings were that during acquisition the minute ventilation increased across the trials (main effect of Trial $F(2,120)=3.75, p<.03$, partial $\eta^{2}=.06$; lineair trend $F(1,60)=$ $5.02, p<.03)$. 
LOAD- condition

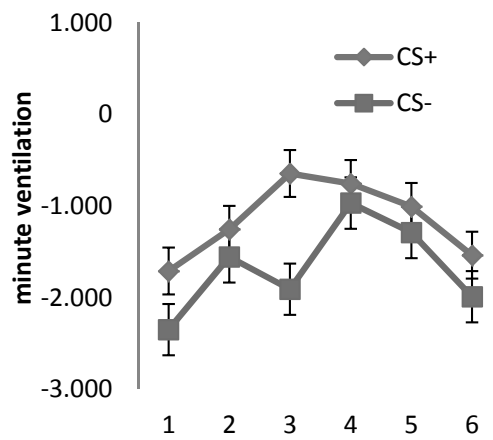

\section{LOAD+ condition}

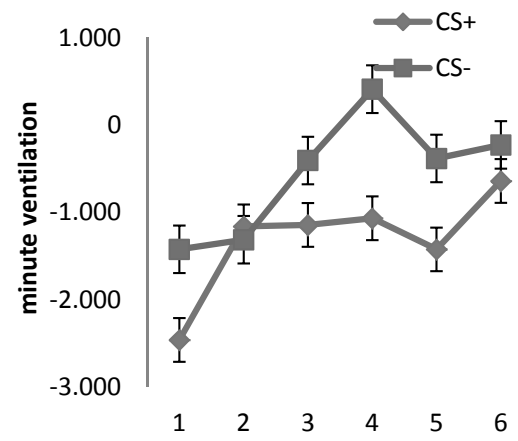

Figure 5. Mean differences of minute ventilation for CS+ and CS- in the LOAD- (left panel) and LOAD+ condition (right panel) across the six trials (1-3 = acquisition; 4-6 = test phase). Standard errors are presented in bars.

Interestingly, the pattern of the fractional end-tidal $\mathrm{CO}_{2}$ (see figure 6) showed that loadrelated differences (moderate load > light load) only emerged for low AS persons, (besides a CS-Type $x$ Condition interaction: $F(1,60)=4.3, p<.04$, partial $\eta^{2}=.07$, a CS-Type $x$ Condition $x$ AS interaction was found, $F(1,60)=.57, p<.02$, partial $\eta^{2}=.09$; low AS: $F(1,32)=8.4, p<.01$, partial $\eta^{2}=.21$; high AS: $F(1,28)=.07$, n.s., partial $\left.\eta^{2}=.002\right)$.

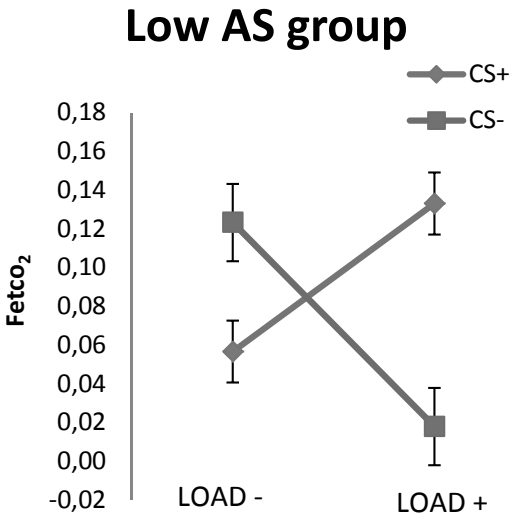

\section{High AS group}

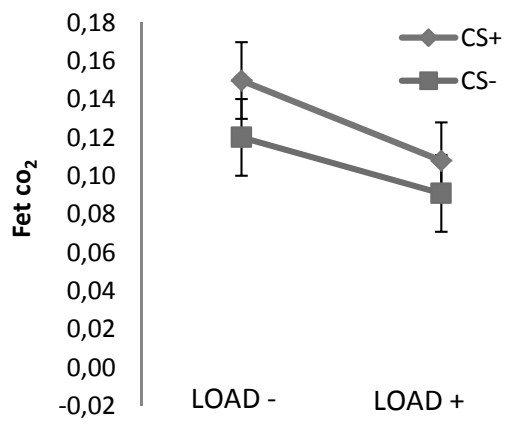

Figure 6. Mean differences of end-tidal fractional $\mathrm{CO}_{2}$ for $\mathrm{CS}+$ and CS- in the low Anxiety Sensitivity group (AS, left panel) and high Anxiety Sensitivity group (AS, right panel) for the LOAD- and LOAD+ condition during acquisition. Standard errors are presented in bars.

Other findings were that only in the high AS group $\mathrm{FetCO}_{2}$ decreased across the trials (Trial $\mathrm{x}$ AS $F(2,120)=3.27, p<.04$, partial $\eta^{2}=.05$; Main effect of Trial: $F(2,56)=9,92, p<.01$, partial $\left.\eta^{2}=.26\right)$. 


\section{Test phase}

Hypoventilation to the different load intensities was modified by the acquisition experiences. The latter effects emerged more clearly in response to the light load compared to the moderate load, suggesting that breathing responses to the moderate loads leave less room for behavioral influences as a result of learning. Indeed, in the test phase the light load as CS(in the LOAD+ condition) causes less hypoventilation compared to the same load as CS+ (in the LOAD- condition, $F(1,29)=3.42, p=.07$, partial $\eta^{2}=.1$, see Figure 7). Figure 5 (trial 4-6) illustrates that participants in the LOAD- condition breathed with the same (reduced) minute ventilation to the CS+ (light load) compared to the CS- (moderate load) $(F(1,29)=1.4$, n.s., partial $\eta^{2}=.05$ ), but in the LOAD+ condition, hypoventilation continued to the moderate load (CS+) but not to the light load (CS-) (CS-Type $x$ Condition interaction: $F(1,59)=7.55, p<.008$, partial $\eta^{2}=.11$; LOAD+: $F(1,30)=6.5, p<.02$, partial $\eta^{2}=.2$ ). Further, only in the LOAD- condition the minute ventilation decreased across the trials (Main effect of Trial: $F(2,118)=$ 3.05, $p<.05$, partial $\eta^{2}=.05$ and Trial $\times$ Condition interaction: $F(2,118)=3.25, p<.05$, partial $\eta^{2}=.05$; LOAD-: $F(2,58)=5.9, p<.01$, partial $\eta^{2}=.2$, lineair trend $\left.F(1,29)=10.9, p<.01\right)$.

For end-tidal fraction $\mathrm{CO}_{2}$, a main effect of CS-Type was found $(F(1,59)=4.5, p<.04$, partial $\left.\eta^{2}=.07\right)$, indicating a higher $\mathrm{FetCO}_{2}$ for $\mathrm{CS}+$ compared to $\mathrm{CS}-$. Further in line with the findings of minute ventilation, the light load as CS+ (LOAD-) caused more FetCO $\mathrm{CO}_{2}$ compared to the light load as CS- (LOAD+) after conditioning $\left(F(1,29)=5.2, p<.03\right.$, partial $\eta^{2}=.15$, see Figure 7).
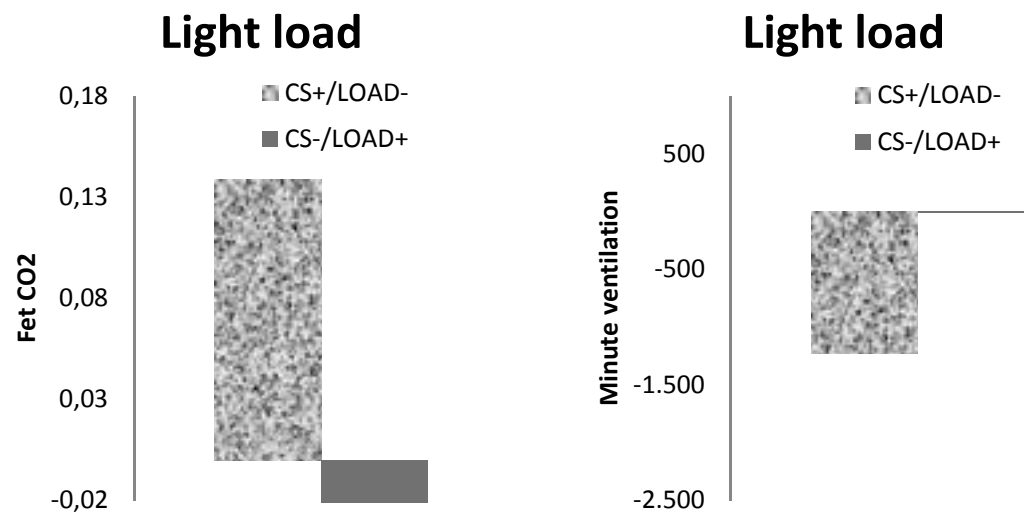

Figure 7. $\mathrm{FetCO}_{2}$ (left panel) and minute ventilation (right panel) for the light load as CS+ and as CS- during test phase.

Skin conductance

\section{Acquisition}

SCR responses habituated across the acquisition trials $(A$ main effect of Trial $(F(2,114)=$ $8.54, p<.01$, partial $\eta^{2}=.13$ ). 
At first sight, SCRs to CS+ did not differ from those to CS- in the LOAD- condition. In contrast, SCRs in response to CS+ were greater than those to CS- in the LOAD+ condition (CSType $x$ Condition interaction was found: $F(1,57)=6.75, p<.01$, partial $\eta^{2}=.11$; LOAD-: $F(1$, $57)=2.05$, n.s.; LOAD+: $F(1,57)=5.12, p<.03)$.

Additional findings indicated, however, similar to the respiratory data, that SCRs (see Figure 8) mainly in the first trial were characterized by mere stimulus differences, but only for the low AS participants. Low AS participants in the LOAD- condition displayed a smaller SCR to the light load (CS+) than to the moderate load (CS-) in the first acquisition trial. This pattern was reversed in trial 2 and non-significant in trial 3, indicating learning effects (CSType $\mathrm{x}$ Trial $\mathrm{x}$ Condition $\mathrm{x}$ AS interaction: $F(2,114)=3.6, p<.03$, partial $\eta^{2}=.06$; Trial 1: $F(1$, $57)=6.45, p<.02$, Trial 2: $F(1,57)=4.12, p<.05$; in trial 3: $F(1,57)=.17$, n.s.). High AS participants in the LOAD- condition showed no differential effect in any trial $(F(1,57)$ 's for trial 1,2 and 3 were 1.63, 1.46 and 0.34 , respectively). Also in the LOAD+ condition, differential effects were not very stable across trials, but were overall stronger for the low compared to the high AS group. More specifically, SCRs did display a mere load effect (CS+ $>$ CS-) for the low AS participants in trials $1(F(1,57)=5.38, p<.03)$ and $2(F(1,57)=4.99, p<.05)$, but not in trial $3(F(1,57)=.13$, n.s.). For the high AS group, the differential effect was marginally significant in trial $2(F(1,57)=3.71, p=.07)$ but absent in trials $1(F(1,57)=.70$, n.s. $)$ and 3 $(F(1,57)=.21$, n.s. $)$.

\section{LOAD- condition}
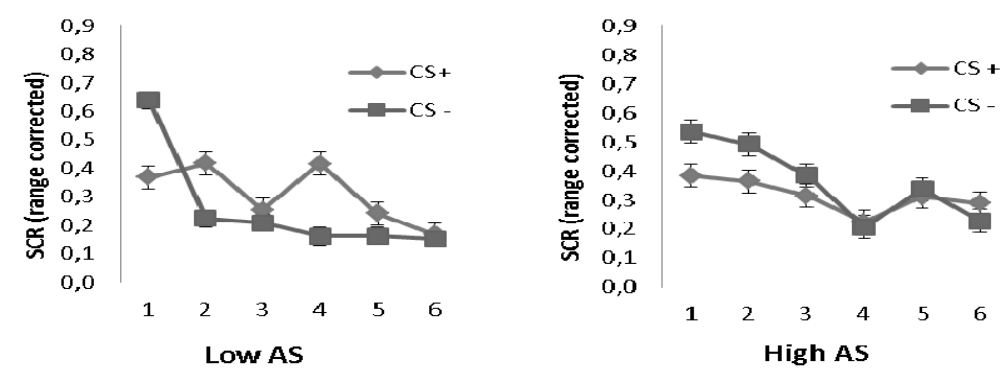

LOAD+ condition
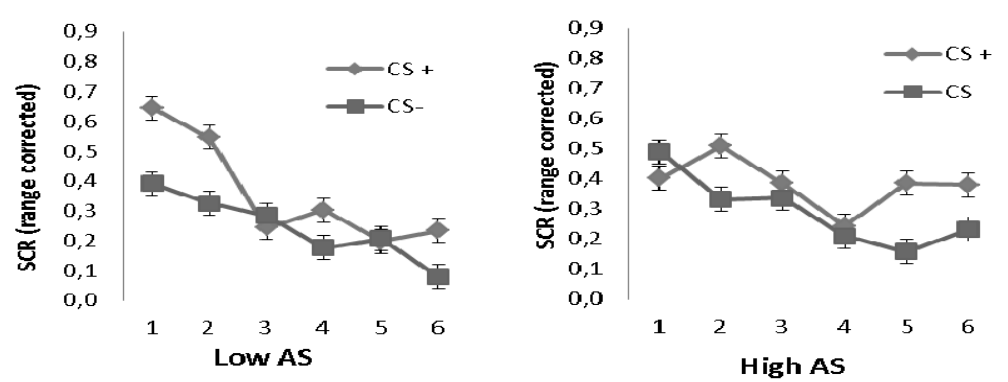

Figure 8. SCR for CS+ and CS- in the low Anxiety Sensitivity group for LOAD (+/-) condition (AS, left panel) and in the high Anxiety Sensitivity group (AS, right panel) across the six trials. Standard errors are presented in bars. 
Test phase

During test phase a stronger SCR in response to the CS+ compared to the CS- was found (a main effect of CS- Type $\left(F(1,57)=8.7, p<.01\right.$, partial $\left.\eta^{2}=.13\right)$ indicating differential learning. Further, only low AS participants habituated across the trials (Trial $x$ AS interaction $(F(2,114)$ $=3.3, p<.04$, partial $\eta^{2}=.05$; low AS: main effect of Trial: $F(2,58)=3.3, p<.04$, partial $\eta^{2}=$ .10). High AS participants showed no habituation across the trials $(F(2,56)=1.03$, n.s., partial $\left.\eta^{2}=.03\right)$.

\section{Discussion}

The aim of the present study was to examine whether feelings of dyspnea could be conditioned to a panic attack in a differential intero-interoceptive fear conditioning paradigm. In addition, this paradigm allowed investigating how breathing responses, self reports and skin conductance responses would be altered by conditioned anxiety (CR) to dyspneic feelings. Two inspiratory loads of different intensities acted as $\mathrm{CS}$ and $35 \% \mathrm{CO}_{2}$-enriched air was used as UCS, representing an operationalization with high ecological validity for PD. The use of two load CSs of different intensities in a differential conditioning paradigm requires careful analysis to separate learning effects from mere responding to the loads. Overall, in accordance with our main hypothesis, our results seem to indicate that feelings of dyspnea can be conditioned to $35 \% \mathrm{CO}_{2}$ inhalation (as laboratory model for panic attacks). However, when looking in more detail by subdividing the different measurements (self-reports, respiration and $\mathrm{SCR}$ ) a more complex picture arises and additional assumptions will be discussed.

The anxiety ratings during the acquisition phase may reflect a mere load effect, which was particularly pronounced in the LOAD- condition (the moderate load induced more anxiety than the light load). However, during the test phase a clear CS+/CS- difference showed up mainly in the LOAD+ condition. While this can possibly attributed to the mere load effect (moderate load > light load), the absence of a CS+/CS- difference in the LOAD- condition suggests that a moderate load raised less anxiety in the LOAD- condition (where it is CS-) compared to the same load in the LOAD+ condition (where it is CS+). As expected, a conditioning effect for the moderate load could be demonstrated. In addition, regardless of the load intensity, high anxiety sensitivity persons responded with more anxiety to the final test trial.

Breathing behavior during the CSs in the acquisition phase was also dominated by mere responding to the differences in loads: breathing was more depressed by the moderate than by the light load regardless of the LOAD (+/-) condition, but this relative hypoventilation became less across trials. Hypoventilation leads also to a built up of $\mathrm{CO}_{2}$ which, in keeping with the ventilatory behavior, was larger in the moderate than in the light load condition and it became less across repeated acquisition trials. Interestingly however, $\mathrm{CO}_{2}$ mirrored ventilation only in low anxiety sensitivity persons, whereas in high anxiety sensitivity participants both load intensities did not affect $\mathrm{PCO}_{2}$ differently. In the test phase, breathing behavior 
seemed to remain importantly influenced by mere load effects with little difference in responses to the moderate load as CS+ or CS-, but learning-related differences seemed to show up in response to the light load: hypoventilation to the light load continued in the test phase when it was $\mathrm{CS}+$, but it largely disappeared when it was CS-. In addition, a main effect of conditioning emerged for $\mathrm{FetCO}_{2}$ with higher values for CS+ compared to CS-, especially when the light load acted as CS+.

Finally, skin conductance responses, which are sensitive indicators of arousal, also showed mere load effects during the acquisition phase. This emerged mainly with stronger responses to the moderate than to the light load. However, here again we found less differential responding to the load intensities in high compared to low anxiety sensitivity persons. In the test phase, a significant conditioning effect emerged with stronger SCR to CS+ compared to CS- trials. High anxiety sensitivity persons also showed a lack of habituation across the test trials.

So, in general the acquisition phase was characterized by mere load effects but these effects did not emerge in participants scoring high on Anxiety Sensitivity, neither for both fractional end-tidal $\mathrm{CO}_{2}$ nor for skin conductance. People typically increase breathing when fearful (Van Diest et al., 2001). Apparently high anxiety sensitive participants behaviorally compensate the load-induced breathing differences in such a way that $\mathrm{FetCO}_{2}$ for both loads (light/moderate) is the same. Interestingly, Pappens, Smets, Van den Bergh \& Van Diest (2012) also demonstrated that the degree of 'fear of suffocation' alters respiration during obstructed breathing: Participants with low fear of suffocation showed different minute ventilation in response to differences in load intensity whereas participants with high fear of suffocation did not. Because defending breathing against a resistance increases breathlessness, the latter group runs the risk of becoming trapped in a vicious circle in which fear and breathlessness may mutually reinforce each other.

In the test phase interesting learning effects for all participants seemed to emerge. Furthermore, in contrast with our hypothesis, the influence of the level of anxiety sensitivity as found in the acquisition phase disappeared in the test phase. This pattern of findings seems in line with a fear conditioning study by Lissek et al. (2009) with healthy volunteers and PD patients. A fear-potentiated startle paradigm was used with neutral images as CSs and electric shock as UCS. It was found that PD patients were impaired in the acquisition of discrimination learning (towards the CS-) relative to controls. During the test phase however, the differences between both groups disappeared, indicating that at the end of the acquisition also PD patients had learned. Others did demonstrate differences in conditioning depending on the degree of anxiety or arousal, however (Hugdahl, Fredrikson, \& Öhman, 1977; Lissek et al., 2005). It is suggested (in their meta-analysis, Lissek et al., 2005) that during acquisition and extinction anxiety patients exhibit greater excitatory conditioning to CS+ (danger cue) and impaired inhibitory conditioning to CS- (safety cue) compared to controls (Lissek et al., 2005). Recent studies (Haddad, Pritchett, Lissek, \& Lau, 2012; Lissek et al., 2010; Lissek et al., 
2009) confirmed elevated responding to the safety cue, especially to perceptually similar cues. These authors suggest that these findings may be explained by stimulus generalizationan associative-learning mechanism based on perceptual similarity between safety and danger cue. In our experiment the CSs were also very similar to each other and the process of generalization, in explaining the absence of differential responding during acquisition in the high AS cannot be ruled out.

Whereas learning in the test phase occurred regardless of the anxiety sensitivity level, high AS participants continued to respond differently: They failed to show a reduction in SCR's to the CS's across the test trials as opposed to the low AS participants, and they kept overall higher levels of anxiety in the final test trial. Thus, both AS groups seem able to learn, but the high anxiety sensitive persons appear to maintain a higher level of anxiety and arousal across the test trials indicating reduced extinction. Enhanced resistance to extinction was also found in a differential conditioning study comparing PD patients with healthy volunteers (Michael, Blechert, Vriends, Margraf, \& Wilhelm, 2007) which is in line with the clinical feature of persistent anticipatory anxiety in PD patients, even in the absence of a panic attack.

The present study elaborates on our former study (De Cort et al., 2012), in which imagery scripts were used as CS and an inhalation of $35 \% \mathrm{CO}_{2}$-enriched air as UCS. Significant differences were found in tidal volume, but no other respiratory responses were affected. One of the explanations proposed for these results was the apparent overall low anxiety level of the participants. Therefore in the present study, we paid special attention to the results in (relatively) high and low AS participants. A further improvement in the present study is the inclusion of SCR as outcome parameter, besides the assessment of minute ventilation and $\mathrm{FetCO}_{2}$.

In studies on exteroceptive conditioning, the use of a differential paradigm is quite common and considered as an appropriate paradigm. In interoceptive conditioning this procedure is more challenging, due to the difficulty of finding an appropriate control stimulus. The present study is the first to apply a differential intero-interoceptive conditioning paradigm in the framework of panic disorder research, allowing parcelling out sensitization effects as far as possible by the use of an appropriate control condition.

Some limitations of the present study should be acknowledged, suggesting directions for future research. First, while the different degrees of dyspnea evoked by the two loads may represent the spectrum of feelings persons can notice in daily life mimicking a naturalistic context, they represent the same stimulus but in a different intensity. Former research used more distinct CSs. However, most participants, in line with former research (Pappens et al., 2011) could discriminate between both, since only eighteen \% (12/64) of all participants answered that they found it difficult to discriminate between both loads, with an equal distribution in the two conditions. Second, despite the fact that most participants indicated they could discriminate between both CSs, only 6 participants seemed aware of the contingencies 
between CS and UCS. Furthermore, in real life the development into PD appears to unfold in an unconscious way highlighting the importance of the present results. These low awareness rates may explain, however, some of the divergent findings between respiration measures and subjective ratings in terms of conditioning. In the literature awaraness is described as an important issue in the field of conditioning and is considered by some authors as necessary (Lovibond \& Shanks, 2002) as demonstrated in a study of Grillon (2002), where differential conditioning was only established in the aware group. Unaware participants were not able to discriminate, but were, however, more anxious and subsequently showed more avoidance. However, also important to indicate is that awareness rates in the present study were only assessed after the experiment on the basis of two questions ("Do you think certain events were linked together? If so, which ones?" and "Was the $\mathrm{CO}_{2}$-enriched air according to you following: a. high resistance; b. low resistance; c. random; d. no idea?"). It is conceivable that although some participants were aware of the contingencies during acquisition they were not able to give the 'right' answer because of the design (acquisition different from test phase). Of course this may underestimate true contingency awareness. Further, it would be interesting to compare aware with unaware participants in terms of conditioning and level of anxiety. Unfortunately, since only $10 \%$ of the participants were aware further comparisons between both are insufficient. Moreover, despite the rather large sample size $(\mathrm{N}=66)$ when analyzing two conditions (LOAD+/LOAD-), this amount loses power when analyzing more than two conditions (high/low AS; high/low awareness). Future research should consider online awareness assessment and an even larger sample size to make proper comparisons. Third, adding a pre-exposure trial would make the probably pre-existing individual differences within the group more clear and would allow to incorporate them into the results. Finally, we did not follow up on the long term effects of the conditioning manipulation. It would be interesting to focus on reinstatement or renewal issues in an interointeroceptive conditioning paradigm.

A strength of this study is the use of an inhalation of $35 \% \mathrm{CO}_{2}$ instead of electric shocks or resistive loads as UCS, because it has been demonstrated to be a valid model for a clinical panic attack (Griez et al., 2007). In line with our expectations, an inhalation of $35 \% \mathrm{CO}_{2}$ caused significantly more symptoms and higher fear levels than room air. Moreover, $40 \%$ of the participants experienced an experimental panic attack. So, in sum, the present study gives indications that slight feelings of dyspnea can become a predictor of panic attacks after conditioning. Overall, our findings seem consistent with the IFC theory of PD (Bouton et al., 2001). 


\section{References}

Acheson, D. T., Forsyth, J. P., \& Moses, E. (2011). Interoceptive fear conditoning and panic disorder. The role of conditioned stimulus-unconditioned stimulus predictability. Behavior Therapy, 43(1), 174-189.

Acheson, D. T., Forsyth, J. P., Prenoveau, J. M., \& Bouton, M. E. (2007). Interoceptive fear conditoning as a learning model of panic disorder: an experimental evaluation using $20 \% \mathrm{CO}_{2}$ enriched air in a non-clinical sample. Behaviour Research and Therapy, 45, 2280-2294.

Bloch-Salisbury, E., Harver, A., \& Squires, N. (1998). Event-related potentials to inspiratory flow-resistive loads in young adults: Stimulus magnitude effects. Biological Psychology, 49, 165-186.

Bouton, M. E., Mineka, S., \& Barlow, D. (2001). A modern learning theory perspective on the etiology of panic disorder. Psychological Review, 108, 4-32.

Colasanti, A., Salamon, E., Schruers, K., Van Diest, R., van Duinen, M., \& Griez, E. (2008). Carbon dioxideinduced emotion and respiratory symptoms in healthy volunteers. Neuropsychopharmacology, 1-8.

De Cort, K., Griez, E., Büchler, M., \& Schruers, K. (2012). The role of "interoceptive" fear conditioning in the development of panic disorder. Behavior Therapy, 43(1), 203-215.

DeClerck, A., Verschuere, B., Crombez, G., \& Devlieger, P. (2006). Psychophysiological analysis (PSPHA): a modular script based program for analyzing psychophysiological data. Research Methods, 38, 504-510.

Griez, E., Colasanti, A., Van Diest, R., Salamon, E., \& Schruers, K. (2007). Carbon dioxide inhalation induces dose-dependent and age-related negative affectivity. PLOS ONE, 2(10), e987.

Grillon, C. (2002). Associative learning deficits increase symptoms of anxiety in humans. Biological Psychiatry, 51, 851-858.

Haddad, A., Pritchett, D., Lissek, S., \& Lau, J. (2012). Trait anxiety and fear responses to safety cues: stimulus generalization or sensitization? Journal of Psychopathology and Behavioral assessement, 34, 323-331.

Hermans, D., Clarysse, J., Baeyens, F., \& Spruyt, A. (2005). Affect (Version 4.0) (computer software). retrieved 07 01, 2011 form psy.Kuleuven.be: http://www.psy.kuleuven.be/leerpsy/affect4.

Hugdahl, K., Fredrikson, M., \& Öhman, A. (1977). "Preparedness" and "arousability" as determinants of electrodermal conditioning. Behaviour Research and Therapy, 15, 345-353.

Kessler, R., Chiu, W., Jin, R., Ruscio, A., Shear, K., \& Walters, E. (2006). The epidemiology of panic attacks, panic disorder, and agoraphobia in the National Comorbidity Survey Replication. Archives of General Psychiatry, 63, 415-424.

Lecrubier, Y., Sheehan, D., Weiller, E., Amorim, P., Bonora, I., Sheehan, K. H., et al. (1997). The Mini International Neuropsychiatric Interview (MINI). A short diagnostic structured interview: reliability and validity according to the CIDI. European Psychiatry, 12, 224-231.

Lissek, S., Powers, A., McClure, E., Phelps, E., Woldehawariat, G., Grillon, C., et al. (2005). Classical fear conditioning in the anxiety disorders: a meta-analysis. Behaviour Research and Therapy, 43, 1391-1424.

Lissek, S., Rabin, S., Heller, R., Geraci, M., Pine, D., \& Grillon, C. (2010). Overgeneralization of conditioned fear as a pathogenic marker of panic disorder. American Journal of psychiatry, 167(1), 47-55.

Lissek, S., Rabin, S., McDowell, D., Dvir, S., Bradford, D., Geraci, M., et al. (2009). Impaired discriminative fearconditioning resulting from elevated fear responding to learned safety cues among individuals with panic disorder. Behaviour Research and Therapy, 47, 111-118.

Lovibond, P. F., \& Shanks, D. R. (2002). The role of awareness in pavlovian conditioning: empirical evidence and theoretical implications. Journal of Experimental Psychology: Animal Behavior Processes, 28(1), 3-26.

Lykken, D., \& Venables, P. (1971). Direct measurement of skin conductance: a proposal for standardization. Psychophysiology, 8(5), 656-672.

Marks, I., \& Matthews, A. (1979). Brief standard self-rating for phobic patients. Behaviour Research and Therapy, 17, 263-267.

McNally, R. J. (2002). Anxiety sensitivity and panic disorder. Biological Psychiatry, 52, 938-946. 


\section{CHAPTER 5}

Michael, T., Blechert, J., Vriends, N., Margraf, J., \& Wilhelm, F. (2007). Fear conditioning in Panic Disorder: Enhanced Resistance to Extinction. Journal of Abnormal Psychology, 116(3), 621-617.

Mineka, S., \& Zinbarg, R. (2006). A contemporary learning theory perspective on the etiology of anxiety disorders: It's not what you thought it was. American Psychologist, 61(1), 10-26.

Montgomery, S., \& Asberg, M. (1979). A new depression scale designed to be sensitive to change. Britisch Journal of Psychiatry, 134, 382-389.

Öhman, A., \& Mineka, S. (2001). Fears, Phobias, and preparedness: toward an evolved module of fear learning. Psychological Review, 108, 483-522.

Pappens, M., Smets, E., Van den Bergh, O., \& Van Diest, I. (2012). Fear of suffocation alters respiration during obstructed breathing. Psychophysiology, 49(6), 829-832.

Pappens, M., Smets, E., Vansteenwegen, D., Van den Bergh, O., \& Van Diest, I. (2012). Learning to fear suffocation: a new paradigm for interoceptive fear conditioning. Psychophysiology, 49(6), 821-828.

Pappens, M., Van den Bergh, O., De Peuter, S., Bresseleers, J., Vansteenwegen, D., \& Van Diest, I. (2010). Defense reactions to interoceptive threats: A comparison between loaded breathing and aversive picture viewing. Biological Psychology, 84, 98-103.

Pappens, M., Van den Bergh, O., Vansteenwegen, D., Ceunen, E. De Peuter, S., \& Van Diest, I. (2013). Learning to fear obstructed breathing: comparing interoceptive and exteroceptive cues. Biological Psychology, 92, 36-42.

Pappens, M., Van den Bergh, O., Vansteenwegen, D., \& Van Diest, I. (2011). Psychophysiological responses to inspiratory resistive loads. International Journal of Psychophysiology, 80, 161-165.

Razran, G. (1961). The observable unconscious and the inferable conscious in current Soviet psychophysiology: Interoceptive conditioning, semantic conditioning, and the orienting reflex. Psychological Review, 68, 81150.

Reiss, S. (1991). Expectancy model of fear, anxiety, and panic. Clinical Psychological Review, 11, 141-153.

Reiss, S. (1997). Triat Anxiety: it's not what you think it is. Journal of Anxiety Disorders, 11, 201-214.

Reiss, S., Peterson, R., Gursky, M., \& McNally, R. (1986). Anxiety, sensitivity, anxiety frequency, and the prediction of fearfulness. Behaviour Research and Therapy, 24, 1-8.

Schmidt, N., Zvolensky, M. J., \& Maner, J. (2006). Anxiety sensitivity: prospective prediction of panic attacks and Axis I pathology. Journal of Psychiatric Research, 40(8), 691-699.

Schruers, K., Van de Mortel, H., Overbeek, T., \& Griez, E. (2004). Symptom profiles of natural and laboratory panic attacks. Acta Neuropsychiatrica, 16(2), 101-106 (106).

Seligman, M. E. P. (1971). Phobias and preparedness. Behavior Therapy, 2, 307-320.

Spielberger, C. (1983). Manual for the State-Trait Anxiety Inventory (Form Y). Palo Alto C.A.: Consultants Psychological Press.

Stegen, K., De Bruyne, K., Rasschaert, W., Van de Woenstijne, K. P., \& Van den Bergh, O. (1999). Fear-relevant images as conditioned stimuli for somatic complaints, respiratory behavior, and reduced end-tidal $\mathrm{pCO}_{2}$. Journal of Abnormal Psychology, 108(1), 143-152.

Van Diest, I., WInters, W., Devriese, S., Vercamst, E., Han, J., Van de Woenstijne, K. P., et al. (2001). Hyperventilation beyond fight/flight; Respiratory responses during emotional imagery. Psychophysiology, 38, 961-968.

Vansteenwegen, D., Iberico, C., Vervliet, B., Marescau, V., \& Hermans, D. (2008). Contextual fear induced by unpredictability in a human fear conditioning preparation is related to the chronic expectation of a threatening US. Biological Psychology, 77, 39-46.

Verburg, K., Perna, G., \& Griez, E. (2001). A case study of the $35 \% \mathrm{CO}_{2}$ challenge. In E. Griez, C. Faravelli, D. Nutt \& J. Zohar (Eds.), Anxiety disorders: An introduction to clinical management and research, 1st ed. (Vol. 1, pp. 341-357). Chichester: John Wiley \& Sons. 
PART II: LEARNING THEORY

von Leupoldt, A., \& Dahme, B. (2005). Differentation between the sensory and affective dimension of dyspnea during resistive load breathing in normal subjects. Chest, 128, 3345-3349.

Zung, W. W. K. (1965). A self-rating depression scale. Archives of General Psychiatry, 12, 63-70. 

General Discussion 
Aim of this thesis was to investigate the underlying mechanisms of Panic Disorder (PD). Over the years cognitive and learning theories were proposed as important models in explaining the pathogenesis of PD. In the first three chapters we highlighted the cognitive view (Clark, 1986) and formulated some verifiable hypotheses. Subsequently we tested these in five experiments. In cognitive theory (CT) panic is believed to be the result of the catastrophic misinterpretation of bodily sensations. Panic attacks are thought to arise when a person interprets occurring somatic sensations as being dangerous and indicative of some impending doom (e.g. heart pounding representing heart attack). Via this way, PD patients become hyper vigilant for bodily sensations resulting in an 'attentional bias' towards physical cues associated with panic. As a result, the patient is more likely to re-activate the circle of misinterpretation. In sum, the core of this cognitive perspective entails three hypotheses: 1 . PD patients have content - specific (e.g. the possible consequences of a panic attack) catastrophic misinterpretations concerning their physical sensations (bias specificity); 2 . This interpretative bias is assumed to be only specific for PD patients (disorder specificity) and 3 . These specific catastrophic cognitions are regarded as sufficient and necessary in the production of panic attacks (causality).

In our first study (chapter 1 ) we explored the existence of such a PD-specific Stroop effect in PD patients, expressed in bias and disorder specificity. Patients with PD ( $N=32$ ), patients with mixed anxiety disorders $(\mathrm{N}=25)$, and a healthy control group $(\mathrm{N}=26)$ performed an emotional Stroop task with three word types: panic threat, general threat, and neutral. We did not find any evidence for disorder specificity nor for bias specificity in PD patients. Our results are in contrast to the conclusions of previous research were the results are generally (and incorrectly) interpreted as favoring the existence of such an effect (Bar-Haim, Lamy, Pergamin, Bakermans-Kranenburg, \& van IJzendoorn, 2007; Williams, Mathews, \& MacLeod, 1996).

On the basis of our study, in which limitations of previous research were taken into account, we strongly doubt the existence of a specific attentional bias in PD.

In the following two experiments (chapter 2) we were interested in the cognitive statement that PD is characterized by a tendency to misinterpret benign bodily symptoms in a catastrophic fashion and whether this is 'specific' to PD. In order to capture the spontaneous/automatic nature of these catastrophic interpretations we performed two experiments in which a priming procedure was used. We used three groups of participants: patients with PD $(\mathrm{N}=31)$, patients with mixed anxiety disorders $(\mathrm{N}=25)$, healthy control group $(\mathrm{N}=30)$ and two word types: panic relevant and neutral. In line with predictions from the cognitive model, facilitated responses were observed for the crucial panic trials in the panic group, but not in the group of anxious controls or the nonclinical group, supporting the specificity of this effect. Interestingly, however, significant priming effects were also observed for a group of mental health professionals (part of the healthy control group) who had no history of panic disorder. Subsequently, this unexpected observation was explicitly addressed in a second experiment, which confirmed the findings of Experiment 1. Therefore, if such selective threat associations 
can be observed in panic-free participants to the same extent as in panic patients, this at least raises doubts about these associations being a sufficient basis for evoking panic attacks.

Together, these results suggest that associations between benign bodily symptoms and catastrophic outcomes might develop as part of professional knowledge and experience, and should not necessarily be viewed as pathogenic. Of course this observation rather undermines the causality hypotheses of $\mathrm{CT}$, where the existence of catastrophic misinterpretations is seen as sufficient and necessary in the development of PD.

Hence, in the next two studies (chapter 3 ) we aimed to experimentally test this last hypothesis concerning the causal role of catastrophic misinterpretations in eliciting panic attacks, especially in PD patients (disorder specificity). Again three groups of participants were selected: patients with PD $(n=20)$, patients with mixed anxiety disorders $(n=20)$ and a healthy control group $(n=30)$. To enhance ecological validity we first conducted a stimulus validation experiment. Subsequently, nine suitable panic and neutral word pairs were presented in block to the participants. Once again, we found no support for the cognitive view. Our results indicate that none of the participants experienced a panic attack upon reading the word pairs. Although PD patients were not panicking, they were slightly more anxious than healthy volunteers when reading panic relevant word pairs compared to neutral word pairs. However, there was no difference in anxiety between the PD patients and the anxious control subjects. Both these observations further confirm the ecological validity of the experimental setup, but also illustrate the non-specificity of catastrophic thinking. The present results suggest that catastrophic thinking is related to anticipatory anxiety in anxious patients, but not necessarily with the occurrence of the panic attacks themselves.

In conclusion, our successive experiments (chapter 1 - 3) do not support the cognitive view on $\mathrm{PD}$, in any of the three hypotheses. There are some indications that catastrophic associations are present in PD patients and that they cause anxiety, however without being disorder specific, nor able to evoke panic attacks. Further, we also demonstrated that health workers also possess catastrophic misinterpretations without causing anxiety, nor panic attacks. Thus, having catastrophic misinterpretations seems not sufficient for the development into PD. It remains, however, an open question if catastrophic misinterpretations are even necessary in evoking panic attacks. It is however very likely that catastrophic thinking plays a central role in the anticipatory anxiety that also characterizes panic disorder patients.

Since cognitive theory seems inconclusive in its explanations, we shifted our focus in the second part of this thesis to the learning account of PD. It is hypothesized that intero- interoceptive conditioning (IC) is crucial in the pathogenesis of PD (Bouton, Mineka, \& Barlow, 2001). Specifically, the initial interoceptive precursors of a panic attack (such as sweating, palpitations...) become Conditioned Stimuli (CS), predicting more intense arousal and provoking anxiety as a Conditioned Response (CR, Razran, 1961). This anxiety response may produce additional and more intense interoceptive stimuli (more palpitations, sweating, faster breathing) that further trigger and potentiate anxiety, spiraling into panic. Anxiety 
thus becomes a precursor of panic. IC may explain why panic attacks occur in both the presence and absence of external cues (and also catastrophic thinking) and seem to come "out of the blue". In the second part of this thesis (chapter 4-5) we aimed at conducting a differential interoceptive paradigm to test the Learning Theory of PD (Bouton et al., 2001). Further, based on previous evidence, Bouton et al. (2001) also proposed that the closer and more similar the CS is to UCS (Unconditioned Stimulus), the stronger and more similar the CR will be to the UCR (Unconditioned Reaction). This is similar to the 'preparedness' of evolutionary relevant cues to become conditioned fear cues in simple phobias (Öhman \& Mineka, 2001; Seligman, 1971). Interoceptive cues such as feelings of dyspnea may be prepared cues for a panic attack, facilitating interoceptive fear conditioning in PD. Therefore in our studies we tried to evoke 'feelings of dyspnea' as a fear-relevant CS. Equally important and further adding to the ecological validity in the research of PD is the use of a truly panicogenic UCS through inhalations of $35 \% \mathrm{CO}_{2}$. In our differential paradigm $3 \mathrm{CS}+$ were followed by a $35 \%$ $\mathrm{CO}_{2}$ inhalation and $3 \mathrm{CS}$ - by a room air inhalation in the acquisitionphase. Subsequently, in the test phase both $\mathrm{CS}+/$ - were followed by room air.

In our first experiment (chapter 4) 'feelings of dyspnea' were evoked through script imagery. Thirty-three healthy volunteers were assigned to one of three script conditions: 'suffocation,' 'neutral,' or 'urgency.' In line with LT and preparedness theory, only participants in the suffocation condition exhibited a selective conditioning effect. They were more fearful and showed a significantly higher increase in tidal volume than participants in the two control conditions. Although participants in the suffocation condition reacted stronger compared to the control condition, they were not able to fully discriminate between CS +/-, which would have been a stronger indication of conditioning. Small sample size, a rather low general level of anxiety in the participants and the use of scripts instead of CS evoking bodily sensations by itself were clear limitations in this study.

Therefore, in our last study (chapter 5) we tried to evoke actual feelings of dyspnea as CS through the administration of resistive respiratory loads. Additionally, the sixty-six healthy participants were divided a priori in a high and low anxiety sensitivity group. Two inspiratory loads, one of low and one of moderate intensity, acted as CS+ and CS- in a differential conditioning paradigm. As expected, self-reported anxiety, breathing behavior and skin conductance during the CSs in the acquisition phase were dominated by mere responding towards the moderate load compared to the low load. Interestingly, for high compared to low anxiety sensitivity persons less differential responding to the load intensities was found in end-tidal $\mathrm{CO}_{2}$ and skin conductance. Overall, learning-related differences showed up for all measurements, seemingly independent of level of anxiety sensitivity and consistent with the IC theory of PD (Bouton et al., 2001).

Interestingly, whereas discriminative learning occurred regardless of the anxiety sensitivity level, high anxiety sensitivity participants showed reduced extinction in their skin conductance responses. This latter observation is interesting in the context of PD, since in the 
PD literature support also is found for enhanced resistance to extinction in PD patients (Michael, Blechert, Vriends, Margraf, \& Wilhelm, 2007). The apparent inability of high anxiety sensitivity persons to learn that the CS+ is no longer a danger cue seems in line with the clinical feature of persistent anticipatory anxiety in PD patients, even in the absence of a panic attack.

Our research is the first to apply a differential intero-interoceptive conditioning paradigm with an inhalation of $35 \% \mathrm{CO}_{2}$ in the framework of PD, allowing parceling out (as far as possible) sensitization effects by the use of an appropriate control condition and a truly panicogenic UCS. This procedure is however very challenging, not only in its design but also in the interpretation of the results. Our last differential conditioning paradigm with two loads of different intensities demands a careful analysis to distinguish between the (expected) responding to the loads and associative learning effects. Since an interoceptive CS has its inevitable physiological properties on its own, it would be worthwhile in future research to add a pre-exposure trial to have a better understanding of the pre-existing effects of the CS. Irrespective of conditioning, differences between high and low anxiety sensitive persons were found in their (mere) responding to loads of different intensity, a finding that seems very relevant for the theory on anxiety and panic.

In both interoceptive studies, awareness of the CS-UCS contingencies was very low. Although the participants in both experiments were unaware of the contingencies between CS and UCS, discriminatory learning could be demonstrated in our last study. This is in line with the idea that the fear module can be activated automatically and without conscious knowledge (Knight, Nguyen, \& Bandettini, 2006; LeDoux, 1996; Mineka \& Öhman, 2002; Schultz \& Helmstetter, 2010) and contradicts the statement that conscious awareness is necessary in most conditioning paradigms (Lovibond \& Shanks, 2002). However, a limitation of our studies is that awareness was only assessed after the experiment, which may underestimate true contingency awareness. Therefore future work may consider to assess contingency awareness continuously during the experiment.

Our CSs were selected in the light of the preparedness view, namely choosing fear relevant CSs. In our first IC study we found support for this view: only in the fear relevant (suffocation) condition compared to the fear-irrelevant (urgency, neutral) condition learning effects could be demonstrated. Findings from our last IC study are less clear-cut concerning preparedness. Here, only fear relevant cues with different intensities were used so that a comparison with fear-irrelevant cues was excluded. However, one could argue that the higher intensity CS (moderate load) is more 'prepared' than the same CS of a lower intensity, (low load) because of the higher resemblance of the first one with the UCS (panic attack). In this respect divergent findings were found in our study, which can be accounted for by the different measurements used (psychophysiology and self-reports) and the mere load effects. Therefore, on the basis of our research it is difficult to draw conclusions concerning preparedness. The use of a truly neutral interoceptive CS could make interpretations easier. 
Based on the combined results of this thesis, two main statements can be made:

First: "Panic attacks are not the result of the catastrophic misinterpretation of bodily sensations, but cognitions do play a role in panic disorder." In line with our findings, it seems that a cognitive account (Clark et al., 1988) is inconclusive in explaining the 'causality' of PD, namely catastrophic thinking as necessary and sufficient in provoking panic attacks. It is however very likely that catastrophic thinking does play a central role in the anticipatory anxiety. Both panic attacks and anticipatory anxiety are essential parts in the diagnosis of PD. With regard to anticipatory anxiety, our findings seem to support both theories as both bodily internal cues (through IC in healthy volunteers) as panic relevant word pairs (through exposure in both anxiety patients) provoke anxiety. Regarding the provocation of panic attacks, the cognitive approach in our experiments appeared unable to provoke any panic attack. However, one should also bear in mind that the testability of cognitive theory (because of operationalization problem of catastrophic thinking) is also an important confounding factor in studying CT. Future research is needed to clarify more clearly the role and necessity of catastrophic thinking in the process of anticipatory anxiety in PD.

Second: "Panic Disorder is the result of intero-interoceptive conditioning of anxiety." On the basis of two studies from the present thesis, there are clear indications supporting the learning theory account of PD. Future research should focus on the difference between the adaptive nature of fear conditioning and the dysfunctional nature of pathological anxiety (Beckers, Krypotos, Boddez, Effting \& Kindt, 2013).

Overall, it appears that learning theory and cognitive theory both have their merit in explaining different aspects of panic disorder and therefore can coexist.

On the long term, this knowledge may also improve the treatment for panic disorder. We suggest that interoceptive exposure is a crucial element in the therapy. Up to now, the potential of interoceptive exposure is not fully realized yet and is mainly established through hyperventilation, spinning, running, and so on. Those exercises each have shown to reproduce only a fraction of the panic symptomatology (Antony, Ledley, Liss, \& Swinson, 2006; Lee et al., 2006). The $35 \% \mathrm{CO}_{2}$ challenge is, however, very reliable in producing panic symptoms in patients as well as in healthy volunteers (Esquivel, Schruers, Maddock, Colasanti, \& Griez, 2010; Griez, Colasanti, Van Diest, Salamon, \& Schruers, 2007; Griez \& Schruers, 1998; Schruers et al., 2011; Schruers, Van de Mortel, Overbeek, \& Griez, 2004). Therefore, we propose to also make use of the $35 \% \mathrm{CO}_{2}$ challenge in producing panic sensations for 'effective' interoceptive exposure. 


\section{References}

Antony, M., Ledley, D., Liss, A., \& Swinson, R. (2006). Responses to symptom induction exercises in panic disorder. Behaviour Research and Therapy, 44, 85-98.

Bar-Haim, Y., Lamy, D., Pergamin, L., Bakermans-Kranenburg, M., \& van IJzendoorn, M. (2007). Threat-related attentional bias in anxious and nonanxious individuals: a meta-analytic study. Psychological Bulletin, 133(1), 1-24.

Beckers, T., Krypotos, A.-M., Boddez, Y., Effting, M. \& Kindt, M. (2013). What's wrong with fear conditioning? Biological Psychology, 92, 90-96.

Bouton, M. E., Mineka, S., \& Barlow, D. (2001). A modern learning theory perspective on the etiology of panic disorder. Psychological Review, 108, 4-32.

Clark, D. (1986). A cognitive approach to panic. Behaviour Research and Therapy, 24, 461-470.

Clark, D., Salkovskis, P., Gelder, M., Koehler, K., Martin, M., Anastasides, P., et al. (1988). Tests of a cognitive theory of panic. In I. Hand \& H.-U. Wittchen (Eds.), Panic and Phobias, vol 2 (pp. 149-158). Berlin: Springer-Verlag.

Esquivel, G., Schruers, K., Maddock, R., Colasanti, A., \& Griez, E. (2010). Acids in the brain: a factor in panic? Journal of Psychopharmacology, 24(5), 639-647.

Griez, E., Colasanti, A., Van Diest, R., Salamon, E., \& Schruers, K. (2007). Carbon dioxide inhalation induces dose-dependent and age-related negative affectivity. PLOS ONE, 2(10), e987.

Griez, E., \& Schruers, K. (1998). Experimental pathophysiology of panic. Journal of Psychosomatic Research, 45(6), 493-503.

Knight, D. C., Nguyen, H. T., \& Bandettini, P. A. (2006). The role of awareness in delay and trace fear conditioning in humans. Cognitive, Affective, \& Behavioral Neuroscience, 6(2), 157-162.

LeDoux, J. E. (1996). The emotional brain. New York: Simon \& Schuster.

Lee, K., Noda, Y., Nakano, Y., Ogawa, S., Kinoshita, Y., Funayama, T., et al. (2006). Interoceptive hypersensitivity and interoceptive exposure in patients with panic disorder: specificity and effectiveness. BMC Psychiatry, 6(32), ArtID 32.

Lovibond, P. F., \& Shanks, D. R. (2002). The role of awareness in pavlovian conditioning: empirical evidence and theoretical implications. Journal of Experimental Psychology: Animal Behavior Processes, 28(1), 3-26.

Michael, T., Blechert, J., Vriends, N., Margraf, J., \& Wilhelm, F. (2007). Fear conditioning in Panic Disorder: Enhanced Resistance to Extinction. Journal of Abnormal Psychology, 116(3), 621-617.

Mineka, S., \& Öhman, A. (2002). Phobias and preparedness: The selective, automatic, and encapsulated nature of fear. Biological Psychiatry, 52, 927-937.

Öhman, A., \& Mineka, S. (2001). Fears, Phobias, and preparedness: toward an evolved module of fear learning. Psychological Review, 108, 483-522.

Razran, G. (1961). The observable unconscious and the inferable conscious in current Soviet psychophysiology: Interoceptive conditioning, semantic conditioning, and the orienting reflex. Psychological Review, 68, 81150.

Schruers, K., Esquivel, G., van Duinen, M., Wichers, M., Kenis, G., Colasanti, A., et al. (2011). Genetic moderation of $\mathrm{CO}_{2}$-induced fear by 5-HTTLPR genotype. Journal of Psychopharmacology, 25(1), 37-42.

Schruers, K., Van de Mortel, H., Overbeek, T., \& Griez, E. (2004). Symptom profiles of natural and laboratory panic attacks. Acta Neuropsychiatrica, 16(2), 101-106 (106).

Schultz, D. H., \& Helmstetter, F. J. (2010). Classical conditioning of automatic fear responses is independent of contingency awareness. Journal of Experimental Psychology: General, 36(4), 495-500.

Seligman, M. E. P. (1971). Phobias and preparedness. Behavior Therapy, 2, 307-320.

Williams, J., Mathews, A., \& MacLeod, C. (1996). The emotional Stroop task and psychopathology. Psychological Bulletin, 120, 3-24. 

Samenvatting en Conclusies 
Het doel van dit proefschrift bestond erin om de onderliggende mechanismen van de Paniekstoornis (PS) te onderzoeken. Een PS kenmerkt zich door onverwachte en steeds terugkerende paniekaanvallen. De hevige anticipatieangst die gepaard gaat met de paniekaanvallen kan iemands leven sterk beperken. Uit onderzoek blijkt dat onverwachte paniekaanvallen in de algemene populatie vaker voorkomen en niet noodzakelijk pathologisch zijn. Pas wanneer iemand ook aanhoudende anticipatieangst voor de paniekaanvallen gaat ontwikkelen kan men van een stoornis spreken. De afgelopen jaren werden de cognitieve theorie en de leertheorie als belangrijk model voor het verklaren van de pathogenese van PS voorgedragen. In de eerste drie hoofdstukken belichtten we de cognitieve visie (Clark, 1986) en formuleerden we drie toetsbare hypotheses. Vervolgens hebben we deze getest in vijf opeenvolgende experimenten. In de cognitieve theorie (CT) wordt gesteld dat paniek het rechtstreeks gevolg is van de catastrofale misinterpretaties van lichamelijke sensaties. Paniekaanvallen treden op wanneer een persoon optredende lichamelijke sensaties gaat interpreteren als gevaarlijk en indicatief voor dreigend onheil (bv. hartslagverhoging als voorbode voor een hartaanval). Op deze manier worden PS patiënten hyperalert op lichamelijke gewaarwordingen. Dit resulteert in een zogenaamde 'aandachtsbias' voor fysieke cues die geassocieerd zijn met paniek. Vervolgens kan deze 'aandachtsbias' ervoor zorgen dat de cirkel van misinterpretaties opnieuw wordt geactiveerd. Samengevat, de kern van de CT omvat drie hypotheses: 1. PS patiënten hebben inhoud-specifieke catastrofale misinterpretaties met betrekking tot hun fysieke gewaarwordingen (bias specificiteit); 2. Deze interpretatieve bias is specifiek voor PS patiënten (en dus niet voor andere angststoornissen) (stoornis specificiteit) en 3. Deze specifieke catastrofale cognities worden beschouwd als voldoende en noodzakelijk in de productie van paniekaanvallen (causaliteit).

In onze eerste studie (hoofdstuk 1) werd het bestaan van een PS-specifiek 'aandachtsbias' effect in PS patiënten nagegaan, uitgedrukt in bias en stoornis specificiteit. Patiënten met PS ( $N=32)$, patiënten met verschillende andere angststoornissen $(N=25)$ en een gezonde controlegroep $(\mathrm{N}=26)$ voerden een emotionele stroop taak uit met drie types van woordparen: paniek bedreigend, algemeen bedreigend en neutraal. We vonden geen enkel bewijs voor stoornis noch voor bias specificiteit in PS patiënten. Onze resultaten zijn in contrast met de conclusies van voorgaand onderzoek, waar de resultaten over het algemeen genomen (incorrect) geïnterpreteerd worden als bewijs voor het bestaan van zulk een specifiek effect (Bar-Haim, Lamy, Pergamin, Bakermans-Kranenburg, \& van IJzendoorn, 2007; Williams, Mathews, \& MacLeod, 1996).

Op basis van ons onderzoek, waarin de beperkingen van eerder onderzoek in aanmerking werden genomen, twijfelen we sterk aan het bestaan van een specifieke aandachtsbias bij PS.

In de daaropvolgende twee experimenten (Hoofdstuk 2) waren we geïnteresseerd in de cognitieve bewering dat PS gekenmerkt wordt door het catastrofaal interpreteren van onschuldige lichamelijke symptomen (= hypothese 1 ) en dit enkel geldt voor PS patiënten (= hypothese 2). Om het spontane/automatische karakter van deze castastrofale misinterpre- 
taties te ondervangen voerden we 2 experimenten uit waarin een priming procedure werd gebruikt. We maakten gebruik van drie groepen deelnemers: patiënten met PS ( $N=31)$, patienten met verschillende andere angststoornissen $(\mathrm{N}=25)$ en een gezonde controle groep $(\mathrm{N}=30)$. Er werden 2 soorten van woordparen aangeboden: paniek relevant en neutraal. In overeenstemming met de verwachtingen vanuit het cognitieve model en de 'specificiteit' assumpties, vertoonden PS patiënten een versnelde respons bij de cruciale paniek trials. Dit was niet zichtbaar bij de angstige en gezonde controle groep. Interessant is echter dat significante priming effecten ook geobserveerd werden voor een deel van de gezonde controle proefpersonen die in de gezondheidszorg werkten en geen voorgeschiedenis hadden van PS. Deze onverwachte bevinding werd vervolgens in een tweede experiment expliciet onderzocht en gerepliceerd. Als zulke selectieve gevaar-associaties in dezelfde mate geobserveerd kunnen worden in paniek-vrije deelnemers als in PS patiënten, veroorzaakt dit op zijn minst twijfels of deze associaties een voldoende basis zijn voor het uitlokken van paniekaanvallen.

Samengevat, deze resultaten suggereren dat associaties tussen onschuldige lichamelijke symptomen en catastrofale gevolgen zowel kunnen voortvloeien uit professionele kennis als uit ervaring en dus niet noodzakelijk mogen gezien worden als pathogeen. Deze observatie ondermijnt eerder de causaliteitshypothese van $\mathrm{CT}$, waar het bestaan van catastrofale misinterpretaties gezien wordt als voldoende en noodzakelijk in de ontwikkeling tot PS.

Derhalve, in de volgende twee studies (hoofdstuk 3) hebben we getracht om deze laatste hypothese met betrekking tot de causale rol van catastrofale misinterpretaties in het uitlokken van paniekaanvallen in PS patiënten (stoornis specificiteit) experimenteel te testen. Opnieuw werden drie groepen van deelnemers geselecteerd: patiënten met PS ( $N=20)$, patiënten met verschillende andere angststoornissen $(\mathrm{N}=20)$ en een gezonde controle groep $(\mathrm{N}=30)$. Om de ecologische validiteit te verhogen hebben we eerst een stimulus validatie experiment uitgevoerd. Hieruitvolgend werden negen geschikte paniek en neutrale woordparen gepresenteerd aan de deelnemers. Opnieuw vonden we geen ondersteuning voor de cognitieve visie. Onze resultaten toonden aan dat geen enkele deelnemer een paniekaanval ervaarde na het lezen van de woordparen. Hoewel de PS patiënten niet in paniek waren, vertoonden ze toch iets meer angst dan gezonde deelnemers bij het lezen van paniek woordparen in vergelijking met neutrale woordparen. Er was echter geen verschil in angstniveau tussen de PS patiënten en angstige controle patiënten. Beide observaties bevestigen de ecologische validiteit van de experimentele opstelling, maar illustreert ook de nonspecificiteit van catastrofaal denken. De huidige resultaten suggereren eerder dat catastrofaal denken een rol speelt bij de anticipatie angst van angstige patiënten, maar niet noodzakelijkerwijs bij het optreden van de paniekaanvallen zelf.

Concluderend kunnen we stellen dat onze opeenvolgende experimenten (hoofdstuk 13) geen enkele van de drie hypotheses van de cognitieve visie kunnen ondersteunen. Er zijn wel aanwijzingen dat catastrofale associaties aanwezig zijn bij PS patiënten en dat deze angst veroorzaken, echter zonder stoornis specifiek te zijn, noch in staat om paniekaanvallen 
uit te lokken. Verder toonden we aan dat hulpverleners eveneens catastrofale misinterpretaties hebben zonder dat deze angst, noch paniekaanvallen uitlokken. Dus, het hebben van catastrofale misinterpretaties lijkt niet voldoende voor het ontwikkelen van een PS. Het blijft echter nog een open vraag of catastrofale misinterpretaties zelfs noodzakelijk zijn voor het uitlokken van paniekaanvallen. Het is wel zeer aannemelijk dat catastrofaal denken een centrale rol speelt in de anticipatieangst (en dus niet paniekaanvallen) hetgeen ook een kenmerk is van PS patiënten.

Aangezien de cognitieve theorie in zijn verklaringen onvoldoende lijkt, verleggen we onze focus in het tweede deel van dit proefschrift naar de leertheorie van PS.

Er wordt verondersteld dat Intero-interoceptieve Conditionering (IC) cruciaal is in de pathogenese van PS (Bouton, Mineka, \& Barlow, 2001). IC ontstaat wanneer een initieel neutrale interoceptieve stimulus angst uitlokt vanwege een contingente aanbieding van deze stimulus met een ongeconditioneerde stimulus (UCS). Hierdoor gaat de initieel neutrale stimulus als voorspeller (geconditioneerde stimulus, CS) fungeren voor de UCS. Met name de eerste interoceptieve voorlopers van een paniekaanval (zoals zweten, hartkloppingen, ...) worden een CS, hetgeen meer intense arousal voorspelt en angst als een geconditioneerde reactie uitlokt (CR, Razran, 1961). Deze angstrespons kan leiden tot extra en meer intense interoceptieve stimuli (meer hartkloppingen, zweten, sneller ademen, ...) die angst triggeren en versterken en uiteindelijk uitmonden in paniek. Angst wordt dus zo een voorloper van paniek. IC kan verklaren waarom paniekaanvallen optreden in zowel de aan- als afwezigheid van externe cues (en ook catastrofaal denken) en lijken "out of the blue" te ontstaan. In het tweede deel van dit proefschrift (hoofdstuk 4-5) hadden we als doel om de leerheorie van PS (Bouton et al., 2001) te testen door middel van een differentieel interoceptief conditioneringsparadigma. Gebaseerd op eerdere gegevens stelden Bouton et al. (2001) voor dat hoe dichter (in tijd) en meer vergelijkbaar de CS is ten opzichte van de UCS des te sterker en meer vergelijkbaar de CR zal zijn ten opzichte van de ongeconditioneerde reactie. Interoceptieve cues zoals gevoelens van ademnood vormen een essentieel onderdeel van een paniekaanval. Het gebruik van dergelijke interoceptieve cues zou dus interoceptieve conditionering bij PS kunnen faciliteren. We trachtten daarom in onze studies 'gevoelens van ademnood' op te roepen als een paniek-relevante CS. Het gebruik van een werkelijke paniekrelevante UCS door middel van inhalaties van $35 \% \mathrm{CO}_{2}$ bevordert de ecologische validiteit in het onderzoek naar PS. In ons differentieel paradigma werd tijdens de acquisitie-fase 3 CSs+ opgevolgd door een inhalatie van $35 \% \mathrm{CO}_{2}$ en 3 CSs- door een inhalatie van kamerlucht. Vervolgens werden in de testfase beide CSs+/- opgevolgd door kamerlucht.

In ons eerste experiment (hoofdstuk 4) werden 'gevoelens van ademnood' opgewekt via imaginatie van scripts. Drieëndertig gezonde deelnemers werden toegewezen aan één van de drie script condities: 'ademnood', 'neutraal', 'aandrang'. In overeenstemming met LT vertoonden enkel deelnemers in de ademnood conditie een selectief conditioneringseffect. Zij vertoonden namelijk meer vrees en hadden een significante hogere toename in hoeveelheid 
ingeademde lucht dan de deelnemers van de controle condities. Echter, hoewel de deelnemers in de ademnood conditie sterker reageerden dan deze in de controle condities, waren ze toch niet geheel in staat om te discrimineren tussen CS+/-. Dit laatste zou namelijk een krachtigere indicatie van conditionering zijn. De relatief kleine proefgroep, het eerder laag algemeen niveau van angst en het gebruik van scripts in plaats van werkelijke interne sensaties als CS waren duidelijke beperkingen van dit onderzoek.

Daarom hebben we in onze laatste studie (hoofdstuk 5) getracht om werkelijke gevoelens van ademnood als een CS uit te lokken via het gebruik van respiratoire ademhalingsweerstanden. Daarenboven werden de zesenzestig gezonde deelnemers op voorhand onderverdeeld in twee groepen op basis van hun angstgevoeligheid. Twee ademhalingsweerstanden, één van een lage en één van middelmatige intensiteit werden gebruikt als CS+ en CS- in een differentieel conditioneringsparadigma. In lijn met de verwachtingen was de zelfgerapporteerde angst, het ademgedrag en de huidgeleiding tijdens de acquisitiefase verhoogd bij de middelmatige ademhalingsweerstand in vergelijking tot de lage ademhalingsweerstand. Een interessante bevinding tijdens de acquisitiefase betrof het verschil in angstgevoeligheid tussen de deelnemers. De hoog angstgevoelige deelnemers vertoonden minder verschil in end-tidal $\mathrm{CO}_{2}$ en huidgeleiding tussen beide ademhalingsweerstanden dan de laag angstgevoelige deelnemers. In overeenstemming met de IC theorie van PS (Bouton et al., 2001) werden in dit onderzoek tijdens de testfase leer-gerelateerde verschillen aangetoond in alle metingen en dit blijkbaar onafhankelijk van het niveau van angstgevoeligheid. Terwijl discriminatief leren tot stand kwam los van het niveau van angstgevoeligheid, vertoonden hoog angstgevoelige deelnemers in hun huidgeleiding toch een verminderde extinctie. Deze laatste observatie is interessant in de context van PS. De schijnbare onmogelijkheid van hoog angstgevoelige personen om te leren dat de CS+ niet langer een 'gevaar cue' is, lijkt in overeenstemming met het klinische beeld van de persisterende anticipatieangst in PS patiënten, zelfs in de afwezigheid van een paniekaanval.

Concluderend kunnen op basis van dit proefschrift 2 conclusies gemaakt worden.

1. "Paniekaanvallen zijn niet het gevolg van de catastrofale misinterpretaties van lichamelijke sensaties, maar cognities spelen een rol in paniekstoornis".

2. "Paniekstoornis is het gevolg van intero-interoceptieve conditionering".

Zowel de leertheorie als de cognitieve theorie lijken waardevol in het verklaren van verschillende aspecten van de paniekstoornis en kunnen naast elkaar bestaan. Deze thesis had als doel om meer inzicht te verkrijgen in de pathogenese van de paniekstoornis. Deze kennis kan op de langere termijn uiteraard ook de behandeling van PS verbeteren. Op basis van dit proefschrift verwachten we dat het gebruik van interoceptieve exposure een cruciaal element zal blijken in de behandeling van PS. Tot op heden wordt deze techniek slechts beperkt ingezet en dan nog meestal via oefeningen die slechts een fractie van de paniek symptomen opwekken. Daarom stellen wij voor om in de behandeling van PS ook gebruik te maken van de $35 \% \mathrm{CO}_{2}$ challenge als een effectieve techniek in het kader van interoceptieve exposure. 


\section{SAMENVATTING EN CONCLUSIES}

\section{Referenties}

Bar-Haim, Y., Lamy, D., Pergamin, L., Bakermans-Kranenburg, M., \& van IJzendoorn, M. (2007). Threat-related attentional bias in anxious and nonanxious individuals: a meta-analytic study. Psychological Bulletin, 133(1), 1-24.

Bouton, M. E., Mineka, S., \& Barlow, D. (2001). A modern learning theory perspective on the etiology of panic disorder. Psychological Review, 108, 4-32.

Clark, D. (1986). A cognitive approach to panic. Behaviour Research and Therapy, 24, 461-470.

Razran, G. (1961). The observable unconscious and the inferable conscious in current Soviet psychophysiology: Interoceptive conditioning, semantic conditioning, and the orienting reflex. Psychological Review, 68, 81150.

Williams, J., Mathews, A., \& MacLeod, C. (1996). The emotional Stroop task and psychopathology. Psychological Bulletin, 120, 3-24. 


\section{Dankwoord}

"Het is niet wat het is het is wat je er mee doet" (Bart Peeters)

Reeds zes jaar ben ik actief met onderzoek bezig, naast mijn baan als gedragstherapeut. Het zijn zeer intense jaren geweest, waarin ik ook tweemaal moeder ben mogen worden van twee schatten van kinderen, Liv en Art. Deze drukke jaren heb ik alleen maar tot een goed einde kunnen brengen dankzij de hulp en steun van een aantal belangrijke mensen. In de eerste plaats mijn co-promotor Koen Schruers. Koen, zonder jou was dit boekje nooit een feit geworden alsook het proces hier naar toe. Vanaf mijn aanstelling als psycholoog wist je mij te prikkelen met allerlei onderzoeksvoorstellen. Zelfs voor ik er zelf erg in had was ik een onderzoeksvoorstel aan het schrijven voor de Medische Ethische Commissie en stagiaires aan het begeleiden in het kader van mijn onderzoek. Gaandeweg werd het mezelf ook steeds duidelijker dat ik de promotieweg aan het afleggen was en werd ik steeds ambitieuzer in mijn eigen ideevorming. Jij stond, als enige, van begin tot dit einde aan mijn zijde en eigenlijk meer als promotor dan als co-promotor. Ook op de moeilijkere momenten, wanneer het allemaal even teveel werd, heb je mij de tijd gegeven om terug op adem te komen zodat ik hierna weer verder kon. Bedankt, voor al je in - en nazicht en hulp bij het schrijven van de papers en je schijnbaar onuitputtelijk vertrouwen en steun. Ik hoop op nog een lange samenwerking. Professor Eric Griez, u was mijn promotor tot aan uw emeritaat. Ik heb het genoegen gehad om een van uw laatste doctoraatsstudenten te zijn. Voornamelijk bij de start en het eerste deel van mijn promotieonderzoek is uw inbreng zeer waardevol geweest zowel met betrekking tot de theorievorming als met betrekking tot het penwerk. $U$ hebt mij, samen met Koen, ondersteund in het schrijven van de papers en steeds getracht mij op het 'juiste' spoor te zetten en te houden. Ik bewonder uw talent om de zaken zo eenvoudig mogelijk te houden. Een uitspraak die me zeer sterk is bijgebleven en ik steeds beter ten volle begrijp is: "Keep it simple". Op het eerst gezicht een eenvoudige uitspraak, maar in de praktijk toch uiterst moeilijk om na te streven. $U$ wees mij als 'clinicus' op het essentieel belang van gedegen onderzoek voor de klinische praktijk. Hierna heeft professor Inez Germeys de fakkel van u overgenomen. Uiteraard wil ik ook haar bedanken voor het overnemen van deze fakkel aangezien al het experimentele werk reeds was uitgevoerd. $U$ bent diegene geweest die het laatste en noodzakelijke duwtje heeft gegeven om over te gaan tot de promotie met de woorden: "Dit is niet het einde, maar het begin", waarvoor mijn dank. En ik hoop ook dat ik dit in de praktijk kan omzetten. Voor het tweede deel van mijn promotie ben ik me meer gaan verdiepen in de conditioneringswereld en werd al snel duidelijk dat de hulp en steun van Ilse Van Diest onontbeerlijk was. Ilse, dankzij jou heb ik de laatste jaren ontzettend veel bijgeleerd over psychofysiologie, conditioneringsparadigma's, statistiek en het 
neerschrijven en interpreteren van de vele data. Tevens heb ik jouw hulp als zeer prettig ervaren, een vraag lijkt nooit teveel bij jou, waarvoor dank. Ook professor Dirk Hermans en professor Omer Van den Bergh mogen niet ontbreken in dit rijtje, aangezien jullie beiden een grote hulp zijn geweest in het opzetten en schrijven van een aantal papers.

Naast mijn promotieteam zijn er natuurlijk ook mijn paranimfen die ik niet zomaar gebombardeerd heb tot 'paranimf'. Bart Rutten en Cindy Debie, twee collega's en vrienden die mij hebben bijgestaan en gesteund doorheen het proces. Het is zo hartverwarmend om te merken hoe jullie beiden met me meeleven en ook werkelijk naast, achter en soms zelfs voor me gaan staan. Echt waar, zonder jullie was het niet gelukt! Bij jullie kon ik steeds terecht, beiden één van de weinige mensen die ik lastig viel met mijn onderzoeksperikelen.

Ook de (oud)-collega's van het Academisch Angstcentrum horen in deze bedanklijst te staan: Marjan, Femmie, Jaimie, Marlies, Lies, Nicole, Mark, Manuela, Mariëtte, Julien, Nicolette, Inge L, Inge K, Marie-Jeanne, An, Thea, Judith, Charlotte, Louis, Rudy, Daphne, MarieClaire, Dafne, Sara, Marie-Cecile, Kirsten, Jos, Linda, Yvonne en Benjamin. Allen op hun eigen(zinnige) manier hebben bijgedragen aan dit proefschrift, waarvoor dank. Ik denk maar aan het aanleveren van proefpersonen, het 'gedogen' beleid zodat ik aan onderzoek mocht doen en de ondersteunende, enthousiaste en bekrachtigende woorden. Voornamelijk deze laatste woorden kunnen toch een onschatbare kracht hebben.

Dit proefschrift heeft veel te danken aan de verschillende stagiaires die mijn onderzoek het hunne maakten in het kader van hun scriptie. Wiesje Arends, Daphne Noortman, Marjolein Büchler, Jojanneke Hoogenhout, Anouk Janssen en Suzanne Claassens. Stuk voor stuk stevige dames die mij met volle kracht en schijnbaar onuitputtelijke moed hebben ondersteund. Mijn dank is groot en mijn bewondering voor jullie is niet minder. Ook tevens dank aan de vele proefpersonen die (meestal) geheel vrijwillig en ondanks hun angst toch deelnamen aan het onderzoek en zich niet lieten afschrikken door de ingewikkelde en vaker ook overweldigende proefopzet.

Mijn vrienden en mijn familie zijn misschien een beetje verrast door mijn promotie, daar ik hier nooit veel over losliet. Ik was altijd meester om het onderwerp over een andere boeg te gooien. Ik had net de meeste steun aan jullie door het gewoon samen gezellig te hebben, weg van de (drukke) onderzoekswereld, net over die (voor sommige verre) grens.

Mijn ouders wil ik ook graag bedanken voor alle kansen die ze mij doorheen mijn leven hebben gegeven. Door jullie geloof in mijn capaciteiten sinds mijn kindertijd hebben jullie me steeds gestimuleerd om vooruit te gaan en hebben hierom ook bijgedragen aan dit proefschrift.

Tot slot mijn steun en toeverlaat, mijn toegewijde en altijd beschikbare man, David. Vlak voor mijn promotieonderzoek startte hebben we elkaars ja-woord gegeven, alleen wist je toen waarschijnlijk nog niet waar je allemaal "ja" op had gezegd. Ik dank je uit het diepste van mijn hart voor al je steun, hulp en sterke schouder om op te leunen. Dankzij jou onvoorwaardelijke liefde voel ik dat ik me ten volle kan en mag ontplooien. En ook jij bent die- 
gene die me ten gepaste tijde afremt en in de zetel neerzet om tot rust te komen. Mijn allerliefste schatten, Liv en Art vragen vaker "ga je comput(t)er werken?". Ook hun komst in mijn leven heeft voor veel vreugde en drukte gezorgd, hetgeen het volbrengen van mijn promotie niet makkelijker heeft gemaakt, maar wel veel rijker. Liefste schatjes, ik ben er voor jullie (met of zonder comput(t)er). 



\section{Curriculum vitae}

Klara De Cort werd geboren op 10 april 1979 te Tienen in België. Zij volgde Latijn-Wiskunde aan het Koninklijk Atheneum in Tienen van 1991 tot 1997. Aansluitend studeerde zij psychologie aan de Katholieke Universiteit van Leuven en behaalde haar diploma 'met onderscheiding' in 2002 met als afstudeerrichting klinische psychologie. Meteen na haar afstuderen is zij gestart als psycholoog bij het Academisch Angstcentrum van Mondriaan/PsyQ in Maastricht in Nederland. In de daaropvolgende 3 jaren heeft zij zich verder gespecialiseerd in de psychotherapie via de post-universitaire opleiding tot psychotherapeut, richting cognitief-gedragstherapeut van de Katholieke Universiteit van Leuven. Na het behalen van dit laatste diploma in 2005 is zij tevens erkend lid van de Vlaamse Vereniging van Gedragstherapie geworden en is zij in 2006 gestart met haar promotieonderzoek aan de Universiteit van Maastricht. Haar functie binnen het Academisch Angstcentrum werd uitgebreid, naast CGT behandelingen, met coördinerende, superviserende - en onderwijstaken zowel op vlak van klinisch werk als onderzoek. Hieruit volgde in 2009 de erkening als GZ-psycholoog binnen de Nederlandse Wetgeving en in 2012 de erkenning tot supervisor binnen de Vlaamse Vereniging van Gedragstherapie. 
